\title{
IntechOpen
}

\section{Update on Critical Issues on Infant and Neonatal Care}

\author{
Edited by René Mauricio Barría
}





\section{Update on \\ Critical Issues on Infant and Neonatal Care \\ Edited by René Mauricio Barría}



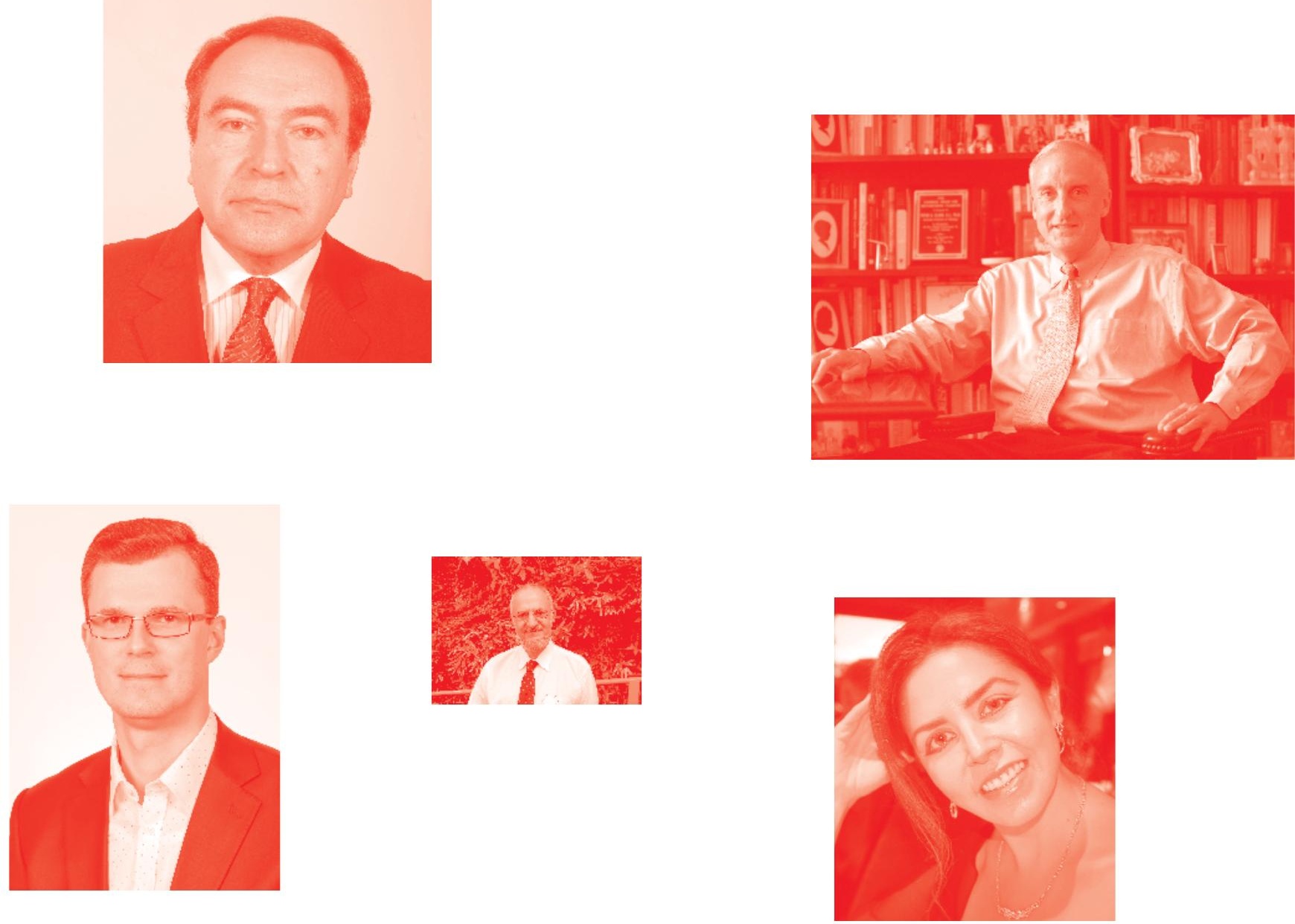

Supporting open minds since 2005
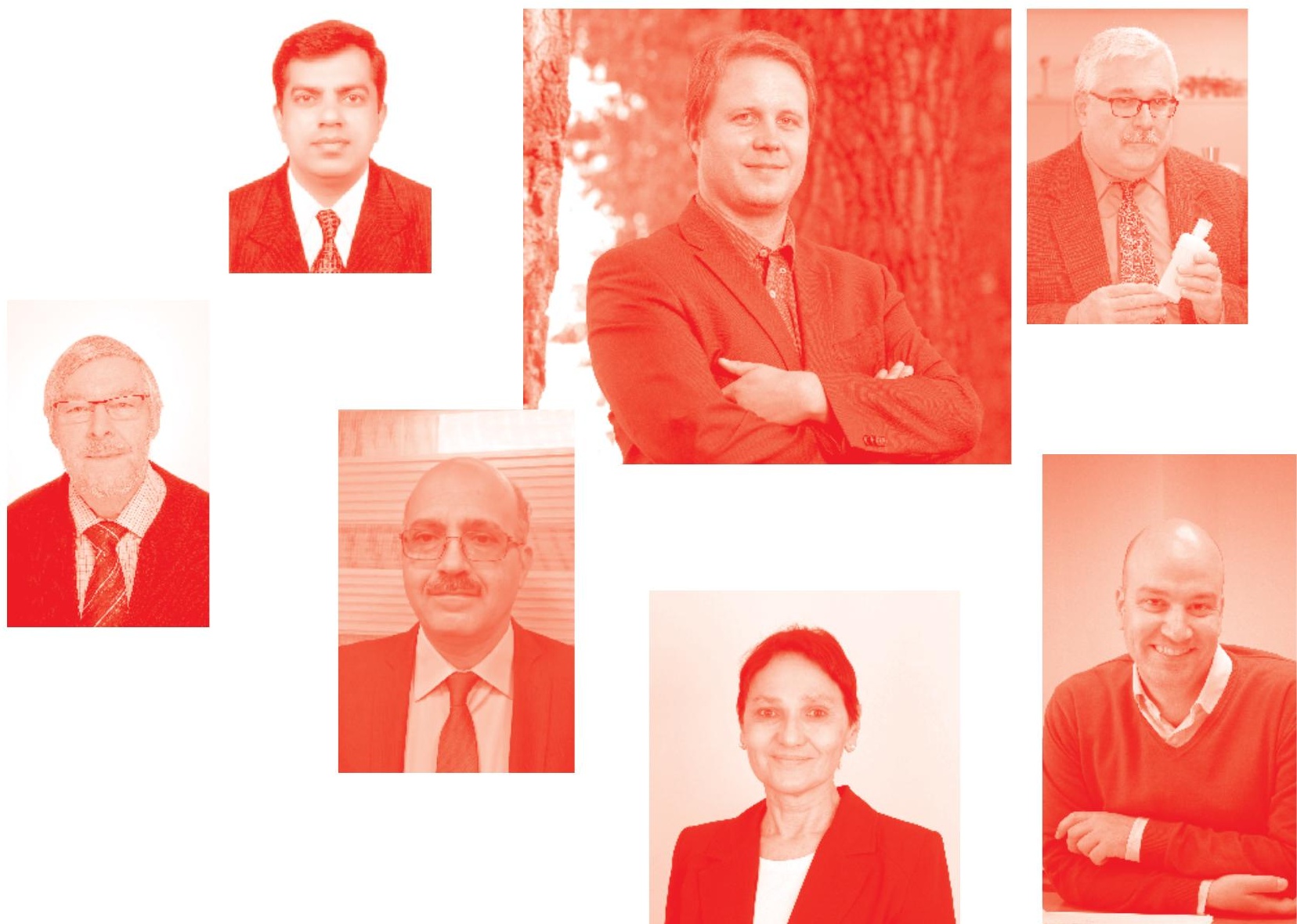
Update on Critical Issues on Infant and Neonatal Care

http : //dx. doi . org/10.5772/intechopen . 80145

Edited by René Mauricio Barría

\section{Contributors}

Anet Papazovska Cherepnalkovski, Natasha Najdanovska Aluloska, Nikolina Zdraveska, Katica Piperkova, Vjekoslav Krzelj, Şule Gökçe, Ivone Martinez, Aline Morales, Gerardo Alvarado, Ulises Blasquez, Shyam Sathanandam, Stephanie Whiting, Sara Lunardi, Francesca Lorenzoni, Paolo Ghirri, Mohammad Hossein Khosravi, Bita Najafian

(๑) The Editor(s) and the Author(s) 2020

The rights of the editor(s) and the author(s) have been asserted in accordance with the Copyright, Designs and Patents Act 1988. All rights to the book as a whole are reserved by INTECHOPEN LIMITED . The book as a whole (compilation) cannot be reproduced, distributed or used for commercial or non-commercial purposes without INTECHOPEN LIMITED's written permission. Enquiries concerning the use of the book should be directed to INTECHOPEN LIMITED rights and permissions department (permissions@intechopen.com).

Violations are liable to prosecution under the governing Copyright Law .

\section{(cc) BY}

Individual chapters of this publication are distributed under the terms of the Creative Commons Attribution 3.0 Unported License which permits commercial use, distribution and reproduction of the individual chapters, provided the original author(s) and source publication are appropriately acknowledged. If so indicated, certain images may not be included under the Creative Commons license. In such cases users will need to obtain permission from the license holder to reproduce the material. More details and guidelines concerning content reuse and adaptation can be found at http : //www . intechopen . com/copyright-policy . html.

\section{Notice}

Statements and opinions expressed in the chapters are these of the individual contributors and not necessarily those of the editors or publisher. No responsibility is accepted for the accuracy of information contained in the published chapters. The publisher assumes no responsibility for any damage or injury to persons or property arising out of the use of any materials, instructions, methods or ideas contained in the book.

First published in London, United Kingdom, 2020 by IntechOpen IntechOpen is the global imprint of INTECHOPEN LIMITED, registered in England and Wales, registration number: 11086078 , 7th floor, 10 Lower Thames Street, London, EC3R 6AF, United Kingdom

Printed in Croatia

British Library Cataloguing-in-Publication Data

A catalogue record for this book is available from the British Library

Additional hard and PDF copies can be obtained from orders@intechopen.com

Update on Critical Issues on Infant and Neonatal Care

Edited by René Mauricio Barría

p. cm.

Print ISBN 978-1-78985-361-2

Online ISBN 978-1-78985-362-9

eBook (PDF) ISBN 978-1-83880-@85-7 


\section{We are IntechOpen, \\ the world's leading publisher of Open Access books}

Built by scientists, for scientists

\section{$4,800+$}

Open access books available

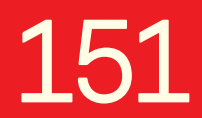

Countries delivered to

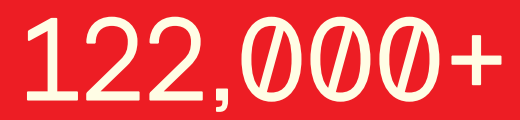

International authors and editors

Our authors are among the

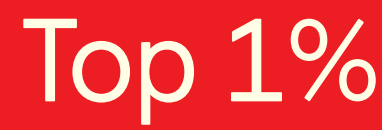

most cited scientists

Contributors from top 500 universities
40010

Downloads

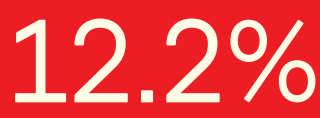

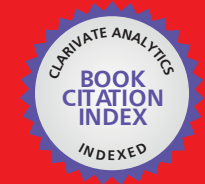

WEB OF SCIENCE ${ }^{\text {MM }}$

Selection of our books indexed in the Book Citation Index in Web of Science ${ }^{\mathrm{TM}}$ Core Collection (BKCI)

Interested in publishing with us?

Contact book.department@intechopen.com

Numbers displayed above are based on latest data collected.

For more information visit www.intechopen.com

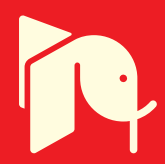





\section{Meet the editor}

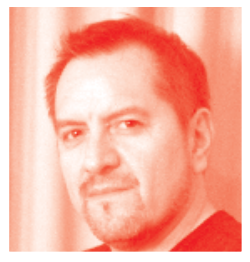

René Mauricio Barría, DrPH, is a principal investigator and assistant professor at the Faculty of Medicine at Universidad Austral de Chile. He was trained as an epidemiologist and received his MSc in Clinical Epidemiology from Universidad de la Frontera in Temuco, Chile, and his DrPH from Universidad de Chile in Santiago, Chile. His research interests lie in the areas of maternal-child health, neonatal care, and environmental health. He is skilled in epidemiological studies with special interest in cohort studies and clinical trials. From 2010 to 2017 he was Director of the Evidence-Based Health Office and currently serves as Director of the Nursing Institute at the Universidad Austral de Chile. He has published several articles related to the care and health of the newborn and is a reviewer of several international journals. 



\section{Contents}

Chapter 1

Neonatal Hyperbilirubinemia in Newborns of the Republic of North Macedonia by Anet Papazovska Cherepnalkovski, Natasha Najdanovska Aluloska,

Nikolina Zdraveska, Katica Piperkova and Vjekoslav Krzelj

Chapter 2

Neonatal Respiratory Distress Syndrome: Things to Consider

and Ways to Manage

by Bita Najafian and Mohammad Hossein Khosravi

Chapter 3

One of the Main Problems of Infants: Bronchiolitis

by Şule Gökçe

Chapter 4

PDA Closure in ELBW Infants: If, When, and How to Do It

by Stephanie Whiting and Shyam Sathanandam

Chapter 5

Universal Screening for Congenital CMV Infection

by Sara Lunardi, Francesca Lorenzoni and Paolo Ghirri

Chapter 6

VANEDELA's Test Screening, Comparison Low, Middle, and High Risk in Mexican Population

by Rosa Ivone Martínez-Vázquez, Blásquez-Martínez Jorge Ulises, Morales Ramírez Aline and Gevardo Alberto Alvarado-Ruiz 



\section{Preface}

This book provides an update on topics related to Update on Critical Issues on Infant and Neonatal Care. Based on the experience and knowledge of professionals from around the world, the book presents an updated review of fundamental topics related to cardiorespiratory, metabolic, infectious, and development disorders.

The book includes six chapters. The first chapter presents the analyzed experience from the Republic of North Macedonia on one of the most frequent newborn problems, neonatal hyperbilirubinemia.

Chapters 2 and 3 focus on two respiratory disorders often faced by the health team caring for newborns and infants: neonatal respiratory distress syndrome and bronchiolitis, respectively.

Chapter 4 aims to clarify different aspects of the closure of the patent ductus arteriosus, emphasizing the moment of and the alternatives for closure.

The last two chapters include a description of two screening tools. Chapter 5 discusses screening for a common infectious problem in neonatal units (congenital CMV infection), while Chapter 6 describes the Mexican experience of a neurobehavioral infant development disorder screening tool.

As described, this book includes various topics of interest for health professionals who are dedicated to neonatal and infant health care. I thank all the authors, who through their contributions taken from both experience and context, have allowed for the development of this interesting book that is expected to be useful for professionals and students dedicated to neonatal and infant care. 



\title{
Neonatal Hyperbilirubinemia in Newborns of the Republic of North Macedonia
}

\author{
Anet Papazovska Cherepnalkovski, \\ Natasha Najdanovska Aluloska, Nikolina Zdraveska, \\ Katica Piperkova and Vjekoslav Krzelj
}

\begin{abstract}
Neonatal indirect hyperbilirubinemia is one of the most frequent neonatal problems that affect almost two thirds of term infants. Although etiology of jaundice has been widely studied, identification of pathological causes presents constant clinical challenge. Our study group performed an extensive retrospective study of etiology of neonatal hyperbilirubinemia and showed high frequency $(44.37 \%)$ of jaundice of undefined etiology. The group included exaggerated physiological jaundice, earlyand late-onset breast-milk jaundice, and no identifiable etiology. Other etiologies were neonatal infection, prematurity, birth trauma, and hemolysis represented with $15 \%$. We described hematological parameters in both non-hemolytic and hemolytic type of jaundice; a significant correlation of relevant laboratory findings with etiology was established. In this chapter we will present our own data and perform a data-relevant literature review. Furthermore, investigation and management plan of neonatal indirect hyperbilirubinemia will be presented in accordance with own data and available literature.
\end{abstract}

Keywords: neonatal indirect hyperbilirubinemia, etiology, undefined jaundice, hemolysis, hematological parameters

\section{Introduction}

Neonatal hyperbilirubinemia is defined as a total serum bilirubin level $>5 \mathrm{mg} / \mathrm{dL}$ $(86 \mu \mathrm{mol} / \mathrm{L})$. This is a frequently encountered problem during the first week of life that affects approximately $60 \%$ of term and $80 \%$ of preterm babies $[1,2]$. About $10 \%$ of breastfed babies are still jaundiced at 1 month of age [1]. The yellowish coloration results from deposition of unconjugated bilirubin pigment into the skin and mucous membranes [2]. Generally, neonatal jaundice is considered a transitional phenomenon without noticeable clinical impact, related to hepatic, red cell, and gastrointestinal immaturity $[1,3]$. However, hyperbilirubinemia in the newborn period can be associated with severe illnesses such as hemolytic disease, metabolic and endocrine disorders, anatomic abnormalities of the liver, and infections [2]. Acute bilirubinassociated neuropathy caused by a dangerous rise of the total serum bilirubin level can often progress into a chronic neurologic condition characterized as kernicterus. 
The latter is characterized by a severe athetoid cerebral palsy, auditory and visual problems, dental enamel dysplasia, and, less frequently, intellectual and other dysfunctions $[1,2,4,5]$. Neonatal hyperbilirubinemia develops as an interaction between environmental and genetic factors; however, growing attention is turned to the genetically determined conditions. Gene variants related with neonatal hyperbilirubinemia are those that encode the erythrocyte enzyme glucose-6-phosphate dehydrogenase (G6PD), the hepatic isoenzyme uridine diphosphate (UDP) glucuronosyl transferase 1A1 (UGT-1A1), as well as the hepatic solute carrier organic anion transporter 1B1 [6-8].

\subsection{Pathophysiology of jaundice}

Neonatal hyperbilirubinemia results from a predisposition to a higher production of bilirubin in newborn infants and their limited ability of bilirubin excretion [9].

Newborns, especially preterm newborns, have higher rates of bilirubin production than adults, because they have a higher red cell turnover and a shorter life span. Newborns produce bilirubin at a rate of approximately 6-8 $\mathrm{mg}$ per $\mathrm{kg}$ per day which is more than twice the production rate in adults [2].

Other limitations that are evident in newborn infants are decreased hepatic uptake of bilirubin from plasma due to decreased ligandin and limited ability to conjugate bilirubin due to decreased activity of the hepatic conjugating enzyme UDP glucuronosyl transferase (UGT-1A1) $[9,10]$. The products of the conjugation reaction are transferred via the bile into the intestines. In the newborns' intestines, considerable amount of the conjugated bilirubin is hydrolyzed back to unconjugated bilirubin. This reaction is catalyzed by the enzyme beta glucuronidase. The unconjugated bilirubin is reabsorbed back into the bloodstream by means of the enterohepatic circulation, thus adding an additional bilirubin load to the alreadyoverstretched liver. Hence, enterohepatic circulation of bilirubin represents an important contributor to neonatal jaundice [10].

All the abovementioned features in the newborn infants' bilirubin metabolism contribute concurrently to the appearance of physiologic neonatal jaundice.

Physiologic jaundice refers to the transient increase of the serum bilirubin in term infants during the first week of life, followed by a constant decrease over the next few weeks to normal levels found in adults. Average peak serum bilirubin levels (TSB) found in physiologic jaundice vary between 5 and $6 \mathrm{mg} / \mathrm{dL}$ ( 86 and $103 \mu \mathrm{mol} / \mathrm{L}$ ). Exaggerated form of physiologic jaundice is considered when levels of TSB extend to values of 7-17 mg/dL (104-291 $\mu \mathrm{mol} / \mathrm{L})$ [9]. And, when serum bilirubin levels increase above $17 \mathrm{mg} / \mathrm{dL}(291 \mu \mathrm{mol} / \mathrm{L})$ in term infants, a pathologic cause of jaundice should be pursued $[2,9]$.

\subsection{Etiology of pathologic jaundice}

According to the mechanism of accumulation of bilirubin, causes of neonatal indirect hyperbilirubinemia are classified into three categories (Table 1).

1. Bilirubin overproduction ensues with hemolytic causes of disease such as Coombspositive blood group incompatibilities in the $\mathrm{ABO}$, rhesus, or minor blood group systems. On the other side of the hemolytic spectrum are the Coombs-negative disease causes such as erythrocyte membrane or enzyme defects, defects of hemoglobin $(\mathrm{Hb})$ synthesis, sepsis, and some drugs. Bilirubin overproduction is also a mechanism of bilirubin accumulation in non-hemolytic disease causes such as cephalohematoma, bruising, central nervous system (CNS) hemorrhage, polycythemia, and exaggerated enterohepatic circulation $[2,9,10]$. 


\begin{tabular}{|c|c|c|}
\hline Increased bilirubin load & $\begin{array}{l}\text { Decreased bilirubin } \\
\text { conjugation }\end{array}$ & Impaired bilirubin excretion \\
\hline $\begin{array}{l}\text { Hemolytic causes } \\
\text { - Positive Coombs test } \\
\text { ABO incompatibility, rhesus } \\
\text { incompatibility, other blood group } \\
\text { incompatibilities } \\
\text { - Negative Coombs test } \\
\text { Red blood cell membrane } \\
\text { defects (spherocytosis, } \\
\text { elliptocytosis, pyropoikilocytosis, } \\
\text { stomatocytosis) } \\
\text { Red blood cell enzyme defects } \\
\text { (G6PD deficiency, pyruvate kinase } \\
\text { deficiency, other deficiencies) } \\
\text { Hemoglobinopathies (alpha } \\
\text { thalassemia, beta thalassemia) } \\
\text { Unstable hemoglobins: congenital } \\
\text { Heinz body hemolytic anemia } \\
\text { Drugs (vitamin K) } \\
\text { Sepsis }\end{array}$ & $\begin{array}{l}\text { Physiologic jaundice } \\
\text { Crigler-Najjar } \\
\text { syndrome types } 1 \\
\text { and } 2 \\
\text { Gilbert syndrome } \\
\text { Hypothyroidism } \\
\text { Breast-milk jaundice } \\
\text { G6PD deficiency }\end{array}$ & $\begin{array}{l}\text { - Biliary obstruction } \\
\text { Biliary atresia, choledochal cyst, } \\
\text { primary sclerosing cholangitis, } \\
\text { gallstones, neoplasm, Dubin-Johnson } \\
\text { syndrome, Rotor's syndrome } \\
\text { - Infection } \\
\text { Sepsis, urinary tract infection, syphilis, } \\
\text { toxoplasmosis, tuberculosis, hepatitis, } \\
\text { rubella, herpes } \\
\text { - Metabolic disorder } \\
\text { Alpha-1-antitrypsin deficiency, cystic } \\
\text { fibrosis, galactosemia, tyrosinemia, } \\
\text { glycogen storage disease, Gaucher's } \\
\text { disease, hypothyroidism, Wilson's } \\
\text { disease, Niemann-Pick disease } \\
\text { - Chromosomal abnormality } \\
\text { Turner's syndrome, trisomy } 18 \text { and } 21 \\
\text { syndromes } \\
\text { - Drugs } \\
\text { Aspirin, acetaminophen, sulfonamides, } \\
\text { alcohol, rifampin, erythromycin, } \\
\text { corticosteroids, tetracycline }\end{array}$ \\
\hline $\begin{array}{l}\text { Non-hemolytic causes } \\
\text { - Extravascular sources } \\
\text { Cephalohematoma, bruising, CNS } \\
\text { hemorrhage, swallowed blood } \\
\text { - Polycythemia } \\
\text { Fetal-maternal transfusion, } \\
\text { delayed cord clamping, twin-twin } \\
\text { transfusion } \\
\text { - Exaggerated enterohepatic } \\
\text { circulation } \\
\text { Cystic fibrosis, intestinal atresia, } \\
\text { pyloric stenosis, Hirschsprung's } \\
\text { disease, breast-milk jaundice }\end{array}$ & & \\
\hline ormation from Refs. $[2,10]$. & & \\
\hline
\end{tabular}

Table 1.

Classification of neonatal jaundice based on the mechanism of accumulation.

2. Decreased bilirubin conjugation is present in etiologies such as in physiologic jaundice, breast-milk jaundice, Crigler-Najjar syndrome types 1 and 2, hypothyroidism, Gilbert syndrome, and glucose-6-phosphate dehydrogenase deficiency (G6PD deficiency). Hemolysis was traditionally considered the pathophysiological mechanism of jaundice in G6PD deficiency, and indeed some known hemolysis triggers such as menthol or Chinese remedies applied to the umbilicus for antisepsis have been described in association with this etiology of jaundice. Moreover, other assumed triggers of hemolysis, such as fava transmitted through human breast milk, chemical cleansers, bacterial and viral infections, and henna applied to the newborn's skin in some cultures of the Middle East, have been described into association with G6PD deficiency-linked neonatal hyperbilirubinemia. However, the hematological markers of hemolysis such as hemoglobin and hematocrit (Hct) values and reticulocyte count have only occasionally been reduced in infants with G6PD 
deficiency-associated hyperbilirubinemia [11, 12]. It has been shown that inadequate conjugation capacity of the liver mainly contributes to development of neonatal jaundice in G6PD-deficient infants [12-14]. This has been proven by significantly lower total serum bilirubin level as well as mono- and di-conjugated bilirubin fractions in G6PD-deficient newborns that developed hyperbilirubinemia than the non-hyperbilirubinemic G6PD-deficient newborns [13]. Research that further supports the report that the decreased bilirubin conjugation is the main element of jaundice in G6PD-deficient newborns has shown varying shortening of red cell life span, which could only partially contribute to the jaundice $[11,13]$. Moreover, the problem of jaundice is potentiated in cases of inherited UDP glucuronosyltransferase promoter polymorphism associated with Gilbert syndrome [14, 15]. The combination of the two gene mutations has been shown to significantly increase the incidence of hyperbilirubinemia in a dose-dependent manner [15].

3. And finally, the third mechanism of jaundice marked by impaired bilirubin excretion causes direct (conjugated) hyperbilirubinemia [2, 9, 10, 16]. Neonatal sepsis can be featured by both indirect and direct hyperbilirubinemia $[2,16]$.

\subsection{Neurotoxicity of bilirubin}

\subsubsection{Cellular toxic effects of bilirubin}

Even though being of great clinical importance, hyperbilirubinemia neurotoxicity effects on the cellular level are not entirely understood. It has been established that the mitochondria could be the primary target of the bilirubin neurotoxicity as evidenced by uncoupling of oxidative phosphorylation. Additional effects expressed in neuronal tissue include inhibition of DNA synthesis, induction of DNA strand breakage, inhibition of protein synthesis, and changes in neurotransmitters' synthesis and function. Experiments in immature rats have shown association between hyperbilirubinemia and impaired cerebral glucose metabolism [9].

\subsubsection{Neurotoxicity risk factors}

Of specific clinical importance is to recognize the risk factors associated with brain damage in newborn infants with significant hyperbilirubinemia. According to the 2009 AAP recommendation, neurotoxicity risk factors are isoimmune hemolytic disease, G6PD deficiency, asphyxia, sepsis, acidosis, and albumin $<3.0 \mathrm{mg} / \mathrm{dL}$ [17]. The neurotoxicity risk factors are used in making the decision when to initiate phototherapy or perform an exchange transfusion. These interventions are recommended at a lower bilirubin threshold level in the presence of any of the neurotoxicity risk factors [17].

Prematurity represents a well-recognized predisposition to development of jaundice. In premature newborns the rise of the total serum bilirubin tends to be slightly slower but of longer duration than term newborns [18]. There is still insufficient amount of evidence-based data to provide recommendations for treatment in this group of patients. Recommendations are mainly based on consensus agreementbased guidelines on the safe spectrum of thresholds [19,20]. Bilirubin neurotoxicity has been associated with prematurity; however, birth weight and gestation are not the sole variables predictive of the neuronal damage. Other factors such as the presence of a concurrent neonatal disease, sepsis, cholestasis, drugs that alter the albumin-bilirubin binding, or the use of total parenteral nutrition have been found to enhance the risk of neurotoxicity. Moreover, premature newborns have similar 
but often more subtle clinical manifestations of acute bilirubin encephalopathy than term infants [21-23]. For all the abovementioned reasons, it is reasonable to observe premature newborns as a distinct entity of neonatal jaundice and not assign them to an "undetermined etiology" group as done by certain authors [16].

\subsubsection{Kernicterus}

This term refers to the neurologic consequences of the deposition of unconjugated bilirubin in brain tissue with subsequent damage and scarring of the basal ganglia and brainstem nuclei. Determinants of the neurotoxic effect of bilirubin are the duration of exposure and the concentration of bilirubin in the brain. Poor correlation exists between serum bilirubin level and bilirubin encephalopathy in the absence of hemolysis [9]. Other important determinants of bilirubin influx in the brain are the bilirubin-binding capacity of albumin and the integrity of the bloodbrain barrier. If the serum unconjugated bilirubin level exceeds the bilirubin-binding capacity of albumin, unbound lipid-soluble bilirubin crosses the blood-brain barrier. Conditions that alter the permeability of the blood-brain barrier such as sepsis, acidosis, hypoxia, hyperoxia, hypoperfusion, and hyperosmolality can potentiate bilirubin entry in the brain $[2,9]$. Differentiating neurons are particularly sensitive to bilirubin-related injury; therefore, premature newborns are more susceptible to the effects of bilirubin deposition in the brain [9]. For the purpose of greater consistency when defining bilirubin-induced neurological damage, it has been recommended to separate the terms "acute bilirubin encephalopathy" and "kernicterus." The former is used to describe the acute manifestations of bilirubin toxicity in the first weeks of life, whereas the latter is reserved for the chronic and permanent clinical sequelae of bilirubin toxicity [4]. The exact bilirubin concentration associated with kernicterus in the healthy term infant is unpredictable. Toxicity levels may vary among ethnic groups, also with maturation of an infant, and in the presence of hemolytic disease. The clinician's concerns of possible bilirubin toxicity should rise in the presence of bilirubin $>25 \mathrm{mg} / \mathrm{dL}(428 \mu \mathrm{mol} / \mathrm{L})$ in the term newborn without hemolysis and $>20 \mathrm{mg} / \mathrm{dL}(342 \mu \mathrm{mol} / \mathrm{L})$ in the term newborn with hemolysis [2]. The early phase of acute bilirubin encephalopathy is characterized by lethargy, hypotonia, and poor sucking. In the intermediate phase, irritability and hypertonia develop. The infant may develop a fever and high-pitched cry, which may alternate with drowsiness and hypotonia $[4,24]$. The hypertonia is demonstrated by backward arching of the neck (retrocollis) and trunk (opisthotonos). The advanced phase is characterized by pronounced hypertonia, apnea, and fever, deep stupor to coma, sometimes seizures, and death. Features of chronic bilirubin encephalopathy (kernicterus) include athetoid cerebral palsy, hearing loss, visual and dental problems, and moreover intellectual and other handicaps $[1,2,4,5,9,10]$.

\subsection{Laboratory evaluation of jaundice}

Laboratory evaluation of jaundice is directed by the age of the newborn. The first step in evaluation, for a newborn jaundiced in the first 24 hours of life, is to perform total serum bilirubin (TSB) or transcutaneous bilirubin (TcB) measurement $[2,4,10]$. Transcutaneous bilirubin $(\mathrm{TcB})$ can be a powerful and noninvasive screening tool for bilirubin estimation with reported close correlation to TSB measurement in different populations [10]. When jaundice appears excessive for newborn's age, a TSB should be obtained. In infants under phototherapy and TSB above the $75^{\text {th }}$ percentile or rising rapidly (i.e., crossing percentiles), it is recommended to extend the diagnostic workout by performing additional tests such as complete blood count and smear, reticulocyte count, blood grouping, and Coombs 
test as well as end-tidal carbon monoxide levels. In cases of specific ethnic origin or positive family history, analysis of G6PD and pyruvate kinase deficiencies is considered. Once direct (or conjugated) bilirubin level is elevated, urinalysis, urine culture, and evaluation for sepsis are recommended. As per jaundice persisting beyond the third week of life, a diagnostic protocol for identification of cholestasis causes should be followed $[2,4,10]$.

\subsection{Treatment of jaundice}

\subsubsection{Phototherapy}

It is a standard method for treatment of hyperbilirubinemia that is applied when bilirubin levels exceed gestation and hour-specific treatment thresholds [1, 4, 9, 25-27]. It is effective through photoisomerization of bilirubin to a water-soluble product that is readily excreted via bile or urine. The efficacy depends on the wavelength and the dose of the delivered light, as well as on the illuminated skin surface area $[9,27]$. Specific phototherapy treatment graphs have been developed to address the phototherapy needs in term and in preterm babies [10, 26, 27]. General measures are involved concurrently to phototherapy such as maintenance of fluids and treatment of underlying disease cause such as infection [27].

\subsubsection{Exchange transfusion (ECT)}

It is a method for rapid elimination of the bilirubin and the circulating antibodies from the circulation, therefore most beneficial in cases of ongoing hemolysis. Small amount of blood are removed through a central venous catheter and replaced with the same amount of donor red blood cells suspended in plasma. The procedure is repeated until twice the blood volume of the newborn is replaced with the donor blood. This procedure involves multiple complications among which most pronounced are graftversus-host disease, necrotizing enterocolitis, and portal thrombosis [1,9]. Although being the first therapy for severe jaundice, this intervention is becoming virtually obsolete and reserved only for cases of severe hyperbilirubinemia that could not be managed by intensive phototherapy. Likewise phototherapy, exchange transfusion treatment threshold graphs have been devised for term and preterm gestations to serve as clinical guidance for initiation of therapy $[10,26,27]$. Exchange transfusion should only be performed in highly developed neonatal intensive care units (NICU) adequately equipped for monitoring and resuscitation as well as with trained personnel [4].

\subsubsection{Pharmacologic therapies}

These drugs interfere with variable effectiveness at different stages of the bilirubin metabolism. For example, phenobarbital has been used to improve the conjugation and excretion of bilirubin. Tin mesoporphyrin inhibits heme oxygenase thereby acting on the production of bilirubin. Other drugs are involved with the enterohepatic circulation of bilirubin $[9,10]$. Intravenous immunoglobulin has been shown to significantly reduce the need for exchange transfusion in $\mathrm{Rh}$ or $\mathrm{ABO}$ hemolytic disease [4].

\section{Neonatal hyperbilirubinemia in the Republic of North Macedonia}

Our study group performed an extensive retrospective study for the purpose of evaluation of the etiology and management of indirect hyperbilirubinemia at the 
University Pediatric Clinic in Skopje (UPCS), now Republic of North Macedonia (RNM). The study group included 284 newborns who had been admitted to the neonatology department at the University Pediatric Clinic in Skopje with the diagnosis of neonatal indirect hyperbilirubinemia during the period of 2 years [28]. They represented one quarter of the total number of 1126 hospitalized patients during this period in a tertiary level university teaching clinical hospital setting. Relevant history, clinical data, laboratories, and the type of therapy applied were retrieved from the medical records, recorded on questionnaires, and statistically analyzed. Perinatal history data of relevance were birth parameters, Apgar scores, and delivery mode. Clinical presentations that could potentially influence duration and intensity of jaundice had been searched for such as hematomas, cephalohematoma, intracranial hemorrhages, hypothyroidism, impaired intestinal motility, and infection. All laboratories and investigations of relevance were recorded, as well as the therapies applied. Moreover, the day of the bilirubin peak was noted, as well as two subsequent bilirubin measurements. Standard techniques for analysis of blood count and smear, bilirubin and fractions, serum aminotransferases, and G6PD, as well as infants' and mothers' blood group and direct antiglobulin Coombs test (DAT), were applied as described elsewhere [12, 28]. Statistical Package for the Social Sciences (SPSS) for Windows (SPSS Inc., Chicago, IL, USA) was used for the statistical analyses. Absolute numbers and percentages were used to present the categorical variables, whereas mean, standard deviation, minimum, maximum, median, and rang were used to present the quantitative variables. Testing of significance between groups was performed using Kruskal-Wallis test, student $t$-test, Mann-Whitney $U$ test, and analysis of variance. The result was considered significant if probability value $(p)$ was $<0.05$ and $<0.01$ for high significance. Nine types of jaundice had been identified and grouped as follows: (1) ABO incompatibility, (2) rhesus ( $\mathrm{Rh}$ ) incompatibility, (3) cephalohematoma and bruising, (4) sepsis, (5) prematurity, (6) intracranial hemorrhage, (7) hemolysis (neither ABO nor Rh incompatibility), (8) Down syndrome, and (9) undefined. The highest prevalence was found for jaundice of undefined etiology (44.37\%), and the second most prevalent was etiology of neonatal infection represented with $19.37 \%$. Hemolytic etiologies were represented with $8.45 \%$ for $\mathrm{ABO}$ incompatibility, 5.63\% for $\mathrm{Rh}$ incompatibility, and $0.35 \%$ for hemolysis neither $\mathrm{ABO}$ nor $\mathrm{Rh}$ or in total $14.43 \%$. Least prevalent were cephalohematoma and bruising due to birth trauma (2.82\%), intracranial hemorrhage (2.46\%), and Down syndrome (0.70\%) (Table 2) [28].

Etiology of sepsis was assigned to newborns with a positive blood/cerebrospinal fluid culture or clinically relevant infection requiring antibiotic therapy. Subjects that had sepsis and elevated direct bilirubin were not included $[2,28]$. Prematurity, defined as less than completed 37 weeks of gestational age, was considered a distinct etiology of jaundice. Our group of undefined etiology included cases of early- and late-onset breast-milk jaundice, exaggerated physiological jaundice, $[2,9,28]$, and no identifiable etiology. Cephalohematoma and bruising were representatives of birth trauma.

\subsection{Undefined etiology of jaundice}

We found a high percentage of jaundice of undefined etiology (44.37\%). Another study reported higher prevalence of undetermined etiology (75.8\%) [16]. Clinical evaluation of severe neonatal hyperbilirubinemia in a resource-limited setting similarly showed highest prevalence of idiopathic jaundice (33.3\%) [24]. No cause for the extreme hyperbilirubinemia of $\geq 25 \mathrm{mg}$ per $\mathrm{dL}$ ( $428 \mu \mathrm{mol}$ per $\mathrm{L}$ ) could be identified in $65.6 \%$ of cases admitted for treatment at the NICU in Southern Turkey [29]. Etiology was unknown in 11 of the 79 ECT cases (13.9\%) in the Eastern Mediterranean region of Turkey as reported by Davutoğlu et al. [30]. Dissimilarly, 


\begin{tabular}{lcc}
\hline Etiology & Number & Percentage (\%) \\
\hline Undefined etiology & 126 & 44.37 \\
\hline Neonatal infection & 55 & 19.37 \\
\hline Prematurity & 45 & 15.85 \\
\hline ABO incompatibility & 24 & 8.45 \\
\hline Rh incompatibility & 16 & 5.63 \\
\hline Cephalohematoma and bruising due to birth trauma & 8 & 2.82 \\
\hline Intracranial hemorrhage & 7 & 2.46 \\
\hline Hemolysis (neither ABO nor Rh incompatibility) & 1 & 0.35 \\
\hline Down syndrome & 2 & 0.70 \\
\hline Total & 284 & 100 \\
\hline Information from Ref. [28]. & & \\
\hline
\end{tabular}

Table 2.

Causes of neonatal indirect hyperbilirubinemia in the republic of North Macedonia.

\begin{tabular}{lccccc}
\hline & Mean & Min & Max & M & Interquartile range \\
\hline Age & $4 \pm 2.5$ & 2 & 14 & 3 & $3-4$ \\
\hline GW & $39 \pm 1.2$ & 37 & 42 & 39 & $38-40$ \\
\hline BW & $3247.1 \pm 437.4$ & 2200 & 4500 & 3245 & $2980-3500$ \\
\hline BL & $50.2 \pm 1.8$ & 46 & 56 & 50 & $49-51$ \\
\hline Mode of delivery & $\mathrm{N}$ & $\%$ & & & \\
\hline Spontaneous & 114 & 90.47 & & \\
\hline CS & 9 & 7.14 & & \\
\hline Vacuum extraction & 2 & 1.59 & & \\
\hline Forceps & 1 & 0.8 & & \\
\hline Perinatal hypoxia & $\mathrm{N}$ & $\%$ & & \\
\hline No & 109 & 86.51 & & \\
\hline AS 7 & 16 & 12.7 & & \\
\hline AS 4-6 & 1 & 0.79 & & \\
\hline
\end{tabular}

Min, minimum; Max, maximum; $M$, median; $G W$, gestation weeks; $B W$, birth weight; BL, birth length; CS, cesarean section; AS, Apgar score. Information from Ref. [28].

Table 3.

Basic characteristics of the undefined etiology group at UPCS, RNM.

we did not find undefined etiology among our ECT cases. It could be assumed that the variable prevalence of "undefined etiology" reported in different studies was a result of diverse classification of the causes of neonatal jaundice and also of different levels of TSB considered (pathologic or extreme). We described undefined etiology as such, where intensive workout could not provide an identifiable cause or contributing factor for jaundice. Through a careful selection process, a homogenous group of clinically stable patients was obtained that had normal birth parameters and required treatment with phototherapy (Table 3). We speculated that an imbalance between bilirubin production and conjugation was the primary concept of jaundice in this group since no history, clinical, and laboratory data existed to indicate another mechanism of jaundice $[28,31]$. 
The basic characteristics of the undefined etiology group are presented in Table 3. Newborn infants of this group were generally delivered spontaneously (90.47\%) with normal birth parameters [birth weight (BW) and birth length (BL)] and did not suffer major perinatal hypoxia. The median (interquartile range) age of presentation of jaundice was at day 3 (3-4) (Table 3). In the group of undefined etiology, the median (interquartile range) day at which bilirubin reached its peak was 9 (6-17). The median (interquartile range) of the peak TSB level was 324 (270-394) $\mu \mathrm{mol} / \mathrm{L}$, whereas the mean \pm standard deviation (SD) peak serum bilirubin concentration was $333.4 \pm 91.1 \mu \mathrm{mol} / \mathrm{L}$.

Statistical analyses included comparison of laboratory parameters between five etiological groups: (1) hemolytic etiology of jaundice including ABO incompatibility, Rh incompatibility, and hemolysis (neither ABO nor Rh incompatibility), (2) neonatal infection/sepsis, (3) prematurity, (4) hematomas (cephalohematoma, bruising, intracranial hemorrhage), and (5) undefined etiology.

To summarize the analyzed laboratory parameters, mean peak bilirubin levels in newborns with hemolysis (group 1) were shown to be statistically significantly higher than levels in the groups with neonatal infection, prematurity, and hematomas (groups 2, 3, and 4). The first control serum bilirubin level was significantly higher in newborns with hemolysis (group 1) than prematurity and undefined etiology (groups 3 and 5). No statistically significant differences were found in the second control bilirubin measurement; also levels of hepatic transaminases (AST and ALT) were not found to depend significantly on the etiology of jaundice. Estimation of hepatic transaminases has not proven of substantial influence on jaundice workout and management.

\subsection{Prematurity and jaundice}

Premature newborns, due to physiological characteristics, associated risk factors, and proneness to development of pronounced jaundice, were assigned a separate etiological group contrary to assignment of these patients into the "undetermined etiology" performed by other authors [16]. We were able to show slower increase toward the peak bilirubin level in the group of premature newborns than in groups of hemolysis, hematomas, and infection. Levels of erythrocytes (Er), hemoglobin $(\mathrm{Hb})$, and hematocrit (Hct) in premature newborns were statistically significantly lower than the groups of undefined etiology and infection.

\subsection{G6PD deficiency}

We did not find cases of G6PD deficiency in the studied group. Although no cases of G6PD deficiency were confirmed, a standard was set for a new quantitative spectrophotometric assay for G6PD detection, thereby overcoming the uncertainties connected with the previously used qualitative methods. Previous qualitative studies of the G6PD deficiency in Macedonia are those of Fraser et al. [32] and of Andreeva et al. [33]. The first group of authors assessed the average prevalence of the G6PD deficit in Yugoslavia from 1\% [32] based on tests carried out on 144 samples from then Republic of South Macedonia and 512 samples from the region of Dalmatia. The second group of authors in 1974 examined the prevalence of the G6PD deficiency in 3263 male school children from the area of Southeastern Macedonia (territory of nowadays Republic of North Macedonia) and showed a frequency of 1-2\% of the G6PD deficit in that part of the republic. In the second examination of the same group of authors, realized on samples of 1196 male school children from the territory of Skopje, when processing the enzyme, it was concluded that it was a Mediterranean variant and the prevalence of the 
deficit of $1.02 \%$ was reported among the children of Macedonian nationality and 6.63\% for Roma children [33]. Quantitative testing for G6PD deficiency has been recommended to be performed, thus avoiding partially G6PD-deficient patients such as heterozygous females to be missed $[34,35]$. As much as $1 / 3$ higher levels of G6PD in the neonatal period can be encountered due to the presence of physiologic polycythemia in this period [35]. Therefore, it is reasonable to schedule for another subsequent test in cases of borderline normal results and a specific ethnic origin.

In a subsequent neonatal jaundice study, we showed an incidence of $8.57 \%$ of G6PD-deficient infants in a strictly prospectively selected group of infants with jaundice of undetermined etiology (own unpublished results). From this study, a population-specific range of normal values for the G6PD quantitative spectrophotometric assay will be derived.

\subsection{Extravasation of blood and jaundice}

A separate group of patients with hematomas was developed, encompassing patient with extravascular collections of blood where an increased bilirubin load was presumed the fundamental mechanism of hyperbilirubinemia $[2,9,16,18,28]$. No statistically significant hematological correlations between this group and the other four groups of patients were found.

\subsection{Infection-associated jaundice}

Sepsis is a known perinatal risk factor for both unconjugated and conjugated jaundice $[2,9,18]$ and is also listed as a risk factor for hyperbilirubinemia neurotoxicity [17]. Analysis of prevalence rates in different regions of the world showed varying importance of infection in connection with jaundice. Highest variability of prevalence rates was reported in Asia (from 9.7 to 31.2\%). In Africa infection was related with over $13.9 \%$ of the hyperbilirubinemia or kernicterus cases, whereas in Europe and North America, infection was related with $14.3 \%$ of the kernicterus cases [1].

In our study, the group of infection-associated jaundice was represented with $19.37 \%$. On the contrary, sepsis was found in almost twice as much (35.3\%) severe hyperbilirubinemia cases in South East Nigeria [24]. Similar to the North Macedonian study, sepsis was present in $15.7 \%$ indirect hyperbilirubinemia cases at Zanjan Province of Iran [16]. We assumed our figure an overrepresentation due to the fact that not only culture positive cases were included but also newborns with clinical or biochemical markers of sepsis. Reliable discrimination between culture positive and culture negative cases was not possible due to the variety of processing of initial hemoculture between the tertiary level and the referral hospitals. Therefore, the term "infection" rather than "sepsis" was used for more accurate reflection on this group of patients. Statistically significant higher levels of hematological parameters (Er, Hb, and Hct) were shown for this group than the hemolytic group and the premature newborns.

\subsection{Hemolytic jaundice}

We have established a group of hemolytic jaundice according to the mechanism of the hyperbilirubinemia employed in cases of $\mathrm{ABO}$ and $\mathrm{Rh}$ isoimmunization. According to the 2009 update on the management of newborn infants $\geq 35$ weeks' gestation, isoimmune and other hemolytic diseases (e.g., G6PD deficiency) were included in two important of risk factors' categories: severe hyperbilirubinemia and hyperbilirubinemia-induced neurotoxicity [17]. Furthermore, it has been 
postulated that DAT-positive isoimmune hemolytic disease and severe hyperbilirubinemia exert synergistic effect in potentiating the bilirubin-induced neurotoxicity [36]. Lower phototherapy and exchange transfusion threshold levels have been recommended in isoimmune hemolytic disease in order to prevent the acute manifestations of bilirubin toxicity that might evolve into chronic neurological condition, kernicterus, also a pre-discharge risk assessment and early post-discharge follow-up [4, 17, 25-27]. Tiker et al. report isoimmunization in 19 out of $93(20.43 \%)$ patients admitted for treatment of extreme hyperbilirubinemia in Southern Turkey [29]. $\mathrm{ABO}$ isoimmunization was reported the most common cause of hyperbilirubinemia requiring ECT in two other studies performed in Turkey; the reported rates were $38 \%$ and $27.8 \%$, respectively $[30,37]$. ABO incompatibility was present in $8.45 \%$ of our study cases. Rh incompatibility was represented with $5.63 \%$ of all hyperbilirubinemia cases. We found one hemolysis positive patient who had neither ABO nor Rh incompatibility. The pooled prevalence of all hemolytic etiology cases in our study was $14.43 \%$. When compared to the groups of neonatal infection, prematurity, and hematomas, the group of hemolytic etiology presented with significantly higher peak bilirubin levels. A statistically significant higher level of bilirubin in hemolytic etiology than prematurity and undefined etiology was also noted on the first control bilirubin level estimation. This observation pointed out a slower tendency of reduction of bilirubin under phototherapy in hemolysis than undefined etiology. However, the majority of cases with hemolytic etiology (97.89\%) were managed conventionally by phototherapy using double-surface blue light phototherapy lamps at wavelength of $460 \mathrm{~nm}$, and only $2.11 \%$ Coombs-positive ABO/Rh incompatibility patients were treated by exchange transfusion.

\subsection{Laboratory analyses}

A comparison of hematological and biochemical parameters was performed between groups of patients with undefined (unspecified) etiology (126 patients, $74.5 \%)$ and 41 patients with $\mathrm{ABO}$ or rhesus-type hemolytic disease of the newborn $(24.6 \%)$.

The group of newborns with $\mathrm{ABO} / \mathrm{Rh}$ incompatibility presented with significantly lower mean values of all analyzed hematological parameters than the group of jaundice with unspecific etiology [hemoglobin $(p=0.038)$, erythrocytes $(p=0.0023)$, and hematocrit $(p=0.037)$ ] (Table 4) [38]. Mean reticulocyte count was significantly higher $(p=0.000036)$ in the group of $\mathrm{ABO} / \mathrm{Rh}$ incompatibility $(27.88 \pm 26.4$ vs. $11.94 \pm 7.4)$. The group of hemolytic etiology was characterized by significantly earlier jaundice appearance $(p<0.01)$ than the group of jaundice of unspecified etiology. The mean \pm standard deviation (SD) for hemolysis group was $2.63 \pm 2.4$ days versus $4.02 \pm 2.5$ days for the unspecified etiology group. The peak bilirubin level (mean $\pm \mathrm{SD}$ ) in hemolysis group of $379.76 \pm 133.5 \mu \mathrm{mol} / \mathrm{L}$ was higher than unspecified etiology $(333.44 \pm 91.1 \mu \mathrm{mol} / \mathrm{L})$ although the differences were not statistically significant $(p=0.052)$. Statistically insignificantly higher levels at the first $(p=0.062)$ and second $(p=0.448)$ control bilirubin measurements were registered for the hemolytic etiology group than the unspecific jaundice group.

On the other hand, duration of the bilirubin peak was significantly lengthier $(p=0.036)$ for the group of unspecific jaundice. The mean \pm SD for this group was $15.03 \pm 25.7$ days versus $10.22 \pm 9.02$ days for the $\mathrm{ABO} / \mathrm{Rh}$ incompatibility group (Table 5) [38].

Despite the fact that we did not show statistically significant higher peak levels of bilirubin in the hemolytic etiology group than the other group of jaundice, a propensity toward faster elevation of bilirubin and more pronounced level of jaundice was noted. The peak bilirubin level showed significantly longer duration 


\begin{tabular}{|c|c|c|c|c|}
\hline \multirow[t]{2}{*}{ Groups } & \multicolumn{3}{|c|}{ Descriptive statistics } & \multirow[b]{2}{*}{$t$-value, $p$} \\
\hline & $N$ & Mean \pm SD & Min-max & \\
\hline \multicolumn{5}{|l|}{$\mathrm{Hb}(\mathrm{g} / \mathrm{L})$} \\
\hline $\mathrm{ABO} / \mathrm{Rh}$ & 41 & $155.02 \pm 30.3$ & 74-218 & \multirow[t]{2}{*}{$t=2.09 p=0.038^{*}$} \\
\hline Unspecified & 126 & $165.36 \pm 26.5$ & $105-224$ & \\
\hline \multicolumn{5}{|l|}{$\operatorname{Er}\left(\times 10^{12}\right)$} \\
\hline $\mathrm{ABO} / \mathrm{Rh}$ & 41 & $4.29 \pm 0.8$ & $2.05-5.81$ & \multirow[t]{2}{*}{$t=3.09 p=0.0023$} \\
\hline Unspecified & 126 & $4.67 \pm 0.6$ & $3.27-6.58$ & \\
\hline \multicolumn{5}{|l|}{ Hct (\%) } \\
\hline $\mathrm{ABO} / \mathrm{Rh}$ & 41 & $41.35 \pm 8.9$ & $18.9-61.9$ & \multirow[t]{2}{*}{$t=2.11 p=0.037^{*}$} \\
\hline Unspecified & 126 & $44.26 \pm 7.2$ & $28.4-64.6$ & \\
\hline
\end{tabular}

Table 4.

Hematological parameters in neonatal jaundice, comparison between ABO/Rh incompatibility and unspecified etiology groups.

\begin{tabular}{|c|c|c|c|c|c|}
\hline \multirow[t]{2}{*}{ Groups } & \multicolumn{4}{|c|}{ Descriptive statistics } & \multirow[b]{2}{*}{$t$-value, $p$} \\
\hline & $N$ & Mean \pm SD & Median & Min-max & \\
\hline \multicolumn{6}{|l|}{ Ret } \\
\hline $\mathrm{ABO} / \mathrm{Rh}$ & 41 & $27.88 \pm 26.4$ & 22.0 & $2-121$ & \multirow{2}{*}{$\begin{array}{c}Z=4.13 \\
p=0.000036^{* *}\end{array}$} \\
\hline Unspecified & 126 & $11.94 \pm 7.4$ & 11.0 & $1-39$ & \\
\hline \multicolumn{6}{|c|}{ Day of bilirubin peak } \\
\hline $\mathrm{ABO} / \mathrm{Rh}$ & 41 & $2.63 \pm 2.4$ & 2.0 & $1-14$ & \multirow{2}{*}{$\begin{array}{c}Z=5.78 \\
p=0.000^{* *}\end{array}$} \\
\hline Unspecified & 126 & $4.02 \pm 2.5$ & 3.0 & $2-14$ & \\
\hline \multicolumn{6}{|c|}{ Peak bilirubin level $(\mu \mathrm{mol} / \mathrm{L})$} \\
\hline $\mathrm{ABO} / \mathrm{Rh}$ & 41 & $379.76 \pm 133.5$ & 364.0 & $158-801$ & \multirow{2}{*}{$\begin{array}{c}Z=1.95 \\
p=0.052 \mathrm{NS}\end{array}$} \\
\hline Unspecified & 126 & $333.44 \pm 91.1$ & 324.0 & $107-598$ & \\
\hline \multicolumn{6}{|c|}{ Duration of the bilirubin peak (days) } \\
\hline $\mathrm{ABO} / \mathrm{Rh}$ & 41 & $10.22 \pm 9.02$ & 6.0 & $1-37$ & \multirow{2}{*}{$\begin{array}{c}Z=2.09 \\
p=0.036^{*}\end{array}$} \\
\hline Unspecified & 126 & $15.03 \pm 25.7$ & 9.0 & $2-279$ & \\
\hline \multicolumn{6}{|c|}{ First control bilirubin $(\mu \mathrm{mol} / \mathrm{L})$} \\
\hline $\mathrm{ABO} / \mathrm{Rh}$ & 40 & $274.2 \pm 124.9$ & 235.5 & $96-682$ & \multirow{2}{*}{$\begin{array}{c}Z=1.87 \\
p=0.062 \mathrm{NS}\end{array}$} \\
\hline Unspecified & 112 & $227.39 \pm 80.7$ & 211.5 & $60-473$ & \\
\hline \multicolumn{6}{|c|}{ Second control bilirubin $(\mu \mathrm{mol} / \mathrm{L})$} \\
\hline $\mathrm{ABO} / \mathrm{Rh}$ & 24 & $227.46 \pm 83.4$ & 206.0 & $111-437$ & \multirow{2}{*}{$\begin{array}{c}Z=0.76 \\
p=0.448 \mathrm{NS}\end{array}$} \\
\hline Unspecified & 48 & $221.92 \pm 48.3$ & 228.5 & $51-314$ & \\
\hline \multicolumn{6}{|c|}{$\begin{array}{l}{ }_{*}^{*} p<0.05 . \\
{ }^{*} p<0.01 . \\
Z, \text { (Mann-Whitney U test); N, number of patients; SD, standard deviation; } p \text {, probability value; NS, not significant. } \\
\text { Information from Ref. [38]. }\end{array}$} \\
\hline
\end{tabular}

\section{Table 5.}

Reticulocytes and bilirubin analyses in neonatal jaundice, comparison between ABO/Rh incompatibility and unspecified etiology groups. 
in the group of unspecific jaundice. It remains speculative whether this was due to different mechanisms of jaundice involved, different responses to the phototherapy applied, or other influences such as diverse stringency to phototherapy.

According to an evidence-based review on neonatal hyperbilirubinemia, the majority of kernicterus cases occurred in infants with a bilirubin level higher than $20 \mathrm{mg} / \mathrm{dL}(342 \mu \mathrm{mol} / \mathrm{L})$ [39]. It was obvious that our hemolysis cases with mean peak bilirubin levels of $379.8 \pm 133.5 \mu \mathrm{mol} / \mathrm{L}$ were eligible for the neurotoxic effects of the hyperbilirubinemia, especially the ones toward the higher end of the spectrum and candidates for long-term neurodevelopmental follow-up. Therefore, clinicians' awareness of potential treats and harms that might be associated with isoimmunization is vital.

\section{Conclusions}

Neonatal indirect hyperbilirubinemia is a common phenomenon during the first week of postnatal life affecting almost two thirds of term newborns. The mechanism of neonatal jaundice is multifactorial, involving delicate balance between processes that potentiate bilirubin production and the ones that diminish bilirubin clearance. Although etiology of jaundice has been widely studied, identification of pathological causes presents constant clinical challenge.

Hyperbilirubinemia was found to be a common clinical presentation at the neonatology department of the University Pediatric Clinic in Skopje, Republic of North Macedonia, and encompassing one quarter of the hospitalized patients. Most cases suffered from a less severe jaundice of undefined etiology that had tendency to longer duration. Almost $15 \%$ of the hyperbilirubinemia cases presented with hemolytic causes of jaundice that had earlier and more severe peak of the bilirubin level. Those required immediate clinicians' attention and prompt management plan and were candidates for subsequent neurodevelopmental follow-up.

\section{Conflict of interest}

The authors declare no conflict of interest. 


\section{Author details}

Anet Papazovska Cherepnalkovski ${ }^{1 *}$, Natasha Najdanovska Aluloska ${ }^{2}$, Nikolina Zdraveska ${ }^{2}$, Katica Piperkova ${ }^{2}$ and Vjekoslav Krzelj ${ }^{3}$

1 University Clinic for Gynecology and Obstetrics, University Hospital Split and School of Medicine, University of Split, Croatia

2 University Children's Hospital, Medical Faculty, University Ss. Cyril and Methodius, Skopje, Republic of North Macedonia

3 University Clinic for Children's Diseases, University Hospital Split and School of Medicine, University of Split, Croatia

*Address all correspondence to: anet.cherepnalkovski@gmail.com

\section{IntechOpen}

(C) 2019 The Author(s). Licensee IntechOpen. This chapter is distributed under the terms of the Creative Commons Attribution License (http://creativecommons.org/licenses/ by/3.0), which permits unrestricted use, distribution, and reproduction in any medium, provided the original work is properly cited. (cc) BY 


\section{References}

[1] Detection and treatment of neonatal jaundice-NICE guideline. Lancet. 2010;375(9729):1845. DOI: $10.1016 /$ S0140-6736(10)60852-5

[2] Porter ML, Dennis BL. Hyperbilirubinemia in the term newborn. American Family Physician. 2002;65(4):599-606

[3] Watchko JF, Lin Z, Clark RH, et al. Complex multifactorial nature of significant hyperbilirubinemia in neonates. Pediatrics. 2009;124(5):e868-e877. DOI: 10.1542/ peds.2009-0460

[4] American Academy of Pediatrics, Subcommittee on Hyperbilirubinemia. Management of hyperbilirubinemia in the newborn infant 35 or more weeks of gestation. Pediatrics. 2004;114(1): 297-316. DOI: 10.1542/peds.114.1.297

[5] Bhutani VK, Johnson LH, Maisels MJ, et al. Kernicterus: Epidemiologic strategies for its prevention through systems-based approaches. Journal of Perinatology. 2004;24(10):650-662. DOI: 10.1038/sj.jp.7211152

[6] Watchko JF, Daood MJ, Biniwale M. Understanding neonatal hyperbilirubinemia in the era of genomics. Seminars in Neonatology. 2002;7(2):143-152. DOI: 10.1053/ siny.2002.0102

[7] Kaplan M, Hammerman C, Maisels MJ. Bilirubin genetics for the nongeneticist: Hereditary defects of neonatal bilirubin conjugation. Pediatrics. 2003;111(4):886-893. DOI: 10.1542/peds.111.4.886

[8] Kaplan M, Hammerman C. Bilirubin and the genome: The hereditary basis of unconjugated neonatal hyperbilirubinemia. Current Pharmacogenomics. 2005;3(1):21-42. DOI: $10.2174 / 1570160053174992$
[9] Dennery PA, Seidman DS, Stevenson DK. Neonatal hyperbilirubinemia. The New England Journal of Medicine. 2001;344(8):581-590. DOI: 10.1056/ NEJM200102223440807

[10] Maisels MJ. Neonatal jaundice. Pediatrics in Review. 2006;27(12): 443-454. DOI: 10.1542/pir.27-12-443

[11] Kaplan M, Abramov A. Neonatal hyperbilirubinemia associated with glucose-6-phosphate dehydrogenase deficiency in Sephardish-Jewish neonates: Incidence, severity and the effect of phototherapy. Pediatrics. 1992;90:401-405

[12] Papazovska Cherepnalkovski A, Marusic E, Piperkova K, Lozic B, Skelin A, Gruev T, et al. Influence of the inherited glucose-6-phosphate dehydrogenase deficiency on the appearance of neonatal hyperbilirubinemia in southern Croatia. Acta Informatica Medica. 2015;23(5):264-267. DOI: 10.5455/ aim.2015.23.264-267

[13] Kaplan M, Muraca M, Hammerman C, et al. Bilirubin conjugation, reflected by conjugated bilirubin fractions, in glucose6-phosphate dehydrogenase-deficient neonates: A determining factor in the pathogenesis of hyperbilirubinemia. Pediatrics. 1998;102:E37. DOI: 10.1542/ peds.102.3.e37

[14] Kaplan M, Hammerman C. Severe neonatal hyperbilirubinemia, a potential complication of glucose-6-phosphate dehydrogenase deficiency. Current Controversies in Perinatal Care III. 1998;25(3):575-590. DOI: https://doi. org/10.1016/S0095-5108(18)30098-8

[15] Kaplan M, Renbaum P, LevyLahad E, Hammerman C, Lahad A, Beutler E. Gilbert syndrome and 
glucose-6-phosphate dehydrogenase deficiency: A dose-dependent genetic interaction crucial to neonatal hyperbilirubinemia. Proceedings of the National Academy of Sciences of the United States of America. 1997;94:12128-12132. DOI: 10.1073/ pnas.94.22.12128

[16] Koosha A, Rafizadeh B.

Evaluation of neonatal indirect hyperbilirubinaemia at Zanjan Province of Iran in 2001-2003: Prevalence of glucose-6-phosphate dehydrogenase deficiency. Singapore Medical Journal. 2007;48(5):424-428

[17] Maisels MJ, Bhutani VK, Bogen D, Newman TB, Stark AR, Watchko JF. Hyperbilirubinemia in the Newborn infant $>35$ weeks of gestation: An update with clarifications. Pediatrics. 2009;124:1193-1198. DOI: 10.1542/ peds.2009-0329

[18] Piazza AJ, Stoll BJ. 102.3 Jaundice and hyperbilirubinemia in the newborn. In: Kliegman RM, Behrman RE, Jenson HB, Stanton BF, editors. Nelson Textbook of Pediatrics. 18th ed. Saunders; Elsevier; 2007. pp. 756-761

[19] Maisels MJ, Watchko JF, Bhutani VK, Stevenson DK. An approach to the management of hyperbilirubinemia in the preterm infant less than 35 weeks of gestation. Journal of Perinatology. 2012;32(9):660-664. DOI: 10.1038/ jp.2012.71

[20] van Imhoff DE, Dijk PH, Hulzebos CV, BARTrial study group, Netherlands Neonatal Research Network. Uniform treatment thresholds for hyperbilirubinemia in preterm infants: Background and synopsis of a national guideline. Early Human Development. 2011;87(8):521-525. DOI: 10.1016/j.earlhumdev.2011.04.004

[21] Bhutani VK, Wong RJ. Bilirubin neurotoxicity in preterm infants: Risk and prevention. Journal of Clinical
Neonatology. 2013;2(2):61-69. DOI:

$10.4103 / 2249-4847.116402$

[22] Wallenstein MB, Bhutani VK. Jaundice and kernicterus in the moderately preterm infant. Clinics in Perinatology. 2013;40(4):679-688. DOI: 10.1016/j.clp.2013.07.007

[23] Watchko JF. Hyperbilirubinemia and bilirubin toxicity in the late preterm infant. Clinics in Perinatology. 2006;33(4):839-852. DOI: $10.1016 / j$. clp.2006.09.002

[24] Osuorah CDI, Ekwochi U, Asinobi IN. Clinical evaluation of severe neonatal hyperbilirubinaemia in a resource-limited setting: $A$ 4-year longitudinal study in southEast Nigeria. BMC Pediatrics. 2018;18(1):202. DOI: 10.1186/ s12887-018-1174-z

[25] Alkalay AL, Simmons CF. Hyperbilirubinemia guidelines in newborn infants. Pediatrics. 2005;115(3):824-825. DOI: $10.1542 /$ peds.2004-2442

[26] Bratlid D, Nakstad B, Hansen TW. National guidelines for treatment of jaundice in the newborn. Acta Paediatrica. 2011;100(4):499-505. DOI: 10.1111/j.1651-2227.2010.02104.x

[27] Evans N. Slhd. Royal Prince Alfred Hospital Guideline. Women and Babies: Neonatal Jaundice [Internet]. 2018. Available from: https://www.slhd.nsw. gov.au/RPA/neonatal\%5Ccontent/pdf/ guidelines/RPAH_Newborn_Jaundice_ GL2018_002.pdf [Accessed: 04 June 2019]

[28] Papazovska Cherepnalkovski A, Piperkova K, Palcevska Kocevska S, Aluloska N, Zdraveska N, Gruev T, et al. Evaluation and management of neonatal indirect hyperbilirubinemia at the University Pediatric Clinic in Skopje, Republic of Macedonia. Medicus. 2015;20(2):221-229 
[29] Tiker F, Gulcan H, Kilicdag H, Tarcan A, Gurakan B. Extreme hyperbilirubinemia in newborn infants. Clinical Pediatrics (Phila). 2006;45(3):257-261. DOI: $10.1177 / 000992280604500308$

[30] Davutoğlu M, Garipardiç M, Güler E, Karabiber H, Erhan D. The etiology of severe neonatal hyperbilirubinemia and complications of exchange transfusion. The Turkish Journal of Pediatrics. 2010;52(2):163-166

[31] Kaplan M, Muraca M, Hammerman C, et al. Imbalance between production and conjugation of bilirubin: A fundamental concept in the mechanism of neonatal jaundice. Pediatrics. 2002;110(4):e47

[32] Fraser GR, Grunwald P, Stamatoyannopoulos G. Glucose6-phosphate dehydrogenase (G6PD) deficiency, abnormal haemoglobins, and thalassaemia in Yugoslavia. Journal of Medical Genetics. 1966;3:35-41. DOI: 10.1136/jmg.3.1.35

[33] Andreeva M, Efremov G, Markovska P, Vandevska M, Stojkovska L, Sajkovski M, et al. Urođeni deficit glukoza-6-fosfat dehidrogenaze i hemoglobinopatije na teritoriji Skoplja. Jug pedijat. 1982;25:19-26

[34] Reclos GJ, Hatzidakis CJ, Schulpis KH. Glucose-6-phosphate dehydrogenase deficiency neonatal screening: Preliminary evidence that a high percentage of partially deficient female neonates are missed during routine screening. Journal of Medical Screening. 2000;7(1):46-51. DOI: 10.1136/jms.7.1.46

[35] Zaffanello M, Rugolotto S, Zamboni G, Gaudino R, Tatò L. Neonatal screening for glucose-6-phosphate dehydrogenase deficiency fails to detect heterozygote females. European Journal of Epidemiology. 2004;19(3):255-257.

DOI: https://doi.org/10.1023/ B:EJEP.0000020445.48298.3f
[36] Kaplan M, Bromiker R, Hammerman C. Hyperbilirubinemia, hemolysis, and increased bilirubin neurotoxicity. Seminars in Perinatology. 2014;38(7):429-437. DOI: 10.1053/j. semperi.2014.08.006

[37] Hakan N, Zenciroglu A, Aydin M, Okumus N, Dursun A, Dilli D.

Exchange transfusion for neonatal hyperbilirubinemia: An 8-year single center experience at a tertiary neonatal intensive care unit in Turkey. The Journal of Maternal-Fetal \& Neonatal Medicine. 2014;22:1-5. DOI: 10.3109/14767058.2014.960832

[38] Papazovska Cherepnalkovski A, Krzelj V, Zafirova Ivanovska B, Gruev T, Markic J, Aluloska N, et al. Evaluation of neonatal hemolytic jaundice: Clinical and laboratory parameters. Open Access Macedonian Journal of Medical Sciences. 2015;3(4):694-698. DOI: 10.3889/oamjms.2015.129

[39] Ip S, Chung M, Kulig J, et al. An evidence-based review of important issues concerning neonatal hyperbilirubinemia. Pediatrics.

2004;114(1):e130-e153. DOI: 10.1542/

peds.114.1.e130 



\title{
Neonatal Respiratory Distress Syndrome: Things to Consider and Ways to Manage
}

\author{
Bita Najafian and Mohammad Hossein Khosravi
}

\begin{abstract}
Involving more commonly the premature (less than 37 weeks of gestational age) infants, neonatal respiratory distress syndrome is an important clinical syndrome responsible for a high rate of mortality and morbidity. The main progress in respiratory distress syndrome (RDS) management is attributable to prescription of surfactant for fastening pulmonary maturation. Respiratory protection, such as mechanical ventilation and nasal continuous positive airway pressure, and surfactant are building blocks of disease treatment. In this chapter, we are going to have a rapid review on epidemiology, diagnosis and treatments of RDS.
\end{abstract}

Keywords: respiratory distress syndrome, epidemiology, treatment, etiology

\section{Introduction}

Involving more commonly the premature (less than 37 weeks of gestational age) infants, neonatal respiratory distress syndrome (NRDS), is an important clinical syndrome responsible for a high rate of mortality and morbidity. Reports have shown that about $12 \%$ of infants are preterm in the United States, while the prevalence ranges between 6 and 11\% in European countries [1, 2]. NRDS is a leading cause of admission to neonatal intensive care unit (NICU) with estimated incidence rate of $7.8 \%$ and mortality rate of $50 \%$ in premature infants [3-5]. The severity usually increases during the first 48 hours of birth [6]. The prevalence and the severity of NRDS decrease as the gestational age increases [7-9].

A variety of factors including cesarean section, prematurity, maternal diabetes and genetic variations have been reported to play role in pathogenesis of NRDS $[10,11]$. Damage to type II alveolar cells is another considered mechanism for NRDS. Diffuse alveolar capillary injury results in progressive increased permeability as well as pulmonary and alveolar edema, which make the type II alveolar cells nonfunctional. All these processes lead into severe hypoxemia due to abnormal ventilation/perfusion ratio $[12,13]$.

NRDS is a result of pulmonary immaturity mostly caused by insufficient levels of surfactant $[14,15]$. The condition is developed through hypoventilation, hypoxemia and respiratory acidosis $[14,15]$. 


\section{Diagnosis}

Early diagnosis is of a high importance due to available management methods $[15,16]$. A combination of clinical signs and different modalities such as chest radiographies and laboratory tests are needed for diagnosing NRDS [14].

\subsection{Clinical signs and symptoms}

There are a wide range of clinical signs from nasal flaring and cyanosis to substernal and intercostal retraction, tachypnea and grunting [16]. A risk assessment tool called "Clinical Risk Index for Babies" (CRIB) is used to estimate the need for admission of infants in NICU [17]. Different factors such as gestational age, birth weight and base excess during the first 12 hours of life, fraction of inspired oxygen and presence of congenital malformations are considered in this assessment (Table 1).

\subsection{Laboratory tests}

Arterial oxygen pressure $\left(\mathrm{PaO}_{2}\right)$ is a marker for diagnosis of NRDS. $\mathrm{PaO}_{2}$ less than $50 \mathrm{mmHg}$ with cyanosis in room air or need for supplementary oxygen for maintaining $\mathrm{O}_{2}$ level above $50 \mathrm{mmHg}$ are indicators for NRDS [14]. Metabolic and respiratory acidosis are measured through a blood sample.

Gastric aspirate shake test (GAST) is another laboratory measure with reported sensitivity of $100 \%$ and specificity of $92 \%$ for diagnosis of NRDS [18]. GAST identifies presence or lack of surfactant in the gastric fluid aspirates [19].

Recently published studies have mentioned a new factor for early detection and prediction of NRDS in premature infants. Transforming growth factor $\beta 1$ (TGF- $\beta 1$ ) is a cytokine, which has the responsibility for regulating and differentiating different cell lines $[20,21]$. These studies have marked the role of TGF- $\beta 1$ in development of various acute and chronic lung injuries and concluded that this factor can be used as a diagnostic and prognostic one [22]. The same role has been considered for interleukin-6, which is a glycoprotein secreted mostly from $\mathrm{T}$ cells and mononuclear macrophages causing inflammatory reactions [23, 24].

\subsection{Chest radiographs}

Previous studies have reported a remarkable diagnostic value for chest radiographs [25]. Features such as reduced lung expansions, air bronchograms and dilated bronchioles can be seen in NRDS [15]. In addition to diagnostic use, chest radiographs have another application to confirm endotracheal tube position. Premature infants receive continuous positive airways pressure (CPAP) for augmenting oxygenation in addition to simplifying intra-tracheal administration of surfactants [14]. The precise adverse effects of radiation have not been yet determined; however, some efforts are being done to find an alternative method for chest radiography [26-28].

\subsection{Ultrasound}

Previously, lung ultrasound (LUS) was not used for infant chest imaging due to interference of air levels. This modality has its own potential adverse effects including thermal and mechanical tissue damage [27, 29]. Recently, lung ultrasound 
Neonatal Respiratory Distress Syndrome: Things to Consider and Ways to Manage DOI: http://dx.doi.org/10.5772/intechopen.90885

\begin{tabular}{|c|c|}
\hline Factor & Score \\
\hline \multicolumn{2}{|l|}{ Birth weight (gr) } \\
\hline$>1350$ & 0 \\
\hline $851-1350$ & 1 \\
\hline $701-850$ & 4 \\
\hline$\leq 700$ & 7 \\
\hline \multicolumn{2}{|l|}{ Gestation (week) } \\
\hline$>24$ & 0 \\
\hline$\leq 24$ & 1 \\
\hline \multicolumn{2}{|l|}{ Congenital malformations* } \\
\hline None & 0 \\
\hline Not actually life-threatening & 1 \\
\hline Actually life threatening & 3 \\
\hline \multicolumn{2}{|c|}{ Maximum base excess in first $12 \mathrm{~h}(\mathrm{nmol} / \mathrm{L})$} \\
\hline$>-7$ & 0 \\
\hline-7 to -9.9 & 1 \\
\hline-10 to 14.9 & 2 \\
\hline$\leq-15$ & 3 \\
\hline \multicolumn{2}{|c|}{ Minimum appropriate $\mathrm{FIO}_{2}$ in first $12 \mathrm{~h}$} \\
\hline$\leq 40 \%$ & 0 \\
\hline $41-60 \%$ & 2 \\
\hline $61-90 \%$ & 3 \\
\hline $91-100 \%$ & 4 \\
\hline \multicolumn{2}{|c|}{ Maximum appropriate $\mathrm{FIO}_{2}$ in first $12 \mathrm{~h}$} \\
\hline$<40 \%$ & 0 \\
\hline $41-80 \%$ & 1 \\
\hline $81-90 \%$ & 3 \\
\hline $91-100 \%$ & 5 \\
\hline
\end{tabular}

Table 1.

CRIB score.

has been widely used as an accurate diagnostic tool according to published clinical studies [4, 7, 16, 30-34]. Lack of normal air-filled levels and presence of fluid level is a diagnostic clue for NRDS.

A meta-analysis of six studies comparing LUS to chest $\mathrm{x}$-ray for diagnosing NRDS reported a high diagnostic sensitivity (97\%) and specificity (91\%) for LUS [35]. They have also reported that transthoracic technique is superior to transabdominal approach for diagnosing NRDS.

On the other hand, some researchers believe that lung ultrasound can be helpful only as a complementary diagnostic tool rather than a diagnostic method [36]. They have mentioned in a letter-to-editor that only chest radiographs and CT scan can be reliable for diagnosing neonatal respiratory distress syndrome. 


\section{Management}

\subsection{Mechanical ventilation}

Mechanical ventilation is the most commonly applied treatment method for NRDS in clinical practice [37-39]; although mechanical ventilation and continuous oxygen therapy are independent risk factors for development of NRDS to bronchopulmonary dysplasia (BPD) [40, 41]. Noninvasive respiratory support methods such as nasal intermittent positive pressure ventilation (NIPPV), high flow nasal cannula (HFNC) and nasal continuous positive airway pressure (NCPAP) are being used more commonly as the initial ways of management, which may decrease need for intubation in up to $50 \%$ of infants [42-44]. On the other hand, the failure of noninvasive respiratory support results in delayed administration of surfactant and prolonged mechanical ventilation. Also, this may be associated with higher incidence of bronchopulmonary dysplasia (BPD), major morbidity or even death $[45,46]$. So, it seems that a combination of early respiratory support and prescription of surfactant may improve the treatment results. Administration of surfactant during NCPAP, less-invasive (LISA) and minimalinvasive surfactant administration (MISA) have shown convenient results in management of NRDS [47].

Recently published studies have introduced the aerosolized surfactant as a safe and efficient method of drug delivery [47]. It has been claimed that vibrating and ultrasonic mesh nebulizers have the ability to make surfactant aerosols without interfering with biochemical composition of medication [48-50]. It has been reported that aerosolized surfactant can be delivered using nasal cannula in noninvasive respiratory support [51-55].

\subsection{Surfactant}

Pathophysiology of NRDS (inadequate production of pulmonary surfactant in premature infants) was first discovered by Avery and Mead in 1959, which resulted in changing the former name of the disease "hyaline membrane disease" [56]. This was a window to surfactant replacement therapy.

Lung surfactant is a mixture of phospholipids and some specific proteins secreted by epithelium of alveoli, which lines the small airways. It primarily reduces the surface tension of liquid presented in terminal air spaces [57]. Lack of pulmonary surfactant is the main result of NRDS; so, prescription of pulmonary surfactant can augment respiratory function and pulmonary compliance resulting in elevated oxyhemoglobin level [58-61]. Lack of surfactant results in a chain of problems from collapsed lung, tissue damage, reduced oxygenation and impaired function of alveolar epithelium, resulting in altered production of surfactant [62]. Fujiwara et al. reported the very first application of surfactant-TA in preterm infants with respiratory distress syndrome in 1980 [63].

There are different kinds of animal-derived as well as first- and second-generation synthetic surfactants [64]. As a natural surfactant, Curosurf is taken from pig lung, which is consisted of $41-48 \%$ lecithin and $51-58 \%$ of hydrophobin and other phospholipids. Liquid gel layer has the responsibility to absorb the Curosurf after its administration to the lungs [65]. Also, this medication has some adverse effects including respiratory discomforts and bucking $[66,67]$. Administration of surfactant involves frequent endotracheal intubation (INSURE: INtubation-SURfactantExtubation) and mechanical ventilation, which is associated with inevitable comorbidities $[68,69]$. 
Recently, in addition to the common INSURE method, a new method has come up and is getting more popular. This method is called a less-invasive surfactant administration (LISA), which has been reported to be more effective in prevention of bronchopulmonary dysplasia and reducing preterm infants' mortality. In this method, surfactant is delivered through a thin catheter while the infant is under continuous positive airway pressure (CPAP) treatment. However, more large-scale randomized clinical trials are needed to make this method accepted as a routine in clinical practice [70].

\subsection{Ambroxol hydrochloride}

As an active metabolite of bromhexine, ambrotherxol or ambroxol hydrochloride has a mucolytic activity. A wide range of advantages have been reported for ambroxol hydrochloride from reducing production of hydrogen peroxide, stimulating secretion of pulmonary surfactant, reducing lung damage and alleviating the inflammatory response to relieving pulmonary edema and interstitial exudation. As a low-cost and high-efficacy medication, ambroxol hydrochloride is being used in clinical treatment of NRDS [71, 72]. There are reports about satisfactory results of combination of high-dose ambroxol hydrochloride and surfactant [37].

\subsubsection{Nitric oxide (NO)}

About $2 \%$ of all live births are involved with respiratory failure, which is responsible for more than one-third of neonatal mortalities [73]. Inhaled NO (iNO) reduces pulmonary vascular resistance, edema, lung inflammation and hypoxia, which makes the respiratory difficulties easier for infants [74]. Previous researches have also shown that iNO improves pulmonary angiogenesis and protects pulmonary system against infections with no remarkable adverse effects on growth or neurodevelopmental status [75].

Neonatal respiratory distress syndrome (NRDS), as a result of inadequate surfactant production, leads to atelectasis and ventilation-perfusion (V/Q) mismatching. Beside notable response to exogenous surfactant, it has been reported that iNO transiently improves oxygenation in infants with NRDS. Previous studies have shown that iNO therapy alone reduces mortality rate in preterm infants [76]. iNO improves V/Q matching, selectively dilates the pulmonary vasculature and decreases pulmonary inflammatory response. The most convenient advantage of iNO is reducing incidence of chronic lung disease in premature infants with RDS [77]. In other researches, premature infants with suboptimal response to exogenous surfactant showed beneficial clinical responses to combination therapy with iNO [78].

\section{Prognosis}

Neonatal respiratory distress syndrome is one of the major causes of premature death; however, a notable part of the survivors may develop bronchopulmonary dysplasia and suffer from chronic pulmonary diseases [67]. Prognosis of RDS is highly related to the treatment and management methods, which have been being developed since their discovery. The efficacy of each method for prognosis is under investigation. Also, gestational age has an important role in determining the prognosis, where late preterm infants usually have a better prognosis in comparison with early preterm infants. 


\section{Conclusion}

According to high prevalence and clinical importance of NRDS, seeking new methods of diagnosis and treatment is of a high importance. Available knowledge approves efficacy of surfactant as the stumbling block of medical NRDS management; however, various methods of drug delivery are under development. It seems that a combination of respiratory support and surfactant is the ideal method of management.

\section{Conflict of interest}

There are no conflict of interests in terms of the present chapter.

\section{Author details}

Bita Najafian $^{1 *}$ and Mohammad Hossein Khosravi ${ }^{2}$

1 Department of Pediatrics, Faculty of Medicine, Baqiyatallah University of Medical Sciences, Tehran, Iran

2 International Otorhinolaryngology Research Association (IORA), Universal Scientific Education and Research Network (USERN), Tehran, Iran

*Address all correspondence to: dr.najafian@yahoo.com

\section{IntechOpen}

(C) 2020 The Author(s). Licensee IntechOpen. This chapter is distributed under the terms of the Creative Commons Attribution License (http://creativecommons.org/licenses/ by/3.0), which permits unrestricted use, distribution, and reproduction in any medium, provided the original work is properly cited. (cc) BY 


\section{References}

[1] Glass HC, Costarino AT, Stayer SA, Brett C, Cladis F, Davis PJ. Outcomes for extremely premature infants. Anesthesia and Analgesia. 2015;120(6):1337

\section{[2] Zeitlin J, Szamotulska K,} Drewniak N, Mohangoo A, Chalmers J, Sakkeus L, et al. Preterm birth time trends in Europe: A study of 19 countries. BJOG: An International Journal of Obstetrics and Gynaecology. 2013;120(11):1356-1365

[3] El HE-DGM, Hany S, Mahmoud MK, Ali AM. Lung ultrasonography in evaluation of neonatal respiratory distress syndrome. The Egyptian Journal of Radiology and Nuclear Medicine. 2015;46(2):469-474

\section{[4] Liu J, Cao H-Y, Wang H-W, Kong} $\mathrm{X}-\mathrm{Y}$. The role of lung ultrasound in diagnosis of respiratory distress syndrome in newborn infants. Iranian Journal of Pediatrics. 2014;24(2):147

[5] Zhou B, Zhai J-F, Wu J-B, Jin B, Zhang Y-Y. Different ventilation modes combined with ambroxol in the treatment of respiratory distress syndrome in premature infants. Experimental and Therapeutic Medicine. 2017;13(2):629-633

[6] British Association of Perinatal Medicine. Guidelines for Good Practice in the Management of Neonatal Respiratory Distress Syndrome. London: BAPM; 1999

[7] Lovrenski J. Lung ultrasonography of pulmonary complications in preterm infants with respiratory distress syndrome. Upsala Journal of Medical Sciences. 2012;117(1):10-17

[8] Euro-Peristat. European perinatal health report health and care of pregnant women and babies in Europe in 2010. Available from: www.premup. org/. [2013, Accessed: 27 March 2016]

[9] Khosravi MH, Najafian B, Bigham P, Torkaman M, Shohrati M. Comparison of intravenous dexamethasone and budesonide nebulizer in the treatment of infantile respiratory distress syndrome; A randomized clinical trial. Razavi International Journal Medicine;13(23)

[10] Liszewski MC, Stanescu AL, Phillips GS, Lee EY. Respiratory distress in neonates: Underlying causes and current imaging assessment. Radiologic Clinics. 2017;55(4):629-644

[11] Tochie JN, Choukem S-P, Langmia RN, Barla E, Koki-Ndombo P. Neonatal respiratory distress in a reference neonatal unit in Cameroon: An analysis of prevalence, predictors, etiologies and outcomes. Pan African Medical Journal. 2016;24(1)

[12] Tabit CE, Chung WB, Hamburg NM, Vita JA. Endothelial dysfunction in diabetes mellitus: Molecular mechanisms and clinical implications. Reviews in Endocrine \& Metabolic Disorders. 2010;11(1):61-74

[13] Speer CP. Neonatal respiratory distress syndrome: An inflammatory disease? Neonatology. 2011;99(4):316-319

[14] Sweet DG, Carnielli V, Greisen G, Hallman M, Ozek E, Plavka R, et al. European consensus guidelines on the management of neonatal respiratory distress syndrome in preterm infants-2013 update. Neonatology. 2013;103(4):353-368

[15] Agrons GA, Courtney SE, Stocker JT, Markowitz RI. Lung disease in premature neonates: Radiologicpathologic correlation. Radiographics. 2005;25(4):1047-1073 
[16] Grappone L, Messina F. Hyaline membrane disease or respiratory distress syndrome? A new approach for an old disease. Journal of Pediatric and Neonatal Individualized Medicine (JPNIM). 2014;3(2):e030263

[17] Cockburn F, Cooke R, Gamsu H, Greenough A, Hopkins A, Mcintosh N, et al. The CRIB (clinical risk index for babies) score. The Lancet. 1993;342(8865):193-198

[18] NooriShadkam M, Lookzadeh MH, Taghizadeh M, Golzar A, NooriShadkam Z. Diagnostic value of gastric shake test for hyaline membrane disease in preterm infant. Iranian Journal of Reproductive Medicine. 2014;12(7):487

[19] Ahuja CK, Saxena AK, Sodhi KS, Kumar P, Khandelwal N. Role of transabdominal ultrasound of lung bases and follow-up in premature neonates with respiratory distress soon after birth. The Indian Journal of Radiology and Imaging. 2012;22(4):279

[20] Gaede KI, Amicosante M, Schürmann M, Fireman E, Saltini C, Müller-QuernheimJ.Function associated transforming growth factor- $\beta$ gene polymorphism in chronic beryllium disease. Journal of Molecular Medicine. 2005;83(5):397-405

[21] Kinnula V. Focus on antioxidant enzymes and antioxidant strategies in smoking related airway diseases. Thorax. 2005;60(8):693-700

[22] Chen F, Huang F, Zhan F. Correlation between serum transforming growth factor $\beta 1$, interleukin- 6 and neonatal respiratory distress syndrome. Experimental and Therapeutic Medicine. 2019;18(1):671-677

[23] Iannuzzi MC, Rybicki BA. Genetics of sarcoidosis: Candidate genes and genome scans. Proceedings of the American Thoracic Society. 2007;4(1):108-116

[24] Rincon M, Irvin CG. Role of IL-6 in asthma and other inflammatory pulmonary diseases. International Journal of Biological Sciences. 2012;8(9):1281

[25] Vergine M, Copetti R, Brusa G, Cattarossi L. Lung ultrasound accuracy in respiratory distress syndrome and transient tachypnea of the newborn. Neonatology. 2014;106(2):87-93

[26] Harbron RW. Cancer risks from low dose exposure to ionising radiation-is the linear no-threshold model still relevant? Radiography. 2012;18(1):28-33

[27] Lichtenstein DA, Mauriat P. Lung ultrasound in the critically ill neonate. Current Pediatric Reviews. 2012;8(3):217-223

[28] Pereda MA, Chavez MA, Hooper-Miele CC, Gilman RH, Steinhoff MC, Ellington LE, et al. Lung ultrasound for the diagnosis of pneumonia in children: A meta-analysis. Pediatrics. 2015;135(4):714-722

[29] Sande RK, Kiserud T. Ultrasound safety, power and image quality: What do we know? Fetal and Maternal Medicine Review. 2013;24(4):260-276

[30] Raimondi F, Migliaro F, Sodano A, Ferrara T, Lama S, Vallone G, et al. Use of neonatal chest ultrasound to predict noninvasive ventilation failure. Pediatrics. 2014;134(4):e1089-e1e94

[31] Bober K, Swietliński J. Diagnostic utility of ultrasonography for respiratory distress syndrome in neonates. Medical Science Monitor. 2006;12(10):CR440-CRCR6

[32] Federici M, Federici P, Feleppa F, Gizzi C, Agostino R, Bellelli A, et al. Pulmonary ultrasonography in the follow-up of respiratory distress 
syndrome on preterm newborns.

Reduction of X-ray exposure. Journal of

Ultrasound. 2011;14(2):78-83

[33] Sawires HK, Ghany EAA, Hussein NF, Seif HM. Use of lung ultrasound in detection of complications of respiratory distress syndrome. Ultrasound in Medicine \& Biology. 2015;41(9):2319-2325

[34] Pang H, Zhang B, Shi J, Zang J, Qiu L. Diagnostic value of lung ultrasound in evaluating the severity of neonatal respiratory distress syndrome. European Journal of Radiology. 2019;116:186-191

[35] Hiles M, Culpan A-M, Watts C, Munyombwe T, Wolstenhulme S. Neonatal respiratory distress syndrome: Chest X-ray or lung ultrasound? A systematic review. Ultrasound. 2017;25(2):80-91

[36] Quarato CMI, Verrotti dPV, Sperandeo M. Transthoracic ultrasound in neonatal respiratory distress syndrome (NRDS): Complementary diagnostic tool. European Journal of Radiology. 2019;120:108664

[37] Xiang J, Wang P. Efficacy of pulmonary surfactant combined with high-dose ambroxol hydrochloride in the treatment of neonatal respiratory distress syndrome. Experimental and Therapeutic Medicine. 2019;18(1):654-658

[38] Najafian B, Esmaeili B, Khosravi MH. Comparison of fentanyl and midazolam for the sedation of infants under mechanical ventilation; a randomized clinical trial. Hospital Practices and Research. 2017;2(3):63-67

[39] Najafian B, Eyvazloo H, Khosravi MH. Effects of different doses of fentanyl on the sedation of infants under mechanical ventilation; A randomized clinical trial. Hospital Practices and Research. 2017;2(4):109-112

[40] Lassi ZS, Middleton PF, Crowther C, Bhutta ZA. Interventions to improve neonatal health and later survival: An overview of systematic reviews. eBioMedicine. 2015;2(8):985-1000

[41] Khosravi MH, Najafian B, AnsariBenam I, Torkaman M. Comparing the efficacy of NCPAP and NIPPV in infants with RDS after extubation; A randomized clinical trial. Razavi International Journal Medicine;13(26)

[42] Morley CJ, Davis PG, Doyle LW, Brion LP, Hascoet J-M, Carlin JB. Nasal CPAP or intubation at birth for very preterm infants. The New England Journal of Medicine. 2008;358(7):700-708

[43] Bancalari E, Claure N. The evidence for non-invasive ventilation in the preterm infant. Archives of Disease in Childhood - Fetal and Neonatal Edition. 2013;98(2):F98-F102

[44] Kugelman A, Riskin A, Said W, Shoris I, Mor F, Bader D. A randomized pilot study comparing heated humidified high-flow nasal cannulae with NIPPV for RDS. Pediatric Pulmonology. 2015;50(6):576-583

[45] Miall L, Wallis S. The management of respiratory distress in the moderately preterm newborn infant. Archives of Disease in Childhood-Education and Practice. 2011;96(4):128-135

[46] Dargaville PA, Gerber A, Johansson S, De Paoli AG, Kamlin COF, Orsini F, et al. Incidence and outcome of CPAP failure in preterm infants. Pediatrics. 2016;138(1):e20153985

[47] Sood BG, Cortez J, Kolli M, Sharma A, Delaney-Black V, Chen X. Aerosolized surfactant in neonatal respiratory distress syndrome: Phase 
I study. Early Human Development. 2019;134:19-25

[48] Schermuly R, Schmehl T, Gunther A, Grimminger F, Seeger W, Walmrath D. Ultrasonic nebulization for efficient delivery of surfactant in a model of acute lung injury: Impact on gas exchange. American Journal of Respiratory and Critical Care Medicine. 1997;156(2):445-453

[49] Ellyett K, Broadbent R, Fawcett E, Campbell A. Surfactant aerosol treatment of respiratory distress syndrome in the spontaneously breathing premature rabbit. Pediatric Research. 1996;39(6):953

[50] Marks L, Notter R, Oberdorster G, McBride J. Ultrasonic and jet aerosolization of phospholipids and the effects on surface activity. Pediatric Research. 1983;17(9):742

[51] Bhashyam AR, Wolf MT, Marcinkowski AL, Saville A, Thomas K, Carcillo JA, et al. Aerosol delivery through nasal cannulas: An in vitro study. Journal of Aerosol Medicine and Pulmonary Drug Delivery.

2008;21(2):181-188

[52] Sunbul FS, Fink JB, Harwood R, Sheard MM, Zimmerman RD, Ari A. Comparison of HFNC, bubble CPAP and SiPAP on aerosol delivery in neonates: An in-vitro study. Pediatric Pulmonology. 2015;50(11):1099-1106

[53] DiBlasi RM. Clinical controversies in aerosol therapy for infants and children. Respiratory Care. 2015;60(6):894-916

[54] Ari A. Aerosol drug delivery through high flow nasal cannula. Current Pharmaceutical Biotechnology. 2017;18(11):877-882

[55] Al-Subu AM, Hagen S, Eldridge M, Boriosi J. Aerosol therapy through high flow nasal cannula in pediatric patients.
Expert Review of Respiratory Medicine. 2017;11(12):945-953

[56] Avery ME, Mead J. Surface properties in relation to atelectasis and hyaline membrane disease. AMA Journal of Diseases of Children. 1959;97(5_PART_I):517-523

[57] Johansson J, Curstedt T. Synthetic surfactants with SP-B and SP-C analogues to enable worldwide treatment of neonatal respiratory distress syndrome and other lung diseases. Journal of Internal Medicine. 2019;285(2):165-186

[58] Fan Y-Z, Wen Z-L. Efficacy of different dosages of ambroxol hydrochloride in the prevention of neonatal respiratory distress syndrome. Chinese Journal of Contemporary Pediatrics. 2009;11(9):771-772

[59] Wu X, Li S, Zhang J, Zhang Y, Han L, Deng Q, et al. Meta-analysis of high doses of ambroxol treatment for acute lung injury/acute respiratory distress syndrome based on randomized controlled trials. The Journal of Clinical Pharmacology. 2014;54(11):1199-1206

[60] Najafian B, Karimi-Sari H, Khosravi MH, Nikjoo N, Amin S, Shohrati M. Comparison of efficacy and safety of two available natural surfactants in Iran, Curosurf and Survanta in treatment of neonatal respiratory distress syndrome: $\mathrm{A}$ randomized clinical trial. Contemporary Clinical Trials Communications.

2016;3:55-59

[61] Najafian B, Khosravi MH, Setayesh F, Shohrati M. Comparing the effect of Inhaler $\mathrm{N}$-acetyl cysteine and intravenous dexamethasone on respiratory distress syndrome in premature infants: A randomized clinical trial. Thrita. 2017;6(1)

[62] Sardesai S, Biniwale M, Wertheimer F, Garingo A, 
Ramanathan R. Evolution of surfactant therapy for respiratory distress syndrome: Past, present, and future. Pediatric Research. 2017;81(1-2):240

[63] Fujiwara T, Chida S, Watabe Y, Maeta H, Morita T, Abe T. Artificial surfactant therapy in hyalinemembrane disease. The Lancet. 1980;315(8159):55-59

[64] Jeon GW. Surfactant preparations for preterm infants with respiratory distress syndrome: Past, present, and future. Korean Journal of Pediatrics. 2019;62(5):155

[65] K Ketko A, M Donn S. Surfactantassociated proteins: Structure, function and clinical implications. Current Pediatric Reviews. 2014;10(2):162-167

[66] Gortner L, Schüller SS, Herting E. Review demonstrates that less invasive surfactant administration in preterm neonates leads to fewer complications. Acta Paediatrica. 2018;107(5):736-743

[67] Zhang C, Zhu X. Clinical effects of pulmonary surfactant in combination with nasal continuous positive airway pressure therapy on neonatal respiratory distress syndrome. Pakistan Journal of Medical Sciences. 2017;33(3):621

[68] van Bel F, de Winter PJ, Wijnands HB, van de Bor M, Egberts J. Cerebral and aortic blood flow velocity patterns in preterm infants receiving prophylactic surfactant treatment. Acta Pædiatrica. 1992;81(6-7):504-510

[69] Durrmeyer X, Danan C. Neonatal intubation. In: Rimensberger PC, editor. Pediatric and Neonatal Mechanical Ventilation. Berlin Heidelberg: SpringerVerlag; 2015

[70] Lista G, Bresesti I, Fabbri L. Is less invasive surfactant administration necessary or "only" helpful or just a fashion? American Journal of Perinatology. 2018;35(06):530-533

[71] Baranwal AK, Murthy AS, Singhi SC. High-dose oral ambroxol for early treatment of pulmonary acute respiratory distress syndrome: An exploratory, randomized, controlled pilot trial. Journal of Tropical Pediatrics. 2015;61(5):339-350

[72] Elsayed HF, Elkhaiouby MI, Elsharkawey SM, Elnemr MA. Evaluation of the role of postnatal ambroxol in the prevention and treatment of respiratory distress syndrome in preterm neonates. Sultan Qaboos University Medical Journal. 2006;6(2):41

[73] Steinhorn RH. Neonatal pulmonary hypertension. Pediatric Critical Care Medicine. 2010;11(2 Suppl):S79

[74] Ghanta S, Leeman KT, Christou H. An update on pharmacologic approaches to bronchopulmonary dysplasia. In: Seminars in Perinatology. WB Saunders; 1 Apr 2013;37(2):115-123

[75] Akter F, Coghlan G, de Mel A. Nitric oxide in paediatric respiratory disorders: Novel interventions to address associated vascular phenomena? Therapeutic Advances in Cardiovascular Disease. 2016;10(4):256-270

[76] Dzierba AL, Abel EE, Buckley MS, Lat I. A review of inhaled nitric oxide and aerosolized epoprostenol in acute lung injury or acute respiratory distress syndrome. Pharmacotherapy: The Journal of Human Pharmacology and Drug Therapy. 2014;34(3):279-290

[77] Schreiber MD, Gin-Mestan K, Marks JD, Huo D, Lee G, Srisuparp P. Inhaled nitric oxide in premature infants with the respiratory distress syndrome. The New England Journal of Medicine. 2003;349(22):2099-2107 
[78] Uy IP, Pryhuber GS, Chess PR, Notter RH. Combined-modality therapy with inhaled nitric oxide and exogenous surfactant in term infants with acute respiratory failure. Pediatric Critical Care Medicine. 2000;1(2):107-110 


\title{
One of the Main Problems of Infants: Bronchiolitis
}

\author{
Şule Gökçe
}

\begin{abstract}
Acute bronchiolitis, which is the most common acute lower respiratory system disease, is resulting in significant morbidity and mortality in children less than 2 years. Respiratory syncytial virus (RSV) is the most common causative pathogen for over 30 million new acute lower respiratory infection episodes in children under 5 years of age. Rhinovirus, adenovirus, influenza virus, parainfluenza, and other respiratory viruses also cause acute bronchiolitis as the sole pathogen or as coinfection with or without RSV. Cardiovascular disease, chronic pulmonary disease, immunodeficiency, and premature birth are important risk factors for hospitalization and increase the risk of acute bronchiolitis-associated respiratory failure or even death. Bronchiolitis is a clinical diagnosis that varies from mild illness to severe respiratory failure. The severity of bronchiolitis is evaluated with several parameters including wheezing, retraction, respiratory rate, and general situation. However, the most important clinical finding is the presence or absence of hypoxemia and whether the patient can tolerate respiratory distress. Fluid support and oxygen supplementation by nasal cannula, face mask, or head box are critical for the treatment of bronchiolitis. Commonly used bronchodilators, corticosteroids, ribavirin, and antibiotics have not been shown to be effective in improving the clinical course of the bronchiolitis.
\end{abstract}

Keywords: acute bronchiolitis, infant, RSV

\section{Introduction}

Acute bronchiolitis is the most common lower lung disease that causes substantial morbidity and hospitalization in young infants under 6 months of age $[1,2]$. In the first year of life, approximately $20-30 \%$ of children suffer from acute bronchiolitis that is frequently seen during the winter season, and infants are hospitalized with bronchiolitis [3]. During the epidemic season (late-autumn and winter months), the rate of bronchiolitis requiring hospitalization in all infants smaller than 12 months have been reported as 3\% of in the US and Europe [4]. Prematurity and being born during the RSV season are risks factors for hospitalization [5]. A recent study has stated that the rate of hospitalization for bronchiolitis is $5.4 \%$ in preterm infants in the first 12 months of life [6]. A few studies particularly focused on the costs of bronchiolitis hospitalization reported that bronchiolitis admissions cost more than 500 million dollars annually and a co-diagnosis of bronchiolitis and pneumonia almost doubles the cost of the hospitalization [7].

Bronchiolitis is a viral disease in the infant period. Respiratory syncytial virus (RSV) is the most common agent that causes $50-80 \%$ of the cases. Its peak clinical 
severity is seen between third and fifth days. Respiratory syncytial virus bronchiolitis is responsible for a short history of low-grade fever, cough, coryza, and difficulty in breathing and feeding. Infants who are under 6 weeks of age might be present with apnea alone without other clinical symptoms [8]. There are several predispositions to developing RSV infection in infants. A few of them are presence of an older sibling, birth in the RSV season, low birth weight, male sex, young age ( $<6$ months), exposure to smoking, young maternal age, and suburban residence. Having congenital heart disease, chronic lung disease, immunodeficiency, cystic fibrosis, Down syndrome, or cerebral palsy increases the severity of RSV bronchiolitis [9]. In the pathogenesis of RSV bronchiolitis, there are a defective inflammatory response and cellular damage related to viral replication. Annually, RSV associated with lower respiratory tract infection in infants and young children leads to around 3.2 million hospitalizations and 59,000 deaths worldwide [10]. To date, there is no modality to prevent RSV infection. RSV vaccines, that named a formalin-inactivated RSV vaccine, have been improved in the mid-1960s. Due to the fact that the vaccines had caused "vaccine enhanced disease", the subunit vaccines schedule were not recommended. Afterward, RSV immune globulin (RespiGamTM) that reduced RSV-mediated hospitalizations had been prophylactically developed for infants with several risks for severe RSV disease. Currently, SynagisTM (palivizumab) is used to decrease RSV related hospitalizations by $>55 \%$. SynagisTM is implemented for newborns with a birth age of 35 weeks or less and infants under 6 months in RSV season. Additionally, for under 2 years, children with chronic lung disease treatment and hemodynamically serious congenital heart disease in the last 6 months are proposed to prevent severe RSV infection with the monoclonal antibody. SynagisTM should be given once a month at a dose of $15 \mathrm{mg} / \mathrm{kg}$ as long as the risk of RSV infection persists [11]. No matter what virus, the main treatment of bronchiolitis is liquid and oxygen therapy. However, Alansari et al. tested the efficacy of the anti-RSV monoclonal antibody palivizumab in infants $<3$ months of age with RSV bronchiolitis. Results of clinical trials have shown that intravenous palivizumab did not appear to help young infants with acute RSV-positive bronchiolitis [12]. Not only RSV has been reported as the most common cause of acute bronchiolitis in children younger than 1 year, but also the global annual rate of RSV hospitalization among children $<5$ years is 4.4 per 1000 lower respiratory tract infection in a systematic review and metaanalysis $[8,9,13,14]$. History of prematurity is also reported to be a leading cause of mortality in acute bronchiolitis [15]. Due to the fact that the RSV vaccine is not available, prophylaxis with the monoclonal antibodies, palivizumab and motavizumab, has been developed to prevent RSV associated with mortality-morbidity in premature infants [16].

Rhinovirus is the second most common pathogen in acute bronchiolitis. Epidemiologic studies have stated that rhinoviruses- $\mathrm{A}$ and $-\mathrm{C}$ are to be the more common subtype acute respiratory infections and wheezing illnesses, and have reported that rhinovirus is related to moderate and severe bronchiolitis and in childhood [17]. In COAST cohort study, rhinovirus-A and -C species were associated with a higher risk of moderate-to-severe acute respiratory infection compared with those with rhinovirus-B infection [18]. The prevalence of rhinovirus causing acute lower respiratory infection varies between 17 and 35\% among young children. A study from Turkey conducted by Gökçe et al. showed that the respiratory viral agent exhibited seasonal patterns with the number of RSV and rhinovirus cases peaking in the winter season [19]. Data on long-term outcomes report that the rate of recurrent wheezing is significantly higher in rhinovirus infections. Additionally, several cohorts confirmed that rhinovirus causing wheezing illness in early life is a significant predictor of asthma. Teeratakulpisarn et al. showed that the children 
diagnosed with rhinovirus bronchiolitis could be possessed of recurrent wheezing. However, these symptoms mostly disappeared before the age of 6 , and nearly half of the study patients subsequently had asthma [20,21]. Another study from Italy also showed that recurrent wheezing 36 months after infant bronchiolitis was associated with rhinoviruses and blood eosinophilia [22].

Studies have reported that influenza, coronavirus, adenovirus, human bocavirus, human metapneumovirus, and parainfluenza viruses cause acute bronchiolitis as the sole pathogen or as coinfection with a similar seasonal pattern. Miron et al. aimed a study to assess the prevalence of sole and mixed respiratory organisms infection/detection in young children diagnosed with acute bronchiolitis. In this study, 590 respiratory organisms were detected in 423 (91\%) children, and the two most commonly detected agents were RSV and rhinovirus [23]. In bronchiolitis, the most common dual infection was between RSV and rhinovirus, and the second was between RSV and human bocavirus. Adenovirus coinfections were also reported as the third most frequent. A study conducted in the United States asserted that dual infections had more ratios of hospitalizations than single infections [24]. Contrary, Calvo et al. stated that coinfections do not increase the severity [25].

The risk of acute bronchiolitis-associated respiratory failure or death is more seen in children previously diagnosed with cardiovascular disease, chronic pulmonary disease, and immunodeficiency. Persistently increased respiratory effort, hypoxemia, apnea, and acute respiratory failure define severe bronchiolitis that requires intensive monitoring and repeated examinations. Risks of severe bronchiolitis generally increase in infants with chronic lung disease, congenital heart disease, anatomic defects of the airways, immunodeficiency, and neurologic disease. It has also been reported that male gender, indigenous status, exposure to tobacco smoke, and poor socioeconomic factors were to be associated with severe bronchiolitis. Various polymerase chain reaction (PCR) techniques provide us to diagnose the etiology of acute bronchiolitis.

The clinical studies for new diagnostic measurements have been brought forth by clinicians in order to predict severe bronchiolitis, because severe bronchiolitis might be associated with morbidity and mortality in infants. It has been found that children with RSV had a more severe initial clinical presentation. Bamberger et al. stated that infants with RSV bronchiolitis, especially young infants, had high clinical severity score on admission when compared to those with other respiratory viruses [26]. In this respect, it has been aimed to evaluate the accuracy of virologic testing for RSV in detecting patients at risk for more severe disease. Hasegawa et al. have reported that the major viruses (RSV-A, RSV-B, rhinovirus, adenovirus, and hMPV) had different temporal patterns in a study which was multicenter-multiyear prospective cohorts of the US infants with severe bronchiolitis. Their data provide guidance for optimal timing of RSV immunoprophylaxis, effective prophylactic (e.g., immunoprophylaxis), and treatment (e.g., antiviral agents) strategies in infants at higher risk for severe bronchiolitis [27]. Another study stated that infants attended daycare, had older siblings, had high parental educational levels, had birth weights of $>4 \mathrm{~kg}$, and were born between April and September had a 10-fold higher risk for severe RSV infection than those who had no these factors [28]. These features provide us to differentiate between infants with high risks of RSV bronchiolitis and to target preventive and monitoring approach.

\section{Pathophysiology and pathogenesis}

Generally, acute bronchiolitis is characterized by upper respiratory symptoms (e.g., rhinorrhea) followed by lower respiratory infection with inflammation 
which is commenced by a pathogen and leads to epithelial necrosis in the bronchial epithelium. Classical symptoms of bronchiolitis including wheezing, crackles, and bronchospasm consist of partial obstruction in the lumen through the accumulation of degenerated squamous epithelium secretions [29]. Bronchiolar obstruction with edema and accumulation of mucus and cellular debris in the airways can persist for many weeks or months following acute bronchiolitis [30]. The reconstruction process may result in complete recovery. However, it can also be characterized by exaggerated proliferation of granulation tissue. There is an exaggerated inflammatory response mediated by cytokines especially T-helper 1 in the pathogenesis of acute bronchiolitis with a variable cytokine profile, according to the infective virus. Due to the fact that exaggerated proliferation causes narrowing or obliteration of the airway lumen, severe clinical findings can be seen in some cases [31-33].

The mucosal innate immune system procures a strong barrier to respiratory infections. In particular, RSV and/or rhinovirus can trigger/induce the concomitant production of type I (IFN $\alpha / \beta)$ and type III (IFN $\lambda$ s). A study was designed to investigate the airway type III IFN receptor (IFNLR1/IL10RB) expression during respiratory syncytial virus or human rhinovirus bronchiolitis. The results of this study showed that the association of IFNLR1 with rhinovirus infection could cause more severe bronchiolitis and blood eosinophilia. The type III IFN receptor also dictates an important role in the host immune response during bronchiolitis [34].

\subsection{Etiology}

Respiratory syncytial virus is the most common etiologic pathogen in acute bronchiolitis with a rate of 50-80\%. Various studies have shown that other viruses, including adenovirus, coronavirus, parainfluenza, influenza, rhinovirus, human bocavirus, and human metapneumovirus, are associated with acute bronchiolitis [35]. Rhinovirus (RV), which is the most common human respiratory pathogens and are responsible for most upper respiratory infections (e.g., the common cold), is the second most commonly associated viral bronchiolitis [36-38]. In recent years, new human respiratory viruses like human metapneumovirus, human bocavirus, and new human coronaviruses have also been reported as possible pathogens causing acute bronchiolitis [38]. Respiratory viruses could occur as coinfection with other respiratory viruses: dual, triple, or more $[37,39,40]$. Today, various viral diagnostic tests provide us to determine the epidemiological differences/clinical characteristics of respiratory viruses. One of the diagnostic methods is multiplex polymerase chain reaction which has been the most commonly used method [41]. Rarely, several atypical infections, for instance, Bordetella pertussis, Mycoplasma pneumonia, Simkania negevensis, and a Chlamydia-like intracellular organism have also shown in bronchiolitis [42-44].

\subsection{Diagnosis}

American Academy of Pediatrics Clinical Practice Guidelines has reported the definition of acute bronchiolitis in 2006. According to the guideline, bronchiolitis has been described as the first episode of wheezing in children under 24 months of age who have respiratory findings during the viral infection episode. Tachypnea, nasal flaring, chest retractions, and wheezing and/or rales are clinical characteristic features of acute bronchiolitis. Rhinorrhea, cough, tachypnea, wheezing, rales, and increased respiratory effort manifested as grunting, nasal flaring, and intercostal and/or subcostal retractions are clinical signs and symptoms of bronchiolitis [3]. Early presentations of asthma or wheeze with viral infections may potentially overlap with the diagnosis of bronchiolitis. Chest radiographs and laboratory studies 
may be thought of on clinical suspicion after evaluating the differential diagnosis for secondary or comorbid bacterial infection, complications, or other conditions.

Viral diagnosis methods that are not routinely suggested for testing, including antigen detection or immunofluorescence of nasal secretion wash or nasal aspiration, rapid antigen tests, and PCR, are only suggested for identifying specific viral agents in children with bronchiolitis if the results will determine discontinuation of palivizumab prophylaxis, initiation, or continuation/discontinuation of antibiotic therapy [45-48].

Bronchiolitis must be distinguished from a variety of acute and chronic diseases including asthma, pneumonia, airway lesions, congenital lung disease or diaphragmatic hernia, cystic fibrosis, congenital heart disease, sepsis, and severe metabolic acidosis that might present with similar presentation. Atypical clinical findings like lack of preceding upper respiratory tract symptoms, witnessed an episode of choking, and poor growth may be useful to discriminate from acute bronchiolitis. It should be considered further investigation for the differential diagnosis.

\subsection{Hospital admission and investigations}

Though bronchiolitis is usually a self-limiting entity, several infants have severe bronchiolitis and should be safely managed at hospital. Severity score of bronchiolitis is described with several clinical parameters including wheezing, retraction, respiratory rate, and general situation (Wang respiratory score) [49]. However, the severity score has not been shown to be useful in a clinical setting. Therefore, the scoring system is not generally used in hospitalization decision. If the infants have any of features, such as apnea, difficulty in feeding, severe respiratory distress with accessory muscle use or grunting, respiratory rate greater than $60 / \mathrm{min}$, diagnostic uncertainty, and cyanosis/hemoglobin saturation $<92 \%$, they are should be referred for hospital admission. Infants with specific risk factors, such as poor socioeconomic circumstances, a history of prematurity, congenital heart disease, or chronic lung disease, also need to be hospitalized. Around $1-5 \%$ of infants might need pediatric intensive care support in bronchiolitis [50]. If infants under 6 months of age or with comorbidities, they are more likely to require intensive care unit admission. After hospitalization, the infants with severe respiratory distress, exhaustion, failure to maintain hemoglobin saturation above $92-94 \%$ with supplemental oxygen or with recurrent apnea should be followed-up in intensive care units. Since the diagnosis of acute bronchiolitis is done clinically, infants with bronchiolitis require no further investigations. During the hospitalization, hemoglobin saturation should be measured using pulse oximetry to determine the requirement for supplemental oxygen.

\subsection{Assessment}

Initially, the management of bronchiolitis is assessed by clinical features. Persistently increased respiratory effort, hypoxemia, apnea, and acute respiratory failure show severe bronchiolitis. Therefore, basic airway management and emergency endotracheal intubation should be considered in a child with deterioration and respiratory failure. In nonsevere bronchiolitis, supportive care including adequate hydration and relief of nasal congestion/obstruction are the mainstays of management for infants with bronchiolitis. Disease progression should also be monitored. Although bronchodilators (inhaled or oral), glucocorticoids, nebulized hypertonic saline, or leukotriene inhibitors have been used in some situations, randomized trials do not recommend pharmacologic interventions in nonsevere bronchiolitis. 
Fluid support is absolutely necessary for infants with any level bronchiolitis. Because bronchiolitis causes difficulty in maintaining adequate hydration and children with bronchiolitis may also decrease intake the fluid due to tachypnea and respiratory distress. Related to clinical features, fluid replacement treatment may have been provided by parenteral or small frequent feedings or orogastric or nasogastric feedings in children who can tolerate enteral feedings strategies.

The second most important support treatment is oxygen supplementation by nasal cannula, face mask, or head box to provide the $\mathrm{SpO}_{2}>90-92 \%$ for infants. If there is insufficient oxygen therapy during support treatment, it means that a progression to respiratory failure. In order to reduce the work of breathing, improve gas exchange, and avoid the need for endotracheal intubation, heated humidified highflow nasal cannula (HFNC, also called high-flow warm humidified oxygen) therapy and/or continuous positive airway pressure (CPAP) are recently used mostly.

\subsection{Clinical course}

Bronchiolitis, which is a self-limited disease, often resolves without complications. Generally, the respiratory status improves over 2-5 days in bronchiolitis. Standard strategies include hand hygiene to reduce the risk of bronchiolitis to minimize the transmission of infectious agents. Additionally, avoiding passive exposure to cigarette smoke and contact with individuals with respiratory tract infections might reduce the risk of bronchiolitis.

\section{Author details}

Şule Gökçe

Faculty of Medicine, Department of Pediatrics, Ege Üniversity, Izmir, Turkey

*Address all correspondence to: sule.gokce@ege.edu.tr

\section{IntechOpen}

(C) 2019 The Author(s). Licensee IntechOpen. This chapter is distributed under the terms of the Creative Commons Attribution License (http://creativecommons.org/licenses/ by/3.0), which permits unrestricted use, distribution, and reproduction in any medium, provided the original work is properly cited. (cc) BY 


\section{References}

[1] Shay DK, Holman RC, Newman RD, Liu LL, Stout JW, Anderson LJ. Bronchiolitis-associated hospitalizations among US children, 1980-1996. JAMA. 1999;282:1440-1446

[2] Boyce TG, Mellen BG, Mitchel EF Jr, Wright PF, Griffin MR. Rates of hospitalization for respiratory syncytial virus infection among children in Medicaid. The Journal of Pediatrics. 2000;137:865-870

[3] American Academy of Pediatrics Subcommittee on Diagnosis and Management of Bronchiolitis. Diagnosis and management of bronchiolitis.

Pediatrics. 2006;118:1774-1793

[4] Smyth RL, Openshaw PJ.

Bronchiolitis. Lancet. 2006;368:312-322

[5] Walton RP, Johnston SL. Role of respiratory viral infections in the development of atopic conditions. Current Opinion in Allergy and Clinical Immunology. 2008;8:150-153

[6] Lanari M, Prinelli F, Adorni F, et al. Risk factors for bronchiolitis hospitalization during the first year of life in a multicenter Italian birth cohort. Italian Journal of Pediatrics. 2015;41:40

[7] Pelletier AJ, Mansbach JM, Camargo CA Jr. Direct medical costs of bronchiolitis hospitalizations in the United States. Pediatrics. 2006;118:2418-2423

[8] Ricci V, Delgado Nunes V, Murphy MS, Cunningham S, Guideline Development Group and Technical Team. Bronchiolitis in children: Summary of NICE guidance. BMJ. 2015;350:h2305

[9] Murray J, Bottle A, Sharland M, et al. Risk factors for hospital admission with RSV bronchiolitis in England: A population-based birth cohort study.

PLoS One. 2014;9:89186

[10] Thompson WW, Shay DK, Weintraub E, Brammer L, Cox N, Anderson LJ, et al. Mortality associated with influenza and respiratory syncytial virus in the United States. Journal of the American Medical Association. 2003;289:179-186

[11] The Impact-RSV Study Group. Palivizumab, a humanized respiratory syncytial virus monoclonal antibody, reduces hospitalization from respiratory syncytial virus infection in high-risk infants. Pediatrics. 1998;102:531-537

[12] Alansari K, Toaimah FH, Almatar DH, El Tatawy LA, Davidson BL, Qusad MIM. Monoclonal antibody treatment of RSV bronchiolitis in young infants: A randomized trial. Pediatrics. 2019;143:1-7

[13] Center for Disease Prevention and Control. Acute bronchiolitis-associated outpatient visits and hospitalizations among American Indian and Alaska native children-United States, 19902000. MMWR. Morbidity and Mortality Weekly Report. 2003;52:707-710

[14] Miller EK, Gebretsadik T, Carroll KN, et al. Viral etiologies of infant bronchiolitis, croup and upper respiratory illness during 4 consecutive years. The Pediatric Infectious Disease Journal. 2013;32:950-955

[15] Wainwright C. Acute viral bronchiolitis in children-A very common condition with few therapeutic options. Paediatric Respiratory Reviews. 2010;11:39-45

[16] Resch B, Kurath-Koller S, Eibisberger M, Zenz W. Prematurity and the burden of influenza and respiratory syncytial virus disease. World Journal of Pediatrics. 2016;12:8-18 
[17] Bochkov YA, Gern JE. Rhinoviruses and their receptors: Implications for allergic disease. Current Allergy and Asthma Reports. 2016;16:30

[18] Lee WM, Lemanske RF Jr, Evans MD, et al. Human rhinovirus species and season of infection determine illness severity. American Journal of Respiratory and Critical Care Medicine. 2012;186:886-891

[19] Gökçe Ş, Kurugöl Z, Koturoğlu G, Çiçek C, Aslan A. Etiology, seasonality, and clinical features of viral respiratory tract infections in children hospitalized with acute bronchiolitis: A singleCenter study. Global Pediatric Health. 2017;4:1-7

[20] Teeratakulpisarn J, Pientong C, Ekalaksananan T, Ruangsiripiyakul $\mathrm{H}$, Uppala R. Rhinovirus infection in children hospitalized with acute bronchiolitis and its impact on subsequent wheezing or asthma: A comparison of etiologies. Asian Pacific Journal of Allergy and Immunology. 2014;32:226-234

[21] Jackson DJ, Gangnon RE, Evans MD, Roberg KA, Anderson EL, Pappas TE, et al. Wheezing rhinovirus illness in early life predicts asthma development in high-risk children. American Journal of Respiratory and Critical Care Medicine. 2008;178:667-672

[22] Midulla F, Nicolai A, Ferrara M, Gentile F, Pierangeli A, Bonci E, et al.

Recurrent wheezing 36 months after bronchiolitis is associated with rhinovirus infections and blood eosinophilia. Acta Paediatrica. 2014;103:1094-1099

\section{[23] Miron D, Srugo I, Kra-Oz Z,} Keness Y, Wolf D, Amirav I, et al. Sole pathogen in acute bronchiolitis: Is there a role for other organisms apart from respiratory syncytial virus. The Pediatric Infectious Disease Journal. 2010;29:7-10
[24] Drews AL, Atmar RL, Glezen WP, et al. Dual respiratory virus infections. Clinical Infectious Diseases. 1997;25:1421-1429

[25] Calvo C, García-García M’a L, Pozo F, Paula G, Molinero M, Calderón A, et al. Respiratory syncytial virus coinfections with rhinovirus and human bocavirus in hospitalized children. Medicine. 2015;94:1-7

[26] Bamberger E, Srugo I, Abu Raya B, Segal E, Chaim B, Kassis I, et al. What is the clinical relevance of respiratory syncytial virus bronchiolitis? Findings from a multicenter, prospective study. European Journal of Clinical Microbiology \& Infectious Diseases. 2012;31:3323-3330

[27] Hasegawa K, Goto T, Hirayama A, Laham F, Mansbach J, Piedra P, et al. Respiratory virus epidemiology among US infants with severe bronchiolitis: Analysis of 2 multicenter, multiyear cohort studies. The Pediatric Infectious Disease Journal. 2019;38:180-183

[28] Houben ML, Bont L, Wilbrink B, Belderbos ME, Jan LLK, Visser GHA, et al. Clinical prediction rule for RSV bronchiolitis in healthy newborns: Prognostic birth cohort study. Pediatrics. 2011;127:35-41

[29] Colby TV. Bronchiolitis. Pathologic considerations. American Journal of Clinical Pathology. 1998;109:101-109

[30] Hall CB. Respiratory syncytial virus and parainfluenza virus. The New England Journal of Medicine. 2001;344:1917-1928

[31] Garcia C, Soriano-Fallas A, Lozano J, Leos N, Gomez AM, Ramilo O, et al. Decreased innate immune cytokine responses correlate with disease severity in children with respiratory syncytial virus and human rhinovirus bronchiolitis. Pediatric Infectious Disease. 2012;31:86-89 
[32] McNamara PS, Flanagan BF, Hart CA, Smyth RL. Production of chemokines in the lungs of infants with severe respiratory syncytial virus bronchiolitis. The Journal of Infectious Diseases. 2005;191:1225-1232

[33] Van Schaik SM, Tristram DA, Nagpal IS, Hintz KM, Welliver RC, Welliver RC. Increased production of IFN-gamma and cysteinyl leukotrienes in virus-induced wheezing. The Journal of Allergy and Clinical Immunology. 1999;103:630-636

[34] Pierangelia A, Statzua M, Nennab R, Santinellia L, Petrarcab L, Frassanitob A, et al. Interferon lambda receptor 1 (IFNL1R) transcript is highly expressed in rhinovirus bronchiolitis and correlates with disease severity. Journal of Clinical Virology. 2018;102:101-109

[35] Bezerra PG, Britto MC, Correia JB, et al. Viral and atypical bacterial detection in acute respiratory infection in children under five years. PLoS One. 2011;6:18928

[36] Mansbach JM, Piedra PA, Teach SJ, et al. Prospective, multicenter study of viral etiology and hospital length-of-stay in children with severe bronchiolitis. Archives of Pediatrics and Adolescent Medicine. 2012;166:700-706

[37] Papadopoulos NG, Moustaki M, Tsolia M, et al. Association of rhinovirus infection with increased disease severity in acute bronchiolitis. American Journal of Respiratory and Critical Care Medicine. 2002;165:1285-1289

[38] Berry M, Gamieldien J, Fielding BC. Identification of new respiratory viruses in the millennium. Viruses. 2015;7:996-1019

[39] Stempel HE, Martin ET, Kuypers J, Englund JA, Zerr DM. Multiple viral respiratory pathogens in children with bronchiolitis. Acta Paediatrica. 2009;98:123-126

[40] Ray CG, Minnich LL, Holberg CJ, et al. Respiratory syncytial virusassociated lower respiratory illnesses: Possible influence of other agents. The group health medical associates. The Pediatric Infectious Disease Journal. 1993;12:15-24

[41] Liolios L, Jenney A, Spelman D, Kotsimbos T, Catton M, Wesselingh S. Comparison of a multiplex reverse transcription-PCR-enzyme hybridization assay with conventional viral culture and immunofluorescence techniques for the detection of seven viral respiratory pathogens. Journal of Clinical Microbiology. 2001;39:2779-2783

[42] Nakamura A, Sakano T, Nakayama T, et al. Neonatal pertussis presenting as acute bronchiolitis: Direct detection of the Bordetella pertussis genome using loop-mediated isothermal amplification. European Journal of Pediatrics. 2009;168:347-349

[43] Sung RY, Chan RC, Tam JS, et al. Epidemiology and aetiology of acute bronchiolitis in Hong Kong infants. Epidemiology and Infection. 1992;108:147-154

[44] Kahane S, Greenberg D, Friedman MG, et al. High prevalence of "Simkania Z" a novel Chlamydialike bacterium, in infants with acute bronchiolitis. The Journal of Infectious Diseases. 1998;177:1425-1429

[45] Ahluwalia G, Embree J, McNicol P, Law B, Hammond GW. Comparison of nasopharyngeal aspirate and nasopharyngeal swab specimens for respiratory syncytial virus diagnosis by cell culture, indirect immunofluorescence assay, and enzyme-linked immunosorbent assay. Journal of Clinical Microbiology. 1987;25:763-767 
[46] Macfarlane P, Denham J, Assous J, Hughes C. RSV testing in bronchiolitis: Which nasal sampling method is best? Archives of Disease in Childhood. 2005;90:634-635

[47] Bordley WC, Viswanathan M, King VJ, et al. Diagnosis and testing in bronchiolitis: A systematic review. Archives of Pediatrics and Adolescent Medicine. 2004;158:119-126

[48] Harris JA, Huskins WC, Langley JM, Siegel JD. Pediatric special interest Group of the Society for Healthcare Epidemiology of America. Health care epidemiology perspective on the October 2006 recommendations of the subcommittee on diagnosis and management of bronchiolitis. Pediatrics. 2007;120:890-892

[49] Wang EE, Milner RA, Navas L, Maj H. Observer agreement for respiratory signs and oximetry in infants hospitalized with lower respiratory infections. The American Review of Respiratory Disease. 1992;145:106-115

[50] Parker MJ, Allen U, Stephens D, et al. Predictors of major intervention in infants with bronchiolitis. Pediatric Pulmonology. 2009;44:358-363 


\title{
Chapter 4
}

\section{PDA Closure in ELBW Infants: If, When, and How to Do It}

\author{
Stephanie Whiting and Shyam Sathanandam
}

\begin{abstract}
Patent ductus arteriosus (PDA) is the most common cardiovascular condition afflicting premature neonates especially those born extremely low birth weight (ELBW). Despite five decades of scientific inquiry which has produced thousands of publications including over 65 randomized controlled trials, cardiologists, neonatologists, and surgeons still cannot answer simple questions such as if, when and how to close to the PDA in ELBW infants. This chapter will examine current evidence in order to answer these fundamental questions. The chapter will specifically focus on transcatheter PDA closure (TCPC), which albeit a new therapy, has displayed great potential to be the best therapeutic option in the future. It is about time that physicians from all sub-specialties come together and integrate the evidence to develop a management algorithm for ELBW infants with hemodynamically significant PDA.
\end{abstract}

Keywords: PDA, ELBW, hemodynamics, devicer, ligation

\section{Introduction}

The ductus arteriosus is a fetal vascular structure that connects the descending aorta to the pulmonary artery (PA). It develops from the left sixth aortic arch in the embryo by the sixth week, directing blood flow returning to the heart away from the lungs. Soon after birth, the ductus arteriosus should begin to close spontaneously in response to environmental changes [1]. Patent ductus arteriosus (PDA) can be expected in all infants immediately after birth but may become pathologic if closure fails to occur within the first few days. Non-pathologic PDAs may occur in infants with cyanotic heart disease and increased pulmonary vascular resistance.

\section{Role in fetal life}

In a normal fetus, blood flows from right-to-left (PA to aorta) as a result of high resistance in the pulmonary arterioles and low systemic vascular resistance in the fetus and placenta. Patency of the ductus in fetal life is further influenced by oxygen content in the blood and prostaglandins. Dissolved oxygen content in the blood $\left(\mathrm{pO}_{2}\right)$ leads to constriction of smooth-walled vessels, possibly due to the influx of calcium into the cell, thus ductal exposure to low $\mathrm{pO}_{2}$ in utero promotes patency of the ductus [2]. Prostaglandins are hormone-like compounds derived from arachidonic acid by cyclooxygenase enzymes (COX-1 and COX-2). Prostaglandin E (PGE) and prostacyclin (PGIE) are produced in the ductus and play a large role in maintaining its patency during fetal life [2-5]. 


\section{Normal closure of the ductus}

When a baby takes its first breath, the increased alveolar oxygen content leads to pulmonary vasodilation, resulting in a decreased ratio of pulmonary vascular resistance $\left(R_{P}\right)$ to systemic vascular resistance $\left(R_{S}\right)$. This drop in $R_{P} / R_{S}$ can reverse the flow of blood across the ductus arteriosus from right-to-left to left-to-right (aorta to PA). At this point, the ductus is exposed to high systemic arterial $\mathrm{pO}_{2}$, which results in vasoconstriction of the ductus arteriosus through mechanisms not fully elucidated [3-5]. A sharp decline in circulating PGE and PGIE along with a rapid increase in $\mathrm{pO}_{2}$ following birth contributes to constriction, and ultimately functional closure of the ductus. Nearly all healthy, term infants achieve functional closure with 24-72 h [2-5]. Eventually, hypoxia and fibrosis cause the inner layers of the ductus to permanently close, leaving only a fibrous remnant called the ligamentum arteriosum.

\section{Incidence of PDA in premature infants}

Premature birth prolongs closure as gestational age decreases. As many as $50-70 \%$ of infants at $<28$ weeks of gestation have a moderate-to-large PDA that persists for weeks after birth, whereas most infants born $>28$ weeks of gestation spontaneously close the ductus within the first week. Among infants $>1500 \mathrm{~g}$, spontaneous closure of the ductus occurs within $96 \mathrm{~h}$ in $95 \%$ of neonates [6]. By contrast, only $34 \%$ of extremely low birth weight (ELBW) infants (birth weight $\leq 1000 \mathrm{~g}$ ) are reported to close the ductus by day 10 of life [6].

Little is known about the natural course of PDA in extremely premature infants due to the use of prophylactic and rescue therapy in modern NICUs. Previous studies in the 1960s and 1970s were limited by a lack of modern imaging techniques and likely only captured audible, hemodynamically significant PDAs [7]. The closest approximation is found by examining infants treated with conservative management of the PDA, in which interventions are held until symptoms of distress meet an established threshold. A large retrospective study using conservative management found that $85 \%$ of very low birth weight (VLBW) infants (birth weight $\leq 1500 \mathrm{~g}$ ) closed the ductus spontaneously before discharge, but it should be noted that infants $<26$ weeks gestational age took a median of 71 days to close. Thirty-three infants, many of whom had a PDA, were excluded from the study due to death from infection, intraventricular hemorrhage (IVH), necrotizing enterocolitis (NEC), and pulmonary hemorrhage [8] (Semberova). Another study found spontaneous ductal closure within the first week in 31\% of ELBW infants and $67 \%$ in infants greater than $1000 \mathrm{~g}$. For ELBW infants, spontaneous closure was achieved in $47 \%$ at a median of 56 days at the time of discharge $[8,9]$. Thus, PDA in VLBW and ELBW infants can take weeks to close and may cause morbidity and mortality in this population.

\section{Consequences of PDA in ELBW infants}

While a very tiny ductus may be safely left untreated, a large ductus can cause pulmonary over-circulation and cardiac failure. A moderate ductus can lead to pulmonary hypertension $[10,11]$ in the long-term. Even a small ductus is at risk for developing endocarditis [12].

Persistent PDA in ELBW infants with respiratory distress syndrome (RDS) has been linked to numerous pulmonary complications, including increased flow 
and pressure to the pulmonary vascular bed, increased lung water, decreased lung compliance $[13,14]$, prolonged ventilation [15], worsening pulmonary disease [16], pulmonary hemorrhage [13-16], severe bronchopulmonary dysplasia (BPD) [17], and death [17].

Over the first few days, pulmonary vascular resistance drops markedly while the PDA remains large, allowing significant shunting of blood to the pulmonary vascular bed. As blood from the PDA returns to the left atrium, left atrial dilation occurs. The increased LA pressure causes pulmonary edema and symptoms of congestive heart failure. While the body may compensate at first, pulmonary hemorrhage may eventually occur $[18,19]$. Besides pulmonary hemorrhage the risks of BPD are increased, as ELBW infants require greater ventilatory support as well as increased oxygen $[18,20]$. Although the pathogenesis of BPD is complex, associations between prolonged exposure to a moderate-to-large PDA and BPD have been documented $[18,19]$. Additional research further established the association of PDA with systemic complications such as NEC, renal impairment, IVH, periventricular leukomalacia (PVL), cerebral palsy, and death [20-22].

While numerous sequelae have been associated with the presence of a moderateto-large PDA in ELBW infants, it remains unclear whether these are the result of having a PDA or are the natural consequences of prematurity. Previous randomized control trials (RCT) suggest that long-term morbidities are not affected by shortterm exposure to a PDA (3-4 days) [13, 23], however these conclusions are confounded by early spontaneous closure of the PDA, failure to account for differing shunt sizes, and the early use of rescue treatments, or a lack of equipoise, on behalf of the physicians [13]. There is no consensus on the exact consequences of a PDA in the premature infant, but most agree that persistent and significant left-to-right shunting of blood in the ELBW infant is not helpful [24].

\section{Hemodynamic significance of the PDA}

There is no consensus regarding the definition of a hemodynamically significant PDA (hsPDA), yet it is a key indicator for clinicians when determining whether intervention is needed to close the ductus. Historically, clinical signs have been used as indicators of hsPDA, such as the presence of a systolic murmur, wide pulse pressures,
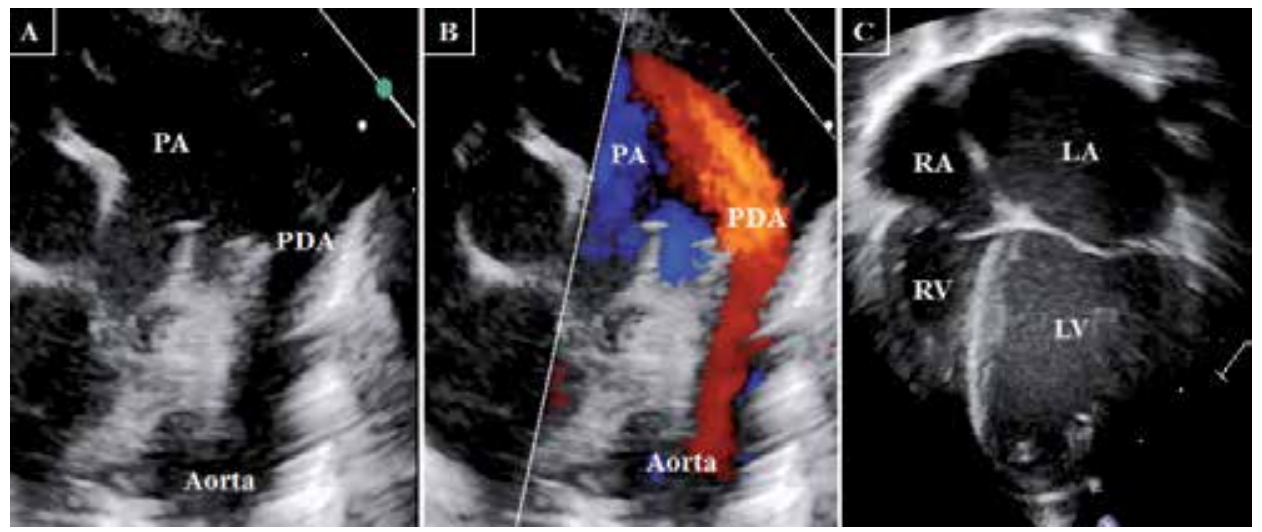

Figure 1.

Transthoracic echocardiogram (TTE) demonstrating a large, hSPDA in a 3 weeks old ex-24 week ELBW infant. (A) 2D-TTE demonstrating a large PDA between the aorta and the pulmonary artery (PA). (B) Color Doppler demonstrating left to right shunt in the PDA from the aorta to the PA. (C) Severe left atrial (LA) and left ventricular $(L V)$ enlargement relative to the right atrium $(R A)$ and the right ventricle $(R V)$. 
bounding pulses, pulmonary edema, and increased oxygen requirements. With the advent of echocardiography in the 1970s, more sophisticated measures can be used to determine hemodynamic significance. Approaches to determine hsPDA now include (1) establishing thresholds based on clinical signs and echocardiographic parameters, (2) the need for treatment as determined by the size of the PDA and its likelihood of closing based on age/size of the infant, (3) probable outcomes based on identifying populations most likely to experience complications related to PDA.

Echocardiographic indices to determine hsPDA can be established by PDA shunt size, the extent of volume overload [19-21], the degree of pulmonary overload, and the magnitude of systemic hypoperfusion (Figure 1). Moderate to large PDAs may be hemodynamically significant if flow patterns through the duct indicate significant left-to-right shunting. Volume overload is determined by calculating the left atrium diameter (LA) relative to a constant, the aortic root diameter (Ao). An LA:Ao ratio greater than 1.4 is one of the most commonly used indicators of hsPDA, since increased volume through the PDA will return to the left atrium and cause dilation [19-21]. Left ventricular output (LVO), a key indicator of pulmonary overload, may be large due to additional volume from the PDA, or may be small to normal (an ominous sign) if the left ventricle fails to compensate for the additional volume through

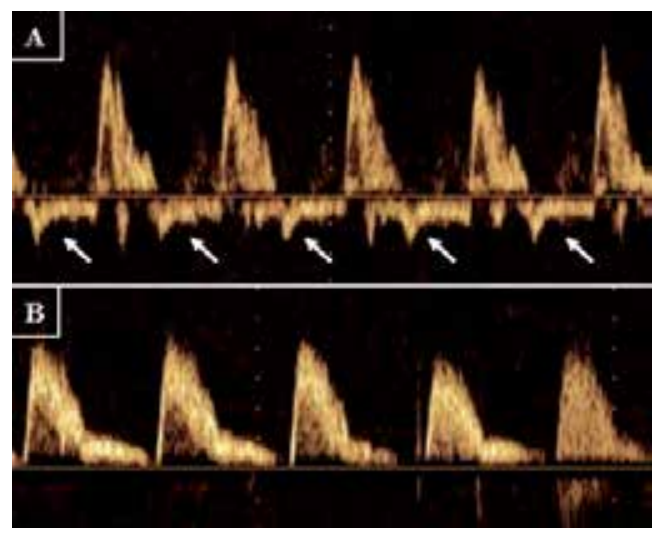

Figure 2.

Pulse wave Doppler assessment in the descending aorta by TTE in the same patient in Figure 1. (A) There is diastolic flow reversal in the descending aorta (arrows) suggesting a large left to right shunt from the aorta to the PA leading to systemic hypoperfusion. (B) Following transcatheter closure, there is normalization in the Doppler pattern.

\begin{tabular}{ll}
\hline Clinical criteria & Echocardiographic criteria \\
\hline - Oxygenation difficulty (oxygenation index $\geq 10)$ & PDA diameter $\geq 2 \mathrm{~mm}$ \\
\hline $\begin{array}{l}\text { - High ventilator settings (Mean airway } \\
\text { pressure } \geq 10 \text { ) }\end{array}$ & $\begin{array}{l}\text { Absent diastolic flow or reversal of end- } \\
\text { diastolic flow in descending aorta, superior } \\
\text { mesenteric, middle cerebral or renal artery }\end{array}$ \\
\hline $\begin{array}{l}\text { - Frequent episodes of oxygen desaturations, apnea or } \\
\text { bradycardia }\end{array}$ & - Unrestrictive pulsatile transductal flow \\
\hline - Inability to feed/abdominal distention & - Left heart enlargement (LA:Ao ratio $\geq 1.4$ ) \\
\hline - Systemic hypotension (low mean or diastolic BP) & \\
\hline - Cardiomegaly \pm Pulmonary edema on chest X-ray & \\
\hline - Metabolic acidosis & \\
\hline
\end{tabular}

Table 1.

Clinical and echocardiographic criteria for hemodynamic significance. 
increased cardiac output. Another indicator of pulmonary overload is the enddiastolic velocity in the PA, where high velocities may indicate pulmonary overload. Retrograde diastolic blood flow through the descending aorta (Figure 2) may be the most telling sign of systemic hypoperfusion due to a PDA, although end-organ blood flow may be assessed to further quantify these effects [19-21].

Echocardiographic evidence alone cannot determine hsPDA, but should be used in conjunction with clinical factors (Table 1), vulnerability of the infant due to gestational and chronological age, and risk of organ overflow (lungs) or hypoperfusion (brain, kidneys, intestines). Clinical findings that may help identify hsPDA include the need for vasopressors/inotropes, ventilator support and pulmonary edema, feeding intolerance, and rising creatinine levels.

\section{Established techniques for closure}

Treatment options are continuously evolving [25], and have included routine pharmacological treatment, conservative management, surgical ligation and transcatheter closure (Table 2). While indications for closure are not fully agreed upon, certain contraindications are noted below:

- Severe pulmonary vascular disease.

- Pulmonary artery hypoplasia.

- Duct dependent congenital heart disease

\subsection{Medical therapy}

Pharmacological treatment with COX inhibitors is usually the initial treatment for PDA. Currently, pharmacological therapy consists of intravenous or oral

\begin{tabular}{|c|c|c|}
\hline Pharmacologic therapy & Surgical ligation & Transcatheter closure \\
\hline Advantages: & Advantages: & Advantages: \\
\hline - Non-Invasive & - Invasive & - Minimally-Invasive \\
\hline - Efficacy $50-70 \%$ & - Efficacy $100 \%$ & - Efficacy $100 \%$ \\
\hline $\begin{array}{l}\text { May take a few days to be } \\
\text { effective }\end{array}$ & $\begin{array}{l}\text { - Immediate and definitive } \\
\text { closure }\end{array}$ & - Immediate and definitive closure \\
\hline \multirow{10}{*}{$\begin{array}{l}\text { Disadvantages: } \\
\text { - Impairment in renal func- } \\
\text { tion, oliguria, proteinuria, } \\
\text { hyperkalemia } \\
\text { - Cerebral white-matter } \\
\text { damage } \\
\text { - Impairment in cerebral } \\
\text { perfusion } \\
\text { - NEC, Gastrointestinal } \\
\text { perforation } \\
\text { - Platelet dysfunction }\end{array}$} & \multirow{4}{*}{$\begin{array}{l}\text { Disadvantages: } \\
\text { - Post-Ligation Syndrome (30\%) } \\
\text { - Vocal cord dysfunction (30\%) } \\
\text { - Impaired neurodevelopmental } \\
\text { outcomes }\end{array}$} & \\
\hline & & \multirow{2}{*}{$\begin{array}{l}\text { - Vascular access complications } \\
\text { (1\%) }\end{array}$} \\
\hline & & \\
\hline & & $\begin{array}{l}\text { - LPA stenosis }(1 \%) \\
\text { - Aortic arch stenosis }(1 \%)\end{array}$ \\
\hline & - Risk of worsening of BPD & \multirow{6}{*}{$\begin{array}{l}\text { - Device embolization }(1 \%) \\
\text { - Tricuspid valve regurgitation } \\
(2 \%) \\
\text { - Exposure to X-Rays and contrast } \\
\text { medium } \\
\text { - Hypothermia }\end{array}$} \\
\hline & - Chylothorax & \\
\hline & - Diaphragmatic paralysis & \\
\hline & • Bleeding & \\
\hline & - Pneumothorax & \\
\hline & - Cardiorespiratory failure & \\
\hline
\end{tabular}

Table 2.

Advantages and disadvantages of therapies. 
indomethacin, ibuprofen, or acetaminophen in varying dosages. The two most common options are intravenous standard doses of indomethacin and ibuprofen. In 2018, a meta-analysis of 68 RCT of 4802 infants found that among all preterm infants $<37$ weeks gestation, the overall PDA closure rate with one of the above treatment modalities was $67 \%$. Oral ibuprofen was the most effective treatment, and none of the treatments increased the risk of mortality, NEC, or IVH compared to placebo or no treatment controls [25]. Slower absorption rates and a longer half-life of oral ibuprofen may increase the time of contact with the PDA, possibly explaining its improved effectiveness over intravenous routes [25]. The effectiveness of medical therapy is at best $50-70 \%$ and lower for those $<32$ weeks gestation [24-26].

Conservative management without the use of pharmacotherapeutics has become a recent trend in management of the PDA $[16,22]$. Because many preterm infants will spontaneously close the ductus within the first week, early routine treatment with pharmacological therapy may not offer any benefit. Targeted therapy towards hsPDA based on clinical and echocardiographic thresholds is becoming the standard of care.

\subsection{Surgical ligation}

Surgical ligation through a limited left thoracotomy, although invasive, offers definitive, immediate closure of the PDA. Robert Gross performed the first successful PDA surgical ligation at Children's Hospital of Boston in 1939 while his chief was out of town. While surgical ligation carries minimal risk of mortality, other risks include pneumothorax, recurrent laryngeal nerve paralysis, chylous effusions, and post-ligation syndrome [12, 24, 26, 27]. Post-ligation syndrome occurs in the first $6-24 \mathrm{~h}$ in approximately $30 \%$ of neonates who undergo surgical ligation; neonates experience hypotension, which in some cases may be resistant to catecholamines, as a result of changes in myocardial function and impaired vascular tone $[20,21]$. Long term complications such as thoracic scoliosis and neurosensory impairment have been reported in some cases following surgical ligation $[24,26,27]$. Only one trial has compared surgical ligation to nonintervention and found that infants undergoing ligation required longer ventilation, oxygen therapy, and hospitalization than control subjects, although differences did not reach statistical significance [28]. Even so, surgical ligation may still be desirable in infants for whom medical therapy has failed and transcatheter closure is not possible [12].

\subsection{Transcatheter therapy}

Transcatheter PDA closure (TCPC) is a minimally invasive therapy associated with low rate of adverse events that has become the procedure of choice for children $>5 \mathrm{~kg}$ [29]. Historically, transcatheter closure of PDA has not been performed in premature neonates for a variety of reasons including: fear of patient fragility, concerns regarding vascular access and arterial injury, unknown effects of intravenous contrast media, concerns regarding catheter manipulation, and most importantly, absence of a suitable PDA closure device. Recently, a growing body of clinical evidence has emerged suggesting that transcatheter closure of PDA can be performed safely and effectively in premature infants [24, 30]. Risks of transcatheter therapy include embolization requiring surgery, cardiac perforation, aortic coarctation, and LPA obstruction, however these risks are very low even among ELBW infants. 


\section{Highlights of transcatheter PDA closure}

- No arterial access is needed for the procedure.

- The procedure time is minimal.

- Therapy is definitive and minimally-invasive.

- Risks of pharmacotherapeutics and surgery can be avoided.

- The procedure can be safely performed in infants as small as $700 \mathrm{~g}$ using an FDA-approved device.

\section{Controversy and practice variation}

Controversy regarding if, when, and how to close the PDA abounds. Survey results of neonatologists and cardiologists in 2018 describe the practice variations in management of the PDA [31]. Some neonatologists responded that even a large, hemodynamically significant PDA in a premature baby never requires treatment including medical management as the majority are likely to close, while no cardiologists agree with this option. Nearly half the neonatologists believe that closing the PDA does not alter outcomes in children born $<28$ weeks' gestation, while most of the cardiologists disagree with this opinion. When institutions do believe that closure is needed after failed medical therapy, the majority of neonatologists and cardiologists currently still prefer surgical ligation to TCPC, while watchful waiting was still preferred by some neonatologists. There are immense variations in the practice of managing PDAs in ELBW infants in the United States. Neonatologists and cardiologists have differing opinions of the consequence of a hsPDA on the eventual outcomes. Certain landmark papers questioning the utility of PDA closure in premature infants may have influenced these opinions [16, 22].

In 2010, William Benitz performed a meta-analysis of 49 RCTs involving nearly 5000 preterm infants who underwent pharmacological or surgical treatment to close the PDA [16]. Evidence showed that while treatment was effective in achieving ductal closure, only a single study showed improvement in other outcomes such as pulmonary hemorrhage, BPD, NEC, or death. Correlations between PDA and IVH were and did not support the hypothesis that closure of the ductus improves neurological outcomes [16-22]. It was concluded that the association of comorbidities with PDA might arise from prematurity itself rather than through prolonged patency of the ductus. Benitz recommended prolonging treatment of the PDA in infants $\leq 1000 \mathrm{~g}$ until the second week after birth to increase the odds of spontaneous closure, and refraining from all treatment specifically intended to close the ductus in infants $>1000$ g. Fluid restriction, diuretics, supplemental oxygen, and other treatments were recommended in lieu of COX inhibitors and surgical ligation [16]. Certain patients at special risk for complications related to PDA would still require ductal closure and should be identified via a scoring system, such as the one proposed by McNamara and Sehgal [21]. Benitz's study provided impetus for the trend against early routine treatment of the PDA in premature infants and towards a more selective approach wherein only certain infants at increased risk received intervention to close the ductus.

In 2018, Ronald Clyman designed the PDA Tolerate Trial [13] to further examine early routine therapy versus conservative management by controlling for variables that had confounded many of the previous RCTs. Inclusion criteria was limited to 
infants with a moderate-to-large PDA that did not close spontaneously within the first week. In so doing, the number of infants who spontaneously closed the ductus was reduced, though not eliminated. Early routine therapy (ERT) with pharmacological treatment was then compared to conservative management. As in previous trials, ERT did not always result in constriction of the ductus. Results indicated that ERT did not improve the incidence of NEC, IVH, BPD or death but instead delayed full feeding and may have increased the rate of sepsis and death in infants between 26 and 28 weeks gestation. Again, evidence did not support broad, routine ductal closure by pharmacotherapeutics in preterm infants.

With evidence mounting against the use of COX inhibitors and surgical ligation, the trend towards permissive conservative observation of this lesion has developed, reserving surgery for only the most severe cases [13-17, 32]. Unfortunately, recent data suggests that this approach is associated with an increased risk for the development of chronic lung disease and death, especially in infants born $\leq 26$ weeks' gestation [8-17]. More recently in the United States, survival of infants born as early as 22 weeks' gestation is now possible [33], making the need for effective PDA therapy in this high risk, ELBW population more important than ever.

\section{Role of transcatheter PDA closure in the future}

Transcatheter therapy has evolved significantly in the last decade. Emerging technology has paved the way for the use of this therapy in smaller and smaller infants [34, 35]. The Amplatzer Piccolo Occluder (Abbott Structural Heart, Plymouth, MN, USA) is a self-expandable, Nitinol mesh device with a central cylindrical waist and low-profile retention discs that are marginally larger than the waist, resulting in a nearly isodiametric device. The device comes pre-loaded on a delivery wire, which has a soft floppy distal end with a microscrew attachment at the tip. It is delivered through a catheter using a loading device. The APO has ideal characteristics (size, shape, delivery system) for closure of PDAs in premature neonates including ELBW infants. With an increasing need for a less invasive therapy for PDA closure in this population, a clinical study evaluating the safety and efficacy of the APO was conducted that led to the approval of this device by the U.S. Food and Drug Administration (FDA) for children $\geq 700 \mathrm{~g}$ [36].

While transcatheter closure of the PDA is common among larger children and adults, several modifications specific for ELBW patients are necessary to ensure success and minimize complications.

- Transportation of ELBW infants to the catheterization lab poses challenges for these fragile patients, but with proper coordination of team members, can be accomplished without complication [37]. Special accommodations for temperature control and ventilator support are essential. One operator has thus far reported success with procedures performed at the bedside. While this procedure may eventually become common at the bedside, transport to the catheterization lab will likely be necessary in most institutions.

- Arterial access in these small patients is very likely to cause damage leading to limb ischemia and should be avoided [34, 38]. Instead, antegrade access through the femoral vein is the method of choice.

- The lack of arterial access and resulting inability to perform aortography postdeployment necessitates the use of TTE [39] to assess aortic flow, residual PDA shunting, and left PA (LPA) flow (Figure 3). 

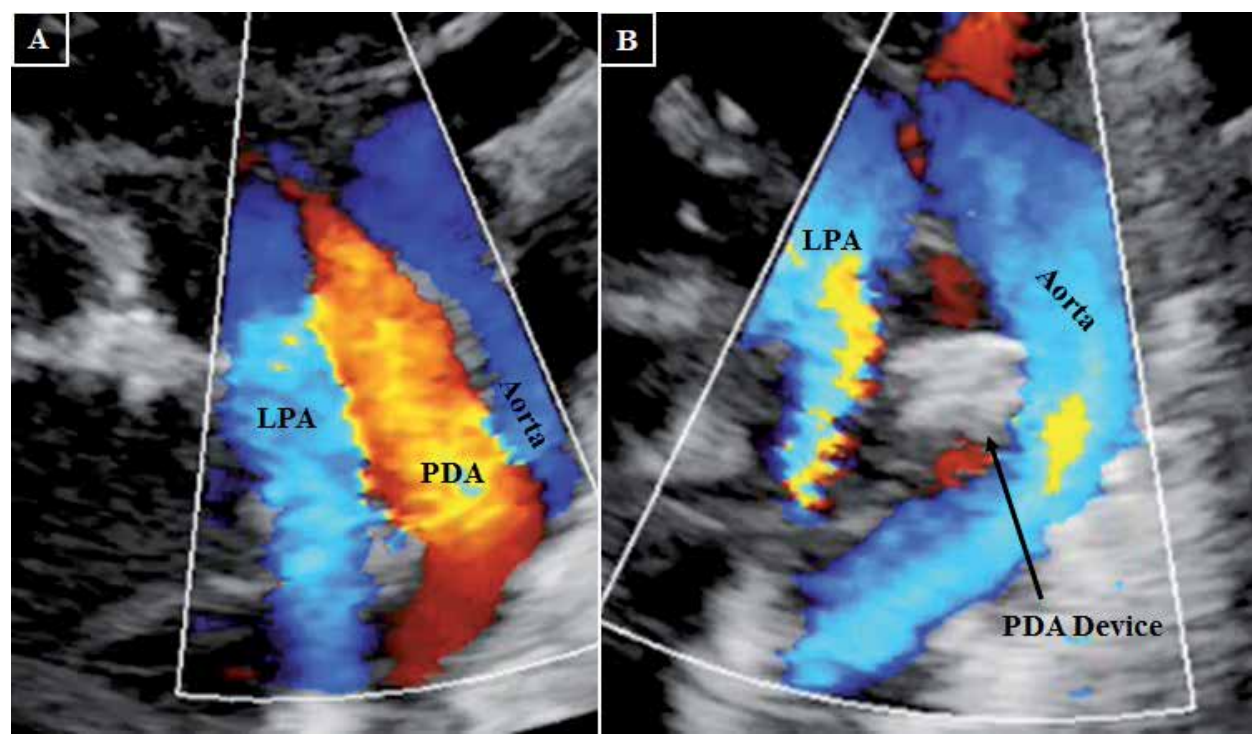

Figure 3.

TTE with color Doppler interrogation of the PDA of patient described in Figures 1 and $\mathbf{2}$ before $(A)$ and after transcatheter device closure (B). The PDA is completely closed following intraductal implantation of the occlusion device. There is no stenosis of the left pulmonary artery (LPA) or the aorta caused by the device (B).

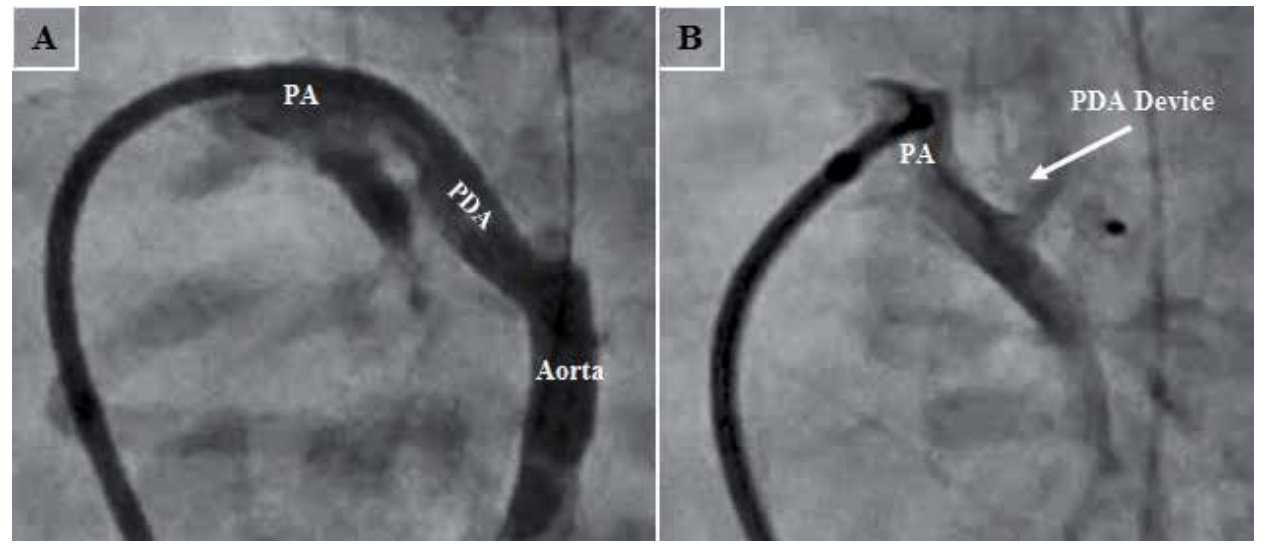

Figure 4.

Angiograms performed during transcatheter device closure of the PDA of patient described in Figures 1 and 2. Prior to closure $(A)$, a large PDA is demonstrated shunting left to right between the aorta and the pulmonary artery (PA). Following device implantation within the PDA (B), there is no residual PDA, and no stenosis of the PA or the aorta caused by the device.

- The central waist of the APO is designed to fill the ductal lumen, and the retention discs are designed to deploy in the pulmonary and the aortic ends of the PDA. However, when treating small infants, especially those $\leq 2 \mathrm{~kg}$, implantation of both retention discs completely within the duct (intraductal placement) to avoid protrusion into the aorta or the LPA (Figure 4) is essential to avoid inadvertent stenosis of these vessels by the device discs $[24,34,40]$.

- Minimization of contrast dosing, intracardiac catheter manipulation, and unnecessary hemodynamic measurements that prolong procedure time are recommended to achieve optimal outcomes [24, 34, 40]. 
- Following deployment, but prior to device release, in addition to echocardiographic assessment as noted above, angiography should be performed to check for stenosis of the proximal LPA caused by the device [39].

By observing these precautions, transcatheter therapy in ELBW infants can be safely performed. This new therapy could shift the paradigm of treatment. Future randomized trials using TCPC are necessary to determine whether PDA closure would impact the short term and long term outcomes of children born prematurely. The benefit of this therapy over other therapies must be demonstrated before it can become standard of care for premature infants [41, 42], but this new option may offer a solution to the substantial unmet need in this population for a minimally invasive, definitive closure of the ductus.

\section{Conclusions}

The role of TCPC in ELBW infants will likely grow steadily, given the potential benefits of TCPC over other therapies. However, the most important question of "whether" the PDA needs to be closed at all still has to be answered. It is also prudent to determine "which" patients will benefit from closure, and in whom it is likely to close spontaneously. An RCT comparing TCPC vs. observation/conservative approach may be important to answer these questions. Hopefully, in the near future we will establish a treatment algorithm for ELBW with hsPDA.

\section{Author details}

Stephanie Whiting and Shyam Sathanandam*

University of Tennessee, Memphis, TN, USA

*Address all correspondence to: ssathan2@uthsc.edu

IntechOpen

(C) 2019 The Author(s). Licensee IntechOpen. This chapter is distributed under the terms of the Creative Commons Attribution License (http://creativecommons.org/licenses/ by/3.0), which permits unrestricted use, distribution, and reproduction in any medium, provided the original work is properly cited. (cc) BY 


\section{References}

[1] Rudolph AM. Fetal and neonatal pulmonary circulation. Annual Review of Physiology. 1979;41:383-395

[2] Coceani F, Olley PM. The response of the ductus arteriosus to prostaglandins. Canadian Journal of Physiology and Pharmacology. 1973;51(3):220-225

[3] Clyman RI, Heymann MA, Rudolph AM. Ductus arteriosus responses to prostaglandin E1 at high and low oxygen concentrations. Prostaglandins. 1977;13(2):219-223

[4] Stoller JZ, Demauro SB, Dagle JM, Reese J. Current perspectives on pathobiology of the ductus arteriosus. Journal of Clinical and Experimental Cardiology. 2012;8(1):pii: S8-001

[5] Clyman RI. Mechanisms regulating the ductus arteriosus. Biology of the Neonate. 2006;89(4):330-335

[6] Koch J, Hensley G, Roy L, Brown S, Ramaciotti C, Rosenfeld CR. Prevalence of spontaneous closure of the ductus arteriosus in neonates at a birth weight of 1000 grams or less. Pediatrics. 2006;117(4):1113-1121

[7] Su BH, Watanabe T, Shimizu M, Yanagisawa M. Echocardiographic assessment of patent ductus arteriosus shunt flow pattern in premature infants. Archives of Disease in Childhood. Fetal and Neonatal Edition. 1997;77:F36-F40

[8] Semberova J, Sirc J, Miletin J, et al. Spontaneous closure of patent ductus arteriosus in infants $\leq 1500 \mathrm{~g}$. Pediatrics. 2017;140(2):e20164258

[9] Nemerofsky SL, Parravicini E, Bateman D, Kleinman C, Polin RA, Lorenz JM. The ductus arteriosus rarely requires treatment in infants $>1000$ grams. American Journal of Perinatology. 2008;25:661-666
[10] Philip R, Johnson J, Naik R, et al. Effect of patent ductus arteriosus on pulmonary vascular disease. Congenital Heart Disease. 2019;14(1):37-41

[11] Philip R, Johnson J, Sathanandam S, et al. Effect of patent ductus arteriosus on the heart in preterm infants. Congenital Heart Disease. 2019;14(1):33-36

[12] Susheel Kumar TK. Surgical management of patent ductus arteriosus. Congenital Heart Disease. 2019;14:57-59

[13] Clyman RI, Liebowitz M, Kaempf J, et al. PDA-TOLERATE trial: An exploratory randomized controlled trial of treatment of moderate-tolarge patent ductus arteriosus at 1 week of age. The Journal of Pediatrics. 2019;205:41.e6-48.e6

[14] Clyman RI, Mauray F, Heymann MA, Roman C. Cardiovascular effects of patent ductus arteriosus in preterm lambs with respiratory distress. The Journal of Pediatrics. 1987;111:579-587

[15] Pérez Fontán JJ, Clyman RI, Mauray F, Heymann MA, Roman C. Respiratory effects of a patent ductus arteriosus in premature newborn lambs. Journal of Applied Physiology (Bethesda, MD: 1985). 1987;63:2315-2324

[16] Benitz WE. Treatment of persistent patent ductus arteriosus in preterm infants: Time to accept the null hypothesis? Journal of Perinatology. 2010;30(4):241-252

[17] Noori S, McCoy M, Friedlich P, Bright B, Gottipati V, Seri I, et al. Failure of ductus arteriosus closure is associated with increased mortality in preterm infants. Pediatrics. 2009;123:e138-e144 
[18] El-Khuffash A, James AT, Corcoran JD, et al. A patent ductus arteriosus severity score predicts chronic lung disease or death before discharge. The Journal of Pediatrics. 2015;167:1354-1361.e2

[19] Shepherd JL, Noori S. What is a hemodynamically significant PDA in preterm infants? Congenital Heart Disease. 2019 Jan;14(1):21-26

[20] Noori S. Patent ductus arteriosus in the preterm infant: To treat or not to treat? Journal of Perinatology. 2010;30(Suppl):S31-S37

[21] McNamara PJ, Sehgal A. Towards rational management of the patent ductus arteriosus: The need for disease staging. Archives of Disease in Childhood. Fetal and Neonatal Edition. 2007;92:F424-F427

[22] Sankar MN, Bhombal S, Benitz WE. PDA: To treat or not to treat. Congenital Heart Disease. 2019;14(1):46-51

[23] Ohlsson A, Walia R, Shah SS. Ibuprofen for the treatment of patent ductus arteriosus in preterm or low birth weight (or both) infants. Cochrane Database of Systematic Reviews. 2015;2:CD003481

[24] Sathanandam S, Balduf K, Chilakala S, et al. Role of transcatheter patent ductus arteriosus closure in extremely low birth weight infants. Catheterization and Cardiovascular Interventions. 2019;93(1):89-96

[25] Mitra S, Florez ID, Tamayo ME, et al. Association of placebo, indomethacin, ibuprofen, and acetaminophen with closure of hemodynamically significant patent ductus arteriosus in preterm infants: A systematic review and meta-analysis. Journal of the American Medical Association. 2018;319(12):1221-1238
[26] Koehne PS, Bein G, AlexiMeskhishvili V, Weng Y, Bührer C, Obladen M. Patent ductus arteriosus in very low birthweight infants: Complications of pharmacological and surgical treatment. Journal of Perinatal Medicine. 2001;29(4):327-334

[27] Zbar RI, Chen AH, Behrendt DM, Bell EF, Smith RJ. Incidence of vocal fold paralysis in infants undergoing ligation of patent ductus arteriosus. The Annals of Thoracic Surgery. 1996;61(3):814-816

[28] Cassady G, Crouse DT, Kirklin JW, Strange MJ, Joiner CH, Godoy G, et al. A randomized, controlled trial of very early prophylactic ligation of the ductus arteriosus in babies who weighed 1000 $\mathrm{g}$ or less at birth. The New England Journal of Medicine. 1989;320:1511-1516

[29] El-Said HG, Bratincsak A, Foerster SR, et al. Safety of percutaneous patent ductus arteriosus closure: An unselected multicenter population experience. American Heart Association. 2013;2(6):e000424

[30] Zahn EM, Peck D, Phillips A, et al. Transcatheter closure of patent ductus arteriosus in extremely premature newborns: Early results and midterm follow-up. JACC. Cardiovascular Interventions. 2016;9(23):2429-2437

[31] Sathanandam S, Whiting S, Cunningham J, et al. Practice variation in the management of patent ductus arteriosus in extremely low birth weight infants in the United States: Survey results among cardiologists and neonatologists. Congenital Heart Disease. 2019;14(1):6-14

[32] Benitz WE. Hey, Doctor, Leave the PDA Alone. Pediatrics. 2017;140(2):pii: e20170566

[33] Younge N, Goldstein RF, Cotten CM, et al. Survival and neurodevelopmental outcomes among periviable infants. 
The New England Journal of Medicine. 2017;376(7):617-628

[34] Sathanandam S, Agrawal H, Chilakala S, et al. Can transcatheter PDA closure be performed in neonates $\leq 1000$ grams? The Memphis experience. Congenital Heart Disease. 2019;14(1):79-84

[35] Sathanandam S, Gianinni A, Sefton E, et al. Live broadcast of transcatheter PDA closure in a 700 grams ELBW infant during the International PDA Symposium. Congenital Heart Disease. 2019;14(1):85-89

[36] https://abbott.mediaroom. com/2019-01-14-FDA-ApprovesWorlds-First-Device-for-Treatmentof-Premature-Babies-and-Newbornswith-an-Opening-in-Their-Hearts-aCommon-Congenital-Defect

[37] Willis A, Pereiras L, Head T, et al. Transport of extremely low birth weight neonates for persistent ductus arteriosus closure in the catheterization lab. Congenital Heart Disease. 2019;14(1):69-73

[38] Alexander J, Yohannan T, Abutineh I, et al. Ultrasound-guided femoral arterial access in pediatric cardiac catheterizations: A prospective evaluation of the prevalence, risk factors and mechanism for acute loss of arterial pulse. Catheterization and Cardiovascular Interventions. 2016;88(7):1098-1107

[39] Johnson J, Sathanandam S, Naik R, Philip R. Echocardiographic guidance for transcatheter patent ductus arteriosus closure in extremely low birth weight infants. Congenital Heart Disease. 2019;14(1):74-78

[40] Sathanandam S, Justino H, Rush Waller B III, Radke W, Qureshi A. Initial clinical experience with the Medtronic
Micro Vascular Plug ${ }^{\mathrm{TM}}$ in transcatheter occlusion of PDAs in extremely premature infants. Catheterization and Cardiovascular Interventions. 2017;89(6):1051-1058

[41] Sathanandam S, Apalodimas L, Weems M, Rush Waller B III, Philip R. Establishing a robust transcatheter PDA closure program for extremely low birth weight infants. Congenital Cardiology Today. 2018. ISSN: 1554-7787; ISSN: 1554-0499

[42] Apalodimas L, Rush Waller B, Philip R, et al. A comprehensive program for preterm infants with patent ductus arteriosus. Congenital Heart Disease. 2019;14(1):90-94 



\title{
Chapter 5
}

\section{Universal Screening for Congenital CMV Infection}

\author{
Sara Lunardi, Francesca Lorenzoni and Paolo Ghirri
}

\begin{abstract}
Congenital cytomegalovirus (CMV) infection is an important public health problem. It is a leading cause of disability in children. Congenitally infected neonates often appear asymptomatic at birth or have nonspecific symptoms. An early diagnosis and subsequent early antiviral therapy associated to nonpharmacological therapy (e.g., hearing rehabilitation, speech-language therapy, and cochlear implants) can reduce long-term disability. Much research has been done in this field, but further studies are still necessary. Looking back at the most recent papers, we will draw a review on this topic trying to answer to the question: could universal CMV screening be a useful and cost-effective diagnostic tool?
\end{abstract}

Keywords: cytomegalovirus, universal screening, congenital infection, hearing loss, disability

\section{Introduction}

Congenital cytomegalovirus (CMV) infection is an important public health problem. It is a leading cause of disability in children. Even if it is a major public concern and a high cost, there is little awareness among the general public and medical officers. Most pregnant women are not aware of CMV and do not know how to prevent it. Congenitally infected neonates often appear asymptomatic at birth or have nonspecific symptoms. An early diagnosis and subsequent early antiviral therapy associated to nonpharmacological therapy (e.g., hearing rehabilitation, speech-language therapy, and cochlear implants) can reduce long-term disability.

Routine ultrasound scans fail to identify signs of cytomegalovirus infection till late gestation. Furthermore, most congenitally infected babies are asymptomatic at birth and thus will not be identified by routine clinical examination or hearing test (the majority of neonates with CMV-related sensorineural hearing loss will have late onset or progressive losses). Although congenital cytomegalovirus infection is more common than most screened newborn conditions, a routine cytomegalovirus screening at birth is not performed [1], even if the existence of reliable tests to early diagnose the condition, the improved outcomes following early diagnosis and the successful antiviral treatment could fulfill the criteria for universal screening $[2,3]$. 


\section{Congenital cytomegalovirus infection}

\subsection{Incidence, transmission routes, and clinical spectrum}

The overall CMV seroprevalence in women of childbearing age depends on age, parity, ethnicity, and social status; differs between countries and regions; and changes over time.

The congenital infection prevalence varies according to the chosen diagnostic criteria and how tests are performed by the laboratory. It affects around the 0.5 $0.7 \%$ of all live births in industrialized countries such as Western Europe, United States, Canada, and Australia. It affects even more babies (1-2\% of all live births) in other countries such as Africa, Latin America, and most Asian countries [1, 4-11].

Cytomegalovirus (CMV) is a herpesvirus spread by almost all human fluids (blood, saliva, breast milk, urine, sperm, and vaginal fluids). Cytomegalovirus usually leads to unknown infection in immunocompetent adults, and so it happens in pregnant women. In Europe, 1-8\% of women are exposed to primary infection [12].

Infants and toddlers often shed the virus for months or even years, and pregnant women could easily be infected by urine and saliva. Intrauterine infection leads to fetal infection with a transmission rate of $32 \%$ in primary maternal infection and $1.4 \%$ in recurrent maternal infection. Consequences are worst if the mother is primary infected (10-18\% of newborns with symptomatic congenital CMV disease at birth and 10-58\% rate of permanent and late sequelae), but also secondary infection (reactivation by a preexistent herpesvirus or infection by a new strand) can lead to neurological sequelae (8\% circa of late sequelae) [12]. Due to the high overall prevalence, two-thirds of babies with congenital CMV infections are born to mothers with preexistent antibodies [13].

The clinical spectrum of congenital CMV varies from the absence of signs (85-90\% of infected neonates are asymptomatic) to potentially life-threatening disease (10-15\% are symptomatic at birth with a wide spectrum of disease expression: clinical manifestations may include sensorineural hearing loss, hepatomegaly, jaundice, petechiae, microcephaly, chorioretinitis, and intrauterine growth restriction) [14].

In Europe, congenital cytomegalovirus infection is a leading cause of neurological disabilities in children such as sensorineural hearing loss (it is the main cause of nongenetic sensorineural hearing loss), blindness, neurodevelopment delays, and cerebral palsy. Permanent impairments mainly target the central nervous system.

Hearing loss may be present at birth or has a delayed onset. About $50 \%$ of sensorineural hearing loss further deteriorates during childhood [14]. At present, no definite markers have been identified to predict which infants with mild signs or asymptomatic disease will develop sensorineural hearing loss: viral load as determined by polymerase chain reaction could probably be useful for this purpose [15].

Even if congenital cytomegalovirus infection is a major public concern and a high cost, there is little awareness among the general public and medical officers.

While cytomegalovirus is a routine test for pregnant women in eight European countries and Israel, it is not a mandatory test in Italy and most obstetrics do not recommend it $[16,17]$ probably due to lack of definite and universally accepted intervention for pregnant women with a primary infection and to the fact that most infected babies are born to mothers experiencing a nonprimary maternal infection [14].

\subsection{Diagnostic timing}

Routine ultrasound scans fail to identify signs of cytomegalovirus infection till late gestation. Furthermore, most congenitally infected babies are asymptomatic 
at birth and thus will not be identified by routine clinical examination or hearing test (the majority of neonates with CMV-related sensorineural hearing loss will have late onset or progressive losses). Early, reliable, and relatively inexpensive tests should be defined in order to identify these babies at risk at an early stage.

To make diagnosis of congenital infection, tests should be performed within the first 2-3 weeks of age. The Joint Committee on Infant hearing states that all babies with hearing loss of uncertain origin, based on an initial evaluation, should be tested for cytomegalovirus [18].

But if CMV diagnosis is reliable and if the test is performed within the first 3 weeks of age, then waiting for a complete audiological and medical evaluation often means that it is too late to diagnose congenital CMV infection.

\subsection{Universal screening: pro and cons}

According to the American College of Medical Genetics Newborn Screening Expert Group "To be included as a primary target condition in a newborn screening program, a condition should meet the following minimum criteria: It can be identified at a period of time ( 24 to 48 hours after birth) at which it would not ordinarily be clinically detected, a test with appropriate sensitivity and specificity is available, there are demonstrated benefits of early detection, timely intervention, and efficacious treatment" [19]. Earlier on the Wilson and Jungner criteria for newborn screening had stated that the condition should represent a public health problem and a well-known condition, a suitable test should exist to early diagnose it and the benefit should outweigh the risks and costs of early intervention [20, 21].

Although congenital cytomegalovirus infection is more common than most screened newborn conditions, a routine cytomegalovirus screening at birth is not performed [1], even if the existence of reliable tests to early diagnose the condition, the improved outcomes following the early diagnosis and the successful antiviral treatment could fulfill the criteria for universal screening $[2,3]$.

In Italy, the prevalence of congenital CMV infection is lower than other countries $(0.15-0.51 \%$ according to Italian Higher Health Institute data) but still higher than other conditions that are routinely screened at birth (e.g., cystic fibrosis that occurs in about one over 2500-3000 healthy neonates, phenylketonuria with an incidence of 1:10.000 newborns, or congenital hypothyroidism with a prevalence of 1/2000-4000).

According to the informal International Congenital Cytomegalovirus Recommendations Group that convened in 2015, "consideration must be given to universal neonatal screening for cytomegalovirus to facilitate early detection and intervention for sensorineural hearing loss and developmental delay" [22].

Cannon et al. in a study published in 2014 estimated the number of babies with the most common CMV-related disabilities (such as hearing loss, visual impairment, and cognitive deficits) in the United States. For each disability, they analyzed the existence of useful therapeutic intervention. They found evidence of benefits of nonpharmacological treatments in babies with cognitive deficits and in babies with delayed hearing loss with onset within the first 2 years of age. No benefits were found for babies with visual impairment [23]. Improved language development should result by a prompt detection and management of late onset hearing loss (e.g., use of hearing aids or cochlear implants).

The economic burden caused by congenital CMV is substantial as many affected babies require ongoing care, special therapeutic, and educational services [23].

Congenital CMV disease (cCMVd) is associated with a substantial economic burden, not only at birth and throughout the first year of life, but also during childhood, adolescence, and adulthood. Although a lot has been published about the 
clinical outcomes and sequelae associated with congenital CMV infection, less data are available regarding health care resource utilization and costs associated with cCMVd.

The Committee to Study Priorities for Vaccine Development estimated in 2000 that there were 40,000 infants born every year in the United States with CMV infection and assumed 400 deaths annually from the congenitally acquired CMV infection and about 8000 children with permanent disabilities [24]. Assuming that these children require diagnostics, hospitalization, long-term care such as regular visits to a specialist for the lifetime and special schooling expense, the estimated annual direct economic cost for caring for these children was estimated at about 1-2 billion dollars [14, 24, 25]. Lifetime costs of hearing impairment are available, and in 2007, costs including devices, medical costs, special education, and lost productivity were estimated to be over 700.000 euro per person with bilateral hearing impairment [20].

Ronchi et al. defined congenital CMV infection a huge public health problem with an estimated annual cost of up to 4 billion dollars in the United States alone [26].

A recent study by Clinthera et al., in line with previously published US data, revealed inpatient costs associated with cCMVd in infants. They focused on birth admission describing a mean long of stay (LOS) between 22.1 and 37.5 days with mean costs between $\$ 46,994$ and $\$ 98,126$, corresponding to accrue costs at birth about 1.5-2.1 times greater than control infants for cesarean and vaginal deliveries. Moreover, during the first year of life, infants with cCMVd had costs about 7 times greater than control infants. The key cost driver among the cCMVd population is represented by inpatient visits. Beyond the direct economic impact, other aspects of congenital CMV (cCMV) infection affect both the patient and the society. In the same study, the annual economic costs, both direct and indirect, associated with care of children with disabilities due to cCMV infection (hearing loss and cognitive disabilities), range between $\$ 20,000$ and $\$ 60,000$, with an average of $\$ 30,000$ per family [27].

Both universal screening and targeted screening have shown to be cost-effective, but the first one probably provides large net savings and better care [26, 28-29].

As already underlined by Gantt et al., introducing a screening program for cCMV at birth would allow for identification of asymptomatic newborns with cCMV, who would previously have gone undiagnosed and provide potentially early treatment and ongoing neurodevelopmental monitoring, including hearing surveillance. With their well-designed cost-effectiveness study, they provide key support for the healthcare system benefits, especially cost savings, for either a targeted or universal approach to screening cCMV. The potential benefits described by this study, in particular those provided by universal screening, when loss of productivity costs is taken into account, make it the most attractive form of screening, compared to targeted screening [30].

Among all infants born in the United States, identification of 1 case of cCMV infection by universal screening was estimated to cost $\$ 2000$ to $\$ 10,000$ and by targeted screening, $\$ 566$ to $\$ 2832$. Net savings from universal screening were estimated to be greater than those from targeted screening, although screening costs are higher. Savings from screening strategies are derived not only from improved hearing with antiviral treatment of affected newborns but also from earlier detection of late-onset hearing loss [28].

The importance of the economic burden of CMV has started to be recognized also in Europe, where a recent Dutch study by Korndewal et al. confirmed that children with cCMV have higher average healthcare costs in the first 6 years of life than cCMV-negative children. The difference in total healthcare costs between these 
groups is more than $€ 2500$ per child. This study again revealed that the large and usually unrecognized groups of children with cCMV who are asymptomatic at birth are responsible for half of the costs, underestimating the real impact. Other causes of underestimation are the fact that children who died were not included and that the evaluation of the costs is only up to 6 years of age, while, at a later follow-up, the difference between cCMV-positive and CCMV-negative children might become even larger. Finally, other costs related to the impairment of children with cCMV, such as special needs education, future reduced productivity, and potential productivity loss of parents, were not taken into account [31].

Even in the United Kingdom, a cost model had been proposed, but, due to the scarcity of robust data preventing inclusion of many expected costs, it is likely that this model underestimates the "true" cost. It estimated that the cost of cCMV to the United Kingdom in 2016 was $£ 732$ million, of which approximately $40 \%$ of the costs were direct and $60 \%$ indirect. Acute management of cCMV was the lowest contributing cost (estimated at $£ 1.2$ million), with costs for management of longterm sequelae being orders of magnitude greater. As well as in the United States, also in the United Kingdom, both universal and targeted newborn screening would be cost-effective options for detecting and reducing hearing loss and other consequences caused by cCMV [32].

Many studies have already evaluated the benefits of a targeted screening program in the United Kingdom. Williams et al. estimated that the cost of "protecting" a case of childhood SNHL from cCMV identified and treated through a national targeted screening program would be $\sim £ 14,000$. In comparison, detailed health economic analysis suggests that the societal cost of bilateral hearing impairment in children aged 7-9 years rises from $£ 9120$ to $£ 21,179$ per year from moderate to severely affected children, and the lifelong cost of a pediatric cochlear implant is $£ 82,000-108,000$. The cost of identifying a case of cCMV-related SNHL varied between $£ 9224$ and $£ 5413$, and the cost of "protecting" a case of cCMV-related SNHL varied between $£ 19,601$ and $£ 11,502$, taking into account only the healthcare costs and no family and wider societal costs [33].

Based on these economic data, it could be the right time to introduce also in Europe a universal screening program even if larger studies to determine the costeffectiveness and utility of this policy would be helpful.

Commonsense says that screening should be performed only if potential benefits outweigh the costs and potential harms. Potentially negative aspects of Universal Screening could be parental stress linked to a positive diagnosis in those CMV infected babies who will never develop clinical problems related to the congenital infection or costs of unnecessary visits or tests. But, on the other hand, a definite diagnosis could reduce parental (and medical) stress and anxiety caused by an uncertain diagnosis in babies with nonspecific symptoms (and could also save anxiety and costs linked to the diagnostic odyssey that is often linked to without-definite-cause late onset hearing or neurological impairment). In studies, universal screening has shown to be well accepted by parents. Early diagnosis could be important, but it is fundamental that children and parents are not left alone after such a diagnosis $[23,34]$.

\subsection{Diagnostic tests}

Early, reliable, and relatively inexpensive tests should be defined in order to identify these babies at risk at an early stage (Table 1 ).

Traditional isolation of the virus by culture of urine or saliva is the gold standard test, but it is not suitable as a mass screening because it cannot be automated, and it is labor- and resource-intensive and requires tissue culture facilities [35]. On the 


\begin{tabular}{|c|c|c|c|c|}
\hline Test & $\begin{array}{l}\text { It could be } \\
\text { performed } \\
\text { on }\end{array}$ & \multicolumn{2}{|l|}{ Pro } & Cons \\
\hline \multirow{2}{*}{$\begin{array}{l}\text { Traditional isolation } \\
\text { of the virus by } \\
\text { culture }\end{array}$} & Urine & \multirow{2}{*}{\multicolumn{2}{|c|}{$\begin{array}{l}\text { Reliable, it is the gold standard to } \\
\text { diagnose CMV infection. }\end{array}$}} & It is not suitable as \\
\hline & Saliva & & & $\begin{array}{l}\text { a mass screening } \\
\text { because it cannot } \\
\text { be automated, and } \\
\text { it is labor- and } \\
\text { resource-intensive } \\
\text { and requires tissue } \\
\text { culture facilities. }\end{array}$ \\
\hline \multirow[t]{3}{*}{$\begin{array}{l}\text { PCR (real-time } \\
\text { polymerase chain } \\
\text { reaction) }\end{array}$} & Urine & \multirow[t]{3}{*}{$\begin{array}{l}\text { PCR could be } \\
\text { automated, } \\
\text { and it is low } \\
\text { cost and does } \\
\text { not seem to } \\
\text { be affected by } \\
\text { sample storage } \\
\text { and transport. }\end{array}$} & $\begin{array}{l}\text { CMV is largely } \\
\text { excreted in urine, } \\
\text { and quantification } \\
\text { of urinary CMV } \\
\text { load could even } \\
\text { predict the } \\
\text { incidence of late- } \\
\text { onset sequelae. }\end{array}$ & $\begin{array}{l}\text { Collecting urine } \\
\text { for a universal } \\
\text { screening could be } \\
\text { difficult. }\end{array}$ \\
\hline & Saliva & & $\begin{array}{l}\text { Saliva swabs are } \\
\text { easy to collect. }\end{array}$ & $\begin{array}{l}\text { False positive } \\
\text { results could } \\
\text { be related to } \\
\text { contamination by } \\
\text { CMV in maternal } \\
\text { milk. }\end{array}$ \\
\hline & $\begin{array}{l}\text { Dried } \\
\text { blood spot } \\
\text { samples }\end{array}$ & & $\begin{array}{l}\text { It could be useful } \\
\text { for retrospective } \\
\text { diagnosis in late- } \\
\text { onset hearing loss. }\end{array}$ & $\begin{array}{l}\text { Studies reported } \\
\text { variable sensitivity } \\
\text { of PCR on DBS. }\end{array}$ \\
\hline $\begin{array}{l}\text { Detection of } \\
\text { CMV specific } \\
\text { immunoglobulin M } \\
\text { antibodies }\end{array}$ & $\begin{array}{l}\text { Neonatal } \\
\text { serum }\end{array}$ & - & & $\begin{array}{l}\text { Only } 20-70 \% \text { of } \\
\text { infected neonates } \\
\text { show specific IgM }\end{array}$ \\
\hline
\end{tabular}

Table 1.

Diagnostic tests.

other hand, PCR (real-time polymerase chain reaction) could be automated, and it is low cost and does not seem to be affected by sample storage and transport. PCR tests could then be suitable as a mass screening and could be performed on urine, saliva, and dried blood spot samples. CMV is largely excreted in urine; thus, PCR on urine is largely used to diagnose congenital CMV infection with a cost per child of about $22 €$ (based on rough cost estimations by our own facilities). According to the study published by Yamaguchi et al. in 2016, quantification of urinary CMV load could even predict the incidence of late-onset sensorineural hearing loss (SNHL) and neurological disorders because urinary CMV copy number seemed to be associated with SNHL and central nervous system damage: CMV viral load in urine not only could so be diagnostic of congenital infection but also predict sequelae [36]. The problem is that collecting urine for a universal screening could be more difficult (and use of cotton balls or filter cards is still to be evaluated in large studies) than PCR on saliva.

Dried blood spots (DBS) are already collected routinely for metabolic screening worldwide and have been suggested as the optimal choice, but according to 2010 Boppana et al. study [35], CMV testing with DBS real-time PCR compared with tests on saliva had low sensitivity, limiting its value as a screening test. Other studies reported variable sensitivity of PCR on DBS, probably due both to technical 
issues and to the fact that not all congenitally infected neonates have detectable viremia at birth. For this reason, it is not suitable for universal screening but could be useful for retrospective diagnosis in late onset hearing loss (even if a positive test is diagnostic while a negative test does not rule out a congenital CMV infection). Detection of CMV specific immunoglobulin $\mathrm{M}$ antibodies in neonatal serum may as well disclose congenital infection, but only $20-70 \%$ of infected neonates show specific IgM [37].

In a multicenter screening study published on New England Journal of Medicine in 2011, Boppana et al. concluded that PCR assays of both liquid and dried saliva showed high sensitivity and specificity and could be used as a potential screening test for congenital CMV infection. The rate of false positive results in both swabs was less than $0.03 \%$ : in case of positive test, a confirmation test within 3 weeks of age could then rule out a false positive result $[14,38]$. Barkai et al. concluded in their report of clinical experience [39] that universal CMV screening using realtime PCR saliva is a feasible and easy-to-use method for newborn infants.

The ease of saliva swab collection makes the PCR on saliva the preferred test for newborn screening (probably with costs similar to those of PCR on urine), but if the test gives a positive result, then confirmation should be obtain by PCR or culture test on urine in order to rule out false positive results due, for example, to contamination by CMV in maternal milk.

\subsection{Antiviral therapy}

The treatment of symptomatic congenital CMV infection with intravenous ganciclovir for 6 weeks has shown to improve audiological outcome at 6 months. Treated infants had fewer development delays than untreated babies according to Denver Developmental evaluation. The Collaborative Antiviral Study Group determined the dose of oral valganciclovir resulting in systemic exposure similar to that with intravenous ganciclovir, so that actually therapy with intravenous ganciclovir or oral valganciclovir for 6 weeks is an accepted therapy for symptomatic CMV [40-42]. Given that the results seemed to wane after 2 years of age, a recent study [2] was performed by Kimberlin et al. in 2015 comparing the 6 weeks versus a 6 -month therapy. It concluded that treating the condition with oral valganciclovir $(16 \mathrm{mg} / \mathrm{kg} /$ dose twice a day) for 6 months appeared to improve developmental and hearing outcomes in the longer term: this is now considered an effective and welltolerated therapeutic option for symptomatic neonates, while currently evidence of benefit of antiviral therapy in asymptomatic babies is still lacking [14] (Table 2). Asymptomatic babies are the majority of congenital CMV infected neonates, and since these babies are at risk of late-onset sequelae, further studies are needed in order to define the best pharmacological and nonpharmacological strategies. For these babies, a universal screening would be fundamental for an early diagnosis as early rehabilitation treatments are vital. Symptomatic neonates, instead, would probably not benefit of a screening program (for example, they would probably be already detected by universal hearing screening), apart from the advantages of a more immediate diagnosis with consequent parental and physician peace of mind.

\subsection{Prevention}

Handwashing and other preventive measures to avoid contact with potentially contaminated body fluids are likely to be effective in preventing seroconversion in pregnant women [12]. Toddlers can shed the virus through saliva and urine for a long period of time, so women dealing with young children are at particular risk. Most women have not ever heard of CMV infection. 
- Treating the condition with oral valganciclovir ( $16 \mathrm{mg} / \mathrm{kg} / \mathrm{dose}$ twice a day) for 6 months is now considered an effective and well-tolerated therapeutic option for symptomatic neonates, while currently evidence of benefit of antiviral therapy in asymptomatic babies is still lacking.

Table 2.

Antiviral therapy for congenital CMV infection.

- Assume that all toddlers and young children could be secreting the virus through saliva and urine.

- Remember hand washing with soap after activities such as changing diapers, bathing or feeding a baby, wiping running nose, touching baby's toys, or surfaces contaminated by saliva or urine.

- Avoid kissing babies on the mouth, sharing kitchen utensils, toothbrushes, or towels

Table 3.

Information should be given to all women of reproductive age about simple hygiene measures and change of behavior that could prevent seroconversion.

Of 643 women surveyed by Jeon et al. in their study published in 2006 [43], only $22 \%$ had heard of congenital CMV, while in a national mail survey of the US population, only $14 \%$ of female respondents had heard of CMV [44].

In our Neonatal Units (University Hospital of Pisa and S Luca Hospital of Lucca), we just started a survey asking mothers of healthy term newborns if they had ever heard of CVM (first question), if they knew their CMV status (second question), and if they knew how to prevent CMV infection (third question). From the few data we have collected since, $65 \%$ of women had somewhere heard of CMV, but $82 \%$ did not know their CMV status, and, most importantly, $90 \%$ of women did not know how to prevent CMV infection.

Information should be given to all women of reproductive age about simple hygiene measures and change of behavior that could prevent seroconversion. All women who are pregnant or planning to become pregnant should be fully informed, especially if dealing with children. They should be educated about hygienic practices to reduce the risk of CMV infection, assuming that all toddlers and young children could be secreting the virus through saliva and urine. Hygienic measures include not only hand washing with soap after activities such as changing diapers, bathing or feeding a baby, wiping running nose, touching baby's toys, or surfaces contaminated by saliva or urine, but also avoiding kissing babies on the mouth, sharing kitchen utensils, toothbrushes, or towels [25] (Table 3).

In 2015, Revello et al. published a mixed interventional and observational controlled study to measure the effectiveness of hygiene information among pregnant seronegative women at risk of primary CMV infection: $1.2 \%$ of women who had been given hygiene information at 11-12 weeks of gestation seroconverted versus $7.6 \%$ in the comparison group, and three newborns were diagnosed with congenital infection in the intervention group versus eight neonates in the group of women who had not been informed [45].

\section{Conclusion}

It is difficult to estimate, on the basis of precise numbers, the potential benefit of a congenital CMV screening, and surely further studies are urgently needed, but we could probably say that it could be an useful tool for an early intervention on those babies whose congenital infection would have never been detected at an early stage on a clinical basis. The main value of a universal screening is to pick up congenitally infected babies who are asymptomatic or with mild symptoms unrevealed 
by clinical examination that pass neonatal hearing screening. These babies may develop late onset hearing impairment or other neurological sequelae and being diagnosed at an early stage by neonatal screening could improve their outcome, before it is too late for a successful rehabilitation [46]. Babies with symptomatic infection should be readily diagnosed by clinical examination (there should be no need for a universal screening in these babies), but sometimes awareness on congenital CMV even among health care professionals is relatively low so that too often being "small for gestational age" or other signs of possible CMV infection are attributed to other conditions and CMV test is not performed [26].

In a study we published in 2014 [47] we found an association between congenital CMV infection and preterm births (3.03\%), and with SGA condition (3.7\%), suggesting that routine CMV urine detection should be at least performed in all babies born before 37 weeks of gestational age and in term SGA newborns. Today, we could say that both universal screening and targeted screening have shown to be costeffective, but the first one provides large net savings and better care [26, 28-29].

None of the benefits of newborn CMV screening will occur if the universal screening is not associated with an adequate follow-up program for an early detection and intervention of hearing loss, visual impairment, and cognitive deficits. Only if families are fully informed and never left alone in this journey, but thoroughly supported, then the potential parental stress, linked to a universal screening, could be outweigh by well-demonstrated advantages of an early diagnosis. But, even more important than universal screening is to clearly and thoroughly inform pregnant women about what CMV is, how it is transmitted, and how to prevent it: early diagnosis is fundamental, but prevention, whereas a vaccination has yet to come, is even more fundamental.

\section{Acknowledgements}

We thank Dr. Angelina Vaccaro, Chief of Pediatric and Neonatal Unit, S. Luca Hospital of Lucca for allowing us to interview mothers of neonates born in the unit. We thank Dr. Paola Petrocelli for calculating costs of neonatal tests.

\section{Conflict of interest}

The authors declare that there is no conflict of interest regarding the publication of this manuscript. 


\section{Author details}

Sara Lunardi ${ }^{1 *}$, Francesca Lorenzoni ${ }^{2}$ and Paolo Ghirri ${ }^{3}$

1 Paediatric and Neonatal Unit, S. Luca Hospital, Lucca, Italy

2 Division of Neonatology and Neonatal Intensive Care Unit, University Hospital of Pisa, Italy

3 Chief Division of Neonatology and Neonatal Intensive Care Unit, University Hospital of Pisa, Italy

*Address all correspondence to: saralunardi@hotmail.it

\section{IntechOpen}

(C) 2019 The Author(s). Licensee IntechOpen. This chapter is distributed under the terms of the Creative Commons Attribution License (http://creativecommons.org/licenses/ by/3.0), which permits unrestricted use, distribution, and reproduction in any medium, provided the original work is properly cited. (cc) BY 


\section{References}

[1] Fowler KB, McCollister FP, Sabo DL, Shoup AG, Owen KE, Woodruff JL, et al. A targeted approach for congenital cytomegalovirus screening within newborn hearing screening. Pediatrics. 2017;139(2):e20162128

[2] Kimberlin DW, Jester PM, Sánchez PJ, et al. National institute of allergy and infectious diseases collaborative antiviral study group. Valganciclovir for symptomatic congenital cytomegalovirus disease. The New England Journal of Medicine. 2015;372(10):933-943

[3] Korver AM, Konings S, Dekker FW, et al. DECIBEL collaborative study group. Newborn hearing screening vs later hearing screening and developmental outcomes in children with permanent childhood hearing impairment. Journal of the American Medical Association. 2010;304(15):1701-1708

[4] Manicklal S, Emery VC, Lazzarotto T, et al. The "silent" global burden of congenital cytomegalovirus. Clinical Microbiology Reviews. 2013;26(1):86-102

[5] Fowler KB, Stagno S, Pass RF. Maternal age and congenital cytomegalovirus infection: Screening of two diverse newborn populations, 1980-1990. The Journal of Infectious Diseases. 1993;168(3):552-556

[6] Dollard SC, Grosse SD, Ross DS. New estimates of the prevalence of neurological and sensory sequelae and mortality associated with congenital cytomegalovirus infection. Reviews in Medical Virology. 2007;17(5):355-363

[7] Kenneson A, Cannon MJ. Review and meta-analysis of the epidemiology of congenital cytomegalovirus (CMV) infection. Reviews in Medical Virology. 2007;17(4):253-276
[8] Dar L, Pati SK, Patro AR, et al. Congenital cytomegalovirus infection in a highly seropositive semi-urban population in India. The Pediatric Infectious Disease Journal. 2008;27(9):841-843

[9] Kaye S, Miles D, Antoine P, et al. Virological and immunological correlates of mother-to-child transmission of cytomegalovirus in the Gambia. The Journal of Infectious Diseases. 2008;197(9):1307-1314

[10] van der Sande MA, Kaye S, Miles DJ, et al. Risk factors for and clinical outcome of congenital cytomegalovirus infection in a periurban west-African birth cohort. PLoS One. 2007;2(6):e492

[11] Yamamoto AY, Mussi-Pinhata MM, Cristina P, Pinto G, Moraes FigueiredoLT, Jorge SM. Congenital cytomegalovirus infection in preterm and full-term newborn infants from a population with a high seroprevalence rate. The Pediatric Infectious Disease Journal. 2001;20(2):188-192

[12] Ludwig A, Hengel $\mathrm{H}$.

Epidemiological impact and disease burden of congenital cytomegalovirus infection in Europe. Eurosurveillance. 2009;14(9):19140

[13] Wang C, Zhang X, Bialek S, Cannon MJ. Attribution of congenital cytomegalovirus infection to primary versus non-primary maternal infection. Clinical Infectious Diseases. 2011;52(2):e11-e13

[14] Marsico C, Kimberlin DW.

Congenital cytomegalovirus infection: Advances and challenges in diagnosis, prevention and treatment. Italian Journal of Pediatrics. 2017;43:38

[15] James SH, Kimberlin DW. Advances in the prevention and treatment of 
congenital cytomegalovirus infection. Current Opinion in Pediatrics. 2016;28(1):81-85

[16] Ranzoni AM. Citomegalovirus, il test di screening in gravidanza è fondamentale. 2014. Available from: https://www.osservatoriomalattierare.it

[17] Guidelines National System. ISS. Linee guida per la gravidanza fisiologica. 2011. Available from: http://www.salute.gov.it/imgs/C_17_ pubblicazioni_1436_allegato.pdf

[18] American Academy of Pediatrics, Joint Committee on Infant Hearing. Year 2007 position statement: Principles and guidelines for early hearing detection and intervention programs. Pediatrics. 2007;120(4):898-921

[19] ACMG Newborn Screening Expert Group. Newborn screening panel and system. Genetics in Medicine. 2006;8(5, Supplement):12S-252S

[20] de Vries JJ, Vossen AC, Kroes AC, van der Zeijst BA. Implementing neonatal screening for congenital cytomegalovirus: Addressing the deafness of policy makers. Reviews in Medical Virology. 2011;21(1):54-61

[21] Wilson JMG, Jungner G. Principles and practice of screening for disease. WHO Public Health Papers. 1968;34:1-163

[22] Rawlinson WD, Boppana SB, Fowler KB, Kimberlin DW, Lazzarotto T, Alain S, et al. Congenital cytomegalovirus infection in pregnancy and the neonate: Consensus recommendations for prevention, diagnosis, and therapy. The Lancet Infectious Diseases. 2017;17(6):e177-e188

[23] Cannon MJ, Griffiths PD, Aston V, Rawlinson WD. Universal newborn screening for congenital CMV infection: What is the evidence of potential benefit? Reviews in Medical Virology. 2014;24(5):291-307

[24] Institute of Medicine. Vaccines for the 21st Century: A Tool for Decisionmaking. Washington, DC: The National Academies Press; 2000. DOI: $10.17226 / 5501$

[25] Cannon MJ, Davis KF. Washing our hands of the congenital cytomegalovirus disease epidemic. BMC Public Health. 2005;5:70

[26] Ronchi A, Shimamura M, Malhotra PS, Sánchez PJ. Encouraging postnatal cytomegalovirus (CMV) screening: The time is NOW for universal screening! Expert Review of Anti-Infective Therapy. 2017;15(5):417-419

[27] Juliana Meyers J, Sinha A, Samant S, Candrilli S. The economic burden of congenital cytomegalovirus disease in the first year of life: A retrospective analysis of health insurance claims data in the United States. Clinical Therapeutics. 2019;41(6):1040-1056.e3

[28] Gantt S, Dionne F, Kozak FK, et al. Cost-effectiveness of universal and targeted newborn screening for congenital cytomegalovirus infection. JAMA Pediatrics. 2016;170(12):1173-1180

[29] Bergevin A, Zick CD, McVicar SB, et al. Cost-benefit analysis of targeted hearing directed early testing for congenital cytomegalovirus infection. International Journal of Pediatric Otorhinolaryngology. 2015;79(12):2090-2093

[30] Hilditch C, Keir AK. Costeffectiveness of universal and targeted newborn screening for congenital cytomegalovirus infection. Commentary on: Gantt S, Dionne F, Kozak FK, et al. Cost-effectiveness of universal and targeted newborn screening for congenital 
cytomegalovirus infection. JAMA

Pediatrics. 2016;170:1173-1180

[31] Korndewal MJ, Weltevrede M, van den Akker-van Marle ME, et al.

Healthcare costs attributable to congenital cytomegalovirus infection. Archives of Disease in Childhood. 2018;103:452-457

[32] Retzler J, Hex N, Bartlett C, et al. Economic cost of congenital CMV in the UK. Archives of Disease in Childhood. 2019;104:559-563

[33] Williams EJ, Gray J, Luck S, et al. First estimates of the potential cost and cost saving of protecting childhood hearing from damage caused by congenital CMV infection. Archives of Disease in Childhood. Fetal and Neonatal Edition. 2015;100:F501-F506

[34] Grosse SD, Dollard S, Ross DS, Cannon M. Newborn screening for congenital cytomegalovirus: Options for hospital-based and public health programs. Journal of Clinical Virology. 2009;46(Suppl 4):S32-S36

[35] Boppana SB, Ross SA, et al. Dried blood spot real-time polymerase chain reaction assays to screen newborns for congenital cytomegalovirus infection. JAMA. 2010;303(14):1375-1382

[36] Yamaguchi A, Ohishi T, Arai $\mathrm{T}$, et al. Screening for seemingly healthy newborns with congenital cytomegalovirus infection by quantitative real-time polymerase chain reaction using newborn urine: An observational study. BMJ Open. 2017;7:e013810

[37] van Zuylen WJ,

Hamilton ST, Naing Z, Hall B, Shand A, Rawlinson WD. Congenital cytomegalovirus infection: Clinical presentation, epidemiology, diagnosis and prevention. Obstetric Medicine. 2014;7(4):140-146
[38] Boppana SB, Ross SA, et al. Saliva polymerase-chain-reactionn assay for cytomegalovirus screening in neowborns. The New England Journal of Medicine. 2011;364(22):2111-2118

[39] Barkai G, Ari-Even Roth D, Barzilai A, Tepperberg-Oikawa M, Mendelson E, Hildesheimer M, et al. Universal neonatal cytomegalovirus screening using saliva-Report of clinical experience. Journal of Clinical Virology. 2014;60(4):361-366

[40] Oliver SE, Cloud GA, Sanchez PJ, et al. Neurodevelopmental outcomes following ganciclovir therapy in symptomatic congenital cytomegalovirus infections involving the central nervous system. Journal of Clinical Virology. 2009;46(Suppl 4): S22-S26

[41] Kimberlin DW, Acosta EP, Sanchez PJ, et al. Pharmacokinetic and pharmacodynamic assessment of oral valganciclovir in the treatment of symptomatic congenital cytomegalovirus disease. The Journal of Infectious Diseases. 2008;197:836-845

[42] Pickering LK, Baker CJ, Long SS, Kimberlin DW, editors. Cytomegalovirus infection. In: Red Book: 2012 Report of the Committee on Infectious Diseases. 29th ed. Elk Grove Village, IL: American Academy of Pediatrics; 2012. pp. 300-305

[43] Jeon J, Victor M, Adler SP, Arwady A, Demmler G, Fowler K, et al. Knowledge and awareness of congenital cytomegalovirus among women. Infectious Diseases in Obstetrics and Gynecology. 2006;2006:80383. 1-7

[44] Ross DS, Victor M, Sumartojo E, Cannon MJ. Women's knowledge of congenital cytomegalovirus: Results from the 2005 HealthStyles survey. Journal of Women's Health. 2008;17(5):849-858 
[45] Revello MG, Tibaldi C, Masuelli G, Frisina V, Sacchi A, Furione M, et al. Prevention of primary cytomegalovirus infection in pregnancy. eBioMedicine. 2015;2(9):1205-1210

[46] Ghirri P, Liumbruno A, Lunardi S, Forli F, Boldrini A, Baggiani A, et al. Universal neonatal audiological screening: Experience of the University Hospital of Pisa. Italian Journal of Pediatrics. 2011;37:16

[47] Lorenzoni F, Lunardi S, Liumbruno A, Ferri G, Madrigali V, Fiorentini E, et al. Neonatal screening for congenital cytomegalovirus infection in preterm and small for gestational age infants. The Journal of Maternal-Fetal \& Neonatal Medicine. 2014;27(15):1589-1593 


\title{
VANEDELA's Test Screening, Comparison Low, Middle, and High Risk in Mexican Population
}

\author{
Rosa Ivone Martínez-Vázquez, Blásquez-Martínez Jorge Ulises, \\ Morales Ramírez Aline and Gerardo Alberto Alvarado-Ruiz
}

\begin{abstract}
The neurodevelopment screening test Valoración Neuroconductual del Lactante (VANEDELA's) allows the professional to follow the rapid and economic application development in which high- and moderate-risk children who do not reach their optimum development potential during the first 2 years of life can be detected in a timely manner. It also provides a tracking tool to follow-up the recommendations and interventions of children who had developmental delays to see how adaptive strategies work.
\end{abstract}

Keywords: VANEDELA's screening test, developmental delays, early childhood development

\section{Introduction}

Infant tracking is one of the important services in pediatrics, as there are different risk factors that affect the structure or those that are the product of parenting either by default or oversolving their needs without allowing the child to explore and participate in the construction of their competences, which are children without any organic pathology; however, they are delayed in development, as we will see later, leaving them unattended until the problem becomes apparent, given that the current health model focuses on the detection of children at risk of disability, escaping or belatedly detecting alterations in growth and development. World Health Organization (WHO) reported in 2010 that 249.4 million (43\%) children under the age of 5 in the world and 9.7 million (18\%) in Latin America and Caribbean presented risks of not reaching their development potential for various causes such as poverty, poor nutrition, unresponsive care and others. In addition, many research in the open population in Mexico reported figures of $40 \%$ of children with mild and moderate delays [1-3]. Mexico's cases are reported and recorded in which the sequel is clearly established, the technique "wait and see" issued, waiting for the infant to solve the problem or to structure the disability through maturation, being late his attention. For example of this is parents who come and go with their children, reporting to health personnel observations of behaviors that do not perform or make them different to other children of the same age, because having no early referrals tend to leave ample waiting times if provide an adequate solution to 
the patient and the family, which causes the delay [4-6] to increase and adequate solutions to the patient and the family, which causes the delay to increase.

The protective factors are intimately linked to organizational possibilities and stimulating variability that allow the child to explore and interpret, creating categories of greater complexity, integrating motor, cognitive, communication, emotional interaction, social interaction, and self-care [7, 8]. Faced with this problem, screening instruments allow timely detection of children who present obstacles at different times in the first years of life, as well as being a useful and quick tool to follow-up [9-11]. "Valoración Neuroconductual del Lactante" (VANEDELA) is a Mexican sieve test with sensitivity (79-89\%) and specificity (83-95\%) [12]. In order to detect early infants at risk for sequelae at the first level of care, six cohorts of ages $1,4,8,12,18$, and 24 months (M) are evaluated, with white-indicators, which children with delays do not perform at the proposed age. The instrument consists of three formats and somatometry is taken into account [13]. For this chapter, the formats of developmental behaviors (CDs) and developmental reactions (RDs) were analyzed in infants.

\section{Development behaviors format (CD)}

It consists of 60 behaviors that are grouped in different areas of development such as feeding, gross and fine motor, receptive and expressive language, cognitive development. The evaluation sheet is presented in six cohorts of ages $1,4,8,12,18$, and 24 months; each cut includes 10 reagents, which qualifies a positive point when the observation or negative reference is met if performing qualitatively prior to that requested, the final score considers risk-free when the child gets 10 points, mild risk 9-8, and risk of alteration 7 or fewer points.

Correlation data were obtained from Pearson and Student's t-test to assess the difference between mean and rating groups in behaviors and reactions of developmental will be used at J MP 8 statistical software.

\section{Reactions of development format (RD)}

A total of 10 reactions divided into 3 groups are evaluated according to their evolution: four are straightening reactions, three defense, and three balance. The evaluation sheet is presented in cohort of age. The first month evaluates the reaction of optical, labyrinth, and head straightening acting on the body; Landau reflux in 4 months; straightening of the body and sitting lateral defense in 8 months; the reaction of defense forward and defense sitting back in 12 months; the sitting equilibrium reaction at four points by 18 months; and the equilibrium reaction stopped in 24 months.

\section{Record format of alarm's signs (SA)}

In this format, a series of signs that can be observed during the evaluation or informed by the caregiver are presented. These involve changes or modifications of behavior that are usually associated with disorders of the functioning of the nervous system. They explore feeding area, visual and auditory perceptions, motor, social emotional, the cognitive year, language, and other additional ones.

They are considered positive when they comply with the criterion and negative if they present a less advanced behavior or are accompanied by signs. The rating 
gives normal when they present the reactions that are evaluated at the age cohort, slight risk to find any of the reactions evaluated that are still in process, and risk of alteration when the expected reaction does not occur or is accompanied by signs. It is necessary to emphasize the reactions of the development, allow the infant to organize the different movement patterns, and reach the bipedal posture and move.

In order to analyze the importance of early monitoring of infants, the first 2 years of life optimize their development. In a study conducted in newborns and infants from 2011 to 2014, in the Neurodevelopment Monitoring Laboratory in National Institute of Pediatrics and the Tlalpan Family Medicine Clinic, ISSSTE, parents accepted and signed the informed consent letter. The VANEDELA's test was applied to determine the behaviors that were being constructed as part of the research "Acquisition ages in Mexican infants of the evolutionary sequences of the white behaviors of the VANEDELA's screening test" approved by the Research Commissions and Ethics of the National Institute of Pediatrics (Registration number INP 030/2011).

The average age of the mothers was $29.32 \pm 5.43$ years, with a minimum age of 16 and a maximum age of 43 years; average age of the father was $33.37 \pm 6.80$ years, with a minimum age of 20 and a maximum age of 53 years. With medium to professional studies and that one of the parents had a stable job, the Gini's coefficient of 0.1292 was obtained, which places them as a population with an adequate level of economic well-being [14].

A total of 442 evaluations were carried out between 1 and 24 months of age, 224 (51\%) boys and 218 (49\%) girls were distributed by gender. According to their performance in the EEC Gesell's development test [15], three low risk groups were configured, which are children who did not present perinatal risk and their performance is as expected. Moderate risk those children who does not present perinatal risk; but a minor problem such as allergy or problems of upbringing or a performance lower than 85. But greater than 76 and high risk those who presented perinatal risk as at birth congenital heart disease, congenital hypothyroidism, premature infants, perinatal asphyxia, and epilepsy who attended mainly to the National Institute of Pediatrics.

With this follow-up, we observed that children can present some obstacles in the process of building different competences in the course of development both without and with perinatal risk [16]. According with the instrument, we have 202 infants from 1 to 24 months, follow the trajectory expected, 127 perform behaviors among 9-8 of the proposals, here we could be seeing both children if perinatal risk or infants at risk who are in follow-up are building the various skills and 113 are at perinatal risk that will have scores of 7 or less.

The relation, the three-risk group and the score obtained in the format of developmental behaviors and developmental reactions is significant when analyzing the relationship for each group the low-moderate risk relationship in development reactions does not show significant difference what is if the alterations in the development reactions will be delayed when neurological damage occurs, however, after 8 months, we observe that the difference between low and high risk, probably the reactions of actively rolling and protection to the front, is not significant, they come a little later.

In the analyze, by month to cohort and month the children (a) of low risk presents a proportion of realization between (1) and (0.92); those of moderate risk between (1) and (0.60), making the reagents of visual tracking $45^{\circ}$ on each side difficult, try to raise the head, activating the muscles of the neck, although the labyrinthine optical reflex is present and the flexion of prone members, possibly some of these children presented low tone; high-risk infants are between (0.36) and (0.93), where the behaviors that occur most often are heard the sound of the rattle 


\begin{tabular}{|c|c|c|c|c|c|}
\hline First month & Areas & & Risk & & $\mathbf{P}$ \\
\hline $\mathbf{n}=75$ & & Low & Middle & High & \\
\hline $\begin{array}{l}\text { 1.1. Child sucking without choking or turning } \\
\text { purple* }\end{array}$ & A & $49(0.96)$ & $8(0.80)$ & $5(0.36)$ & $<0.0001^{*}$ \\
\hline 1.2. Palmar grasp & MF & $51(1)$ & $9(0.90)$ & $9(0.64)$ & \\
\hline $\begin{array}{l}\text { 1.3. Child clearly responds to the sound of the } \\
\text { rattle and stop or increase movement }\end{array}$ & $\mathrm{C}$ & $50(0.98)$ & $10(1)$ & $12(0.86)$ & \\
\hline 1.4. Eye contact & MF & $51(1)$ & $9(0.90)$ & $11(0.79)$ & $0.0017^{*}$ \\
\hline 1.5. Eyes fellow the face $90^{\circ}\left(45^{\circ} / 45^{\circ}\right)$ & MF & $49(0.96)$ & $6(0.60)$ & $7(0.5)$ & \\
\hline $\begin{array}{l}\text { 1.6. Child hold his or her head erect for at } \\
3 \text { seconds or try to straighten it seated }\end{array}$ & MG & $51(1)$ & $6(0.60)$ & $7(0.5)$ & $<0.0001^{*}$ \\
\hline $\begin{array}{l}\text { 1.7. Child turns his or her head from one side } \\
\text { by raising his or her head off the supporting } \\
\text { surface enough to clear the nose }\end{array}$ & MG & $50(0.98)$ & $8(0.80)$ & $8(0.57)$ & $0.0263^{*}$ \\
\hline $\begin{array}{l}\text { 1.8. Child is lying prone on the exam surface } \\
\text { with flexion of the limbs }\end{array}$ & MG & $51(1)$ & $7(0.70)$ & $10(0.71)$ & $0.0246^{*}$ \\
\hline 1.9. Cries loud when is displeasure* & LE & $50(0.98)$ & $10(1)$ & $11(0.79)$ & $0.0275^{*}$ \\
\hline $\begin{array}{l}\text { 1.10. Child calms when picked up and } \\
\text { snuggle* }^{*}\end{array}$ & LR & $51(1)$ & $10(1)$ & $13(0.93)$ & \\
\hline 1. Labyrinth optical reflex & $\mathrm{RD}$ & $48(0.94)$ & $9(0.90)$ & $11(0.77)$ & \\
\hline $\begin{array}{l}\text { 2. Straightening reflex of the head acting on } \\
\text { the body }\end{array}$ & $\mathrm{RD}$ & $49(0.96)$ & $10(1)$ & $9(0.64)$ & $0.0008^{*}$ \\
\hline Quarter month & Areas & & Risk & & $\mathbf{P}$ \\
\hline $\mathbf{n}=77$ & & Low & Middle & High & \\
\hline $\begin{array}{l}\text { 4.1. Child does not reject to eat mashed food, } \\
\text { energetic suction* }\end{array}$ & A & $22(1)$ & $28(0.85)$ & $11(0.5)$ & $0.0091^{*}$ \\
\hline 4.2. Contact grasp & MF & $22(1)$ & $30(0.91)$ & $17(0.77)$ & \\
\hline $\begin{array}{l}\text { 4.3. Child carries and object to his or her } \\
\text { mouth }\end{array}$ & $\mathrm{C}$ & $22(1)$ & $23(0.7)$ & $13(0.59)$ & $0.0004^{*}$ \\
\hline 4.4. Social interaction playing or laughs* & LR & $22(1)$ & $28(0.85)$ & $19(0.86)$ & \\
\hline 4.5. Turns head to follow the ring $180^{\circ}$ & MF & $21(0.95)$ & $26(0.79)$ & $16(0.73)$ & $0.0072^{*}$ \\
\hline $\begin{array}{l}\text { 4.6. Child uses at least one hand to grasp the } \\
\text { object in the midline or while moving }\end{array}$ & MF & $22(1)$ & $24(0.73)$ & $7(0.32)$ & \\
\hline $\begin{array}{l}\text { 4.7. Child holds onto your hands to seat it, the } \\
\text { head is aligned to the body. }\end{array}$ & MG & $22(1)$ & $30(0.91)$ & $14(0.64)$ & $0.0424^{*}$ \\
\hline $\begin{array}{l}\text { 4.8. Child pushes up using both arms so that } \\
\text { the head and chest are lifted off the exam } \\
\text { surface }\end{array}$ & MG & $22(1)$ & $22(0.67)$ & $5(0.23)$ & $0.00134^{*}$ \\
\hline $\begin{array}{l}\text { 4.9. Child is not discomfort by the prone } \\
\text { position }\end{array}$ & MG & $22(1)$ & $21(0.64)$ & $7(0.32)$ & $<0.0001^{*}$ \\
\hline $\begin{array}{l}\text { 4.10. Child vocalizes spontaneously or in } \\
\text { response to the speaker's attention* }\end{array}$ & LE & $22(1)$ & $27(0.82)$ & $16(0.73)$ & $<0.0001^{*}$ \\
\hline 3. Landau's reflex & $\mathrm{RD}$ & $19(0.86)$ & $30(0.91)$ & $11(0.5)$ & $<0.0001^{*}$ \\
\hline Eighth month & Area & & Risk & & $\mathbf{P}$ \\
\hline $\mathrm{n}=83$ & & Low & Middle & High & \\
\hline 8.1. Eats a cookie alone* & A & $46(0.92)$ & $24(0.86)$ & $5(0.63)$ & $0.0044^{*}$ \\
\hline 8.2. Sits alone without support & & $46(0.92)$ & $28(1)$ & $6(0.75)$ & $0.0027^{*}$ \\
\hline
\end{tabular}


VANEDELA's Test Screening, Comparison Low, Middle, and High Risk in Mexican Population DOI: $h$ ttp://dx.doi.org/10.5772/intechopen.88729

\begin{tabular}{|c|c|c|c|c|c|}
\hline 8.3. Takes an object in each hand & MF & $46(0.92)$ & $24(0.86)$ & $6(0.75)$ & $0.0387^{*}$ \\
\hline 8.4. Finds a partially hidden toy & $\mathrm{C}$ & $45(0.9)$ & $24(0.86)$ & $7(0.88)$ & \\
\hline $\begin{array}{l}\text { 8.5. Explores the face of the mother with } \\
\text { interest* }\end{array}$ & $\mathrm{C}$ & $46(0.92)$ & $22(0.79)$ & $6(0.75)$ & $0.0136^{*}$ \\
\hline $\begin{array}{l}\text { 8.6. Child when taking it to a sitting position } \\
\text { puts his head forward and stretches his legs }\end{array}$ & MG & $47(0.94)$ & $24(0.86)$ & $6(0.75)$ & $0.0086^{*}$ \\
\hline $\begin{array}{l}\text { 8.7. Child supports his weight on both hands. } \\
\text { The head and trunk should raised off the } \\
\text { exam surface prone position }\end{array}$ & MG & $46(0.92)$ & $26(0.93)$ & $2(0.25)$ & $<0.0001^{*}$ \\
\hline $\begin{array}{l}\text { 8.8. Child shifts his weight from one arm to } \\
\text { the other when attempting to reach for the } \\
\text { object prone position }\end{array}$ & MG & $46(0.92)$ & $24(0.86)$ & $1(0.13)$ & $<0.0001^{*}$ \\
\hline $\begin{array}{l}\text { 8.9. Infant produces different sounds simple } \\
\text { consonant-vowel ba-ba, ta-ta, ma-ma }\end{array}$ & $\mathrm{LE}$ & $44(0.88)$ & $17(0.61)$ & $1(0.13)$ & $<0.0001^{*}$ \\
\hline 8.10. Responds to name & LR & $44(0.88)$ & $20(0.71)$ & $3(0.38)$ & $0.0003^{*}$ \\
\hline $\begin{array}{l}\text { 4. Straightening reflex of the body acting on } \\
\text { the body }\end{array}$ & $\mathrm{RD}$ & $47(0.94)$ & $26(0.93)$ & $3(0.38)$ & $<0.0001^{*}$ \\
\hline 5. Defense forward reflex & $\mathrm{RD}$ & $42(0.84)$ & $21(0.75)$ & $2(0.25)$ & $<0.0001^{*}$ \\
\hline Twelfth month & Area & & Risk & & $\mathbf{P}$ \\
\hline $\mathbf{n}=77$ & & Low & Middle & High & \\
\hline $\begin{array}{l}\text { 12.1. Drinks from a sippy cup with help, } \\
\text { without spilling liquid or choking* }\end{array}$ & A & $32(0.97)$ & 21(0.7) & $7(0.5)$ & $0.0007^{*}$ \\
\hline $\begin{array}{l}\text { 12.2. Picks up objects with thrumb-fingertip } \\
\text { (pincer grasp) }\end{array}$ & MF & $33(1)$ & $25(0.83)$ & $6(0.43)$ & $<0.0001^{*}$ \\
\hline $\begin{array}{l}\text { 12.3. Child play, imitation games, the infant } \\
\text { mimic with his hands }\end{array}$ & C & $33(1)$ & $27(0.9)$ & $8(0.57)$ & $0.0001^{*}$ \\
\hline 12.4. Sitting, she or he grabs or lifts the ball & & $33(1)$ & $28(0.93)$ & $8(0.57)$ & $<0.0001^{*}$ \\
\hline $\begin{array}{l}\text { 12.5. Sitting, using an overhand or underhand } \\
\text { motion, she or he throws or rolls the ball } \\
\text { gently toward the adult, establishing a game }\end{array}$ & LR & $33(1)$ & $25(0.83)$ & $10(0.71)$ & $0.0114^{*}$ \\
\hline $\begin{array}{l}\text { 12.6. Child raises self to a standing position, } \\
\text { using a convenient object for support* }\end{array}$ & MG & $33(1)$ & $28(0.93)$ & $9(0.64)$ & $0.0004^{*}$ \\
\hline $\begin{array}{l}\text { 12.7. Child moves independently. Crawly } \\
\text { styles: classic hands-and-knees or cross crawl. } \\
\text { Bear crawl. Bottom scooter. Crab crawl. } \\
\text { Rolling crawl. }\end{array}$ & MG & $32(0.97)$ & $24(0.8)$ & $8(0.57)$ & $0.0033^{*}$ \\
\hline $\begin{array}{l}12.8 \text { Child walks by making coordinated } \\
\text { steps, may hold on to one hand for support }\end{array}$ & MG & $29(0.88)$ & $17(0.57)$ & $5(0.36)$ & $0.0009^{*}$ \\
\hline $\begin{array}{l}\text { 12.9. Child uses words: mom and dad } \\
\text { inespecific* }\end{array}$ & LE & $31(0.94)$ & $22(0.73)$ & $1(0.07)$ & $<0.0001^{*}$ \\
\hline $\begin{array}{l}\text { 12.10. Child performs simple orders with } \\
\text { gesture like come here, give me, do not do } \\
\text { that* }\end{array}$ & LR & $33(1)$ & $27(0.9)$ & $8(0.57)$ & $0.0007^{*}$ \\
\hline 6. Sides protection reflex & $\mathrm{RD}$ & $33(1)$ & $28(0.93)$ & $7(0.5)$ & $<0.0001^{*}$ \\
\hline 7. Backwards protection reflex & $\mathrm{RD}$ & $27(0.82)$ & $23(0.77)$ & $4(0.29)$ & $0.0008^{*}$ \\
\hline Eighteenth month & Area & & Risk & & $\mathbf{P}$ \\
\hline $\mathrm{n}=65$ & & Low & Middle & High & \\
\hline 18.1. Eats only with the spoon even if it spills* & A & $22(0.96)$ & $23(0.85)$ & $9(0.6)$ & $0.0354^{*}$ \\
\hline
\end{tabular}




\begin{tabular}{|c|c|c|c|c|c|}
\hline 18.2. Child puts the pellets in the bottle & $\mathrm{C}$ & $23(1)$ & $23(0.85)$ & $13(0.87)$ & $0.0053^{*}$ \\
\hline $\begin{array}{l}\text { 18.3. Child removes the pellets from the } \\
\text { bottle. Dumping the pellet from the bottle. }\end{array}$ & $\mathrm{C}$ & $23(1)$ & $25(0.93)$ & $13(0.87)$ & $0.0194^{*}$ \\
\hline $\begin{array}{l}\text { 18.4. Child identifies two objects or persons } \\
\text { in pictures }\end{array}$ & LR & 23(1) & $27(1)$ & $13(0.87)$ & $<0.0001^{*}$ \\
\hline $\begin{array}{l}\text { 18.5. Child in standing position. she or he } \\
\text { throws the ball with one or both hands }\end{array}$ & & 23(1) & $24(0.89)$ & $13(0.87)$ & $<0.0001^{*}$ \\
\hline $\begin{array}{l}\text { 18.6. Child standing position, she or he } \\
\text { throws the ball toward the adult, establishing } \\
\text { a game }\end{array}$ & LR & 23(1) & $26(0.96)$ & $14(0.93)$ & $0.0003^{*}$ \\
\hline $\begin{array}{l}\text { 18.7. Child comes down from a standing } \\
\text { position to a squat position in a controlled } \\
\text { manner and gets back on his feet* }\end{array}$ & MG & $22(0.96)$ & $22(0.81)$ & $14(0.93)$ & $0.0143^{*}$ \\
\hline 18.8. Child freely walks & MG & $19(0.83)$ & $21(0.78)$ & $8(0.53)$ & $0.0040^{*}$ \\
\hline $\begin{array}{l}\text { 18.9. Child uses words appropriately like } \\
\text { mama and dada plus other three* }\end{array}$ & LE & $22(0.96)$ & $21(0.78)$ & $10(0.67)$ & $<0.0001^{*}$ \\
\hline $\begin{array}{l}\text { 18.10. Child identifies one or more body parts } \\
\text { on himself or herself }\end{array}$ & LR & $23(1)$ & $24(0.89)$ & $14(0.93)$ & $0.0248^{*}$ \\
\hline 8. Sitting balance reflex & $\mathrm{RD}$ & $23(1)$ & $26(0.96)$ & $12(0.80)$ & $0.0339^{*}$ \\
\hline 9. Balance in four points reflex & $\mathrm{RD}$ & $23(1)$ & $23(0.85)$ & $6(0.40)$ & $<0.0001^{*}$ \\
\hline Twenty-fourth month & Area & & Risk & & $\mathbf{P}$ \\
\hline$n=61$ & & Low & Middle & High & \\
\hline 24.1. Wrap up a candy or banana* & A & $24(0.96)$ & $18(0.75)$ & $5(0.42)$ & $0.0091^{*}$ \\
\hline $\begin{array}{l}\text { 24.2. Child wrap up a candy or banana and } \\
\text { will be eating* }\end{array}$ & A & $25(1)$ & $21(0.88)$ & $9(0.75)$ & \\
\hline $\begin{array}{l}\text { 24.3. Copy a line in any direction (trace a } \\
\text { line) }\end{array}$ & MF & 25(1) & $14(0.58)$ & $6(0.5)$ & $0.0004^{*}$ \\
\hline $\begin{array}{l}\text { 24.4. Child can help in housework for } \\
\text { imitation* }\end{array}$ & $\mathrm{C}$ & 25(1) & $22(0.92)$ & $9(0.75)$ & \\
\hline $\begin{array}{l}\text { 24.5. Child kick the ball standing } \\
\text { unsupported }\end{array}$ & MG & $24(0.96)$ & $16(0.67)$ & $6(0.5)$ & $0.0072^{*}$ \\
\hline 24.6. Child can sit in a normal chair* & MG & $25(1)$ & $21(0.88)$ & $10(0.83)$ & \\
\hline $\begin{array}{l}\text { 24.7. Child use location in a chair to reach an } \\
\text { object* }\end{array}$ & $\mathrm{C}$ & $25(1)$ & $24(1)$ & $10(0.83)$ & $0.0424^{*}$ \\
\hline 24.8. Child run without falling & MG & $23(0.92)$ & $23(0.96)$ & $7(0.58)$ & $0.0013^{*}$ \\
\hline 24.9. Child say two-word phrases* & LE & $25(1)$ & $21(0.88)$ & $2(0.17)$ & $<0.0001^{*}$ \\
\hline $\begin{array}{l}\text { 24.10. Child say your name or call yourself } \\
\text { "baby" or "nene" }\end{array}$ & LR & $23(0.92)$ & $14(0.58)$ & $1(0.08)$ & $<0.0001^{*}$ \\
\hline 10. Standing up balance reflex & $\mathrm{RD}$ & $25(1)$ & $20(0.83)$ & $8(0.67)$ & $0.0003^{*}$ \\
\hline
\end{tabular}

Table 1.

Number cases and proportions, will be conducted present in levels risk factors.

and reassures when being charged. At high risk, there are suction problems (Table 1) [17].

Fourth's month cohort in low risk (1)-(0.95) perform the behaviors; those of medium risk between (0.91) and (0.64), presenting a greater difficulty in bringing the hand to the middle line to reach objects, take it to the mouth and in a thick 
motor the prone position; in high-risk children all are kept low and only by playing talk or laughing at (0.86) (Table 1).

Eighth's month cohort, there is a better performance in children with low and moderate risk, in children with moderate risk, interaction behaviors as it shows interest in the face of the mother when she is playing a game and heeds her name when they call it by this, here according to clinical practice, we observe that in the Mexican population mothers tend to sing and talk to their children a little, so we see that this competition to collect syllables is almost not favored, in different researches in open population is reported later the construction of language and in order to appropriate the name tends to name it with different nicknames, so it is difficult for the child to make the association between the word that calls it, these reagents will allow the professional give more advice to the caregivers to encourage singing to make movements that allow your child to pay attention, follow a sequence and foresee what He will come, first paying attention and exploring, then imitating.

In high-risk children, most of the reagents are outlined low $(0.88-0.13)$, the difficulty remains in thick motor, coupled with the forward protection development reaction. The behavior of finding a partially hidden toy is presented in (0.88), which is evaluated as a cognitive competence of permanence of the object, which lead the child to the representation of the object, even if he does not see it and later to the displacements [18] (Table 1).

Cohort 12 months, at high risk all behaviors are presented little, when analyzing them compared with moderate risk, it is observed that drinks from a cup with undrained support [19] is a moderate low proportion (0.70) and high (0.50) risk, this competition is little facilitated since caregivers prefer to use the trainer cup, as it can be manipulated by the infant and does not spill, taking in cup with support allows the development of a good control of lips and jaw, closing the lips around the edge of the cup and push the liquid into the mouth and do not leave the corners. Here we observe two risk factors: the upbringing that does not facilitate its construction and the tone could be involved in high-risk children. Walks well sustained by one hand, both in low and moderate and high risk, are less positive than other behaviors, Gesell's reports it at 13 months $[13,20]$, the protection reaction backwards, comes in moderate (0.77) and high (0.29) risk. As the expressive language has been analyzed, there is little in moderate (0.73) and high (0.07) risk, in this reagent, the rearing plays an important factor, since the caregivers respond to the bisyllabic vocalizations of the infant that is used to name everything he sees and the caregiver helping him with his response to labeling and thus form the first words with meaning, in the literature a period of 11-14 months is proposed [13, 21].

Cohort 18 months, the use of spoon, occurs in a greater number of cases than in the previous cuts, in high risk occurs (0.60) [22]. Saying three words as a specific label to name objects, situations, or people is presented in moderate $(0.78)$ and high (0.67) than in previous cuts. Walk alone, occurs in a low to moderate $(0.78)$ and high (0.53) and at high risk, the equilibrium reaction is presented in four points in (0.40).

Twentieth fourth's month cohort, at high risk, there is a lower proportion of positives, highlighting when comparing the behavior develops a moderate sweet (0.75) and high (0.42) risk. Kick the ball by moving the leg to the moderate front (0.67) and high (0.50), this competition develops when the game is facilitated with the child. The reagent copies a line either vertically or horizontally, defined in moderate (0.58) and high (0.50) risk, this competition we see it more in children who attend childcare, where it is facilitated, the infant requires holding the pencil with the tip down and controlling the movement, decreasing the amplitude and stopping the action while doing it (Table 2).

Working with a population that has not been presented with perinatal risk or conditions that determine a risk for disability, allows us to establish the need to 


\begin{tabular}{|c|c|c|c|c|c|}
\hline & Area & BR & MR & AR & $\mathbf{P}$-values \\
\hline 1.1. Child sucking without choking or turning purple* & A & 0.96 & 0.80 & 0.36 & $<0.0001^{*}$ \\
\hline $\begin{array}{l}\text { 4.1. Child does not reject to eat mashed food, energetic } \\
\text { suction* }\end{array}$ & A & 1 & 0.85 & 0.50 & $0.0091^{*}$ \\
\hline 8.1. Eats a cookie alone* & A & 0.92 & 0.86 & 0.63 & $0.0044^{*}$ \\
\hline $\begin{array}{l}\text { 12.1. Drinks from a sippy cup with help, without spilling } \\
\text { liquid or choking* }\end{array}$ & A & 0.97 & 0.7 & 0.5 & $0.0007^{*}$ \\
\hline 18.1. Eats only with the spoon even if it spills* & A & 0.96 & 0.85 & 0.6 & $0.0354^{*}$ \\
\hline 24.1. Wrap up a candy or banana* & A & 0.96 & 0.75 & 0.42 & $0.0091^{*}$ \\
\hline \multirow[t]{2}{*}{ 24.2. Child wrap up a candy or banana and will be eating* } & A & 1 & 0.88 & 0.75 & \\
\hline & Area & BR & MR & AR & P-values \\
\hline $\begin{array}{l}\text { 1.3. Child clearly responds to the sound of the rattle and stop } \\
\text { or increase movement }\end{array}$ & $\mathrm{C}$ & 0.98 & 1.00 & 0.86 & \\
\hline 4.3. Child carries and object to his or her mouth & $\mathrm{C}$ & 1 & 0.70 & 0.59 & $0.0004^{*}$ \\
\hline 8.4. Finds a partially hidden toy & $\mathrm{C}$ & 0.90 & 0.86 & 0.88 & \\
\hline 8.5. Explores the face of the mother with interest* & C & 0.92 & 0.79 & 0.75 & $0.0136^{*}$ \\
\hline $\begin{array}{l}\text { 12.3. Child play, imitation games, the infant mimic with his } \\
\text { hands }\end{array}$ & C & 1 & 0.9 & 0.57 & $0.0001^{*}$ \\
\hline 18.2. Child puts the pellets in the bottle & $\mathrm{C}$ & 1 & 0.85 & 0.87 & $0.0053^{*}$ \\
\hline $\begin{array}{l}\text { 18.3. Child removes the pellets from the bottle. Dumping the } \\
\text { pellet from the bottle. }\end{array}$ & $\mathrm{C}$ & 1 & 0.93 & 0.87 & $0.0194^{*}$ \\
\hline $\begin{array}{l}\text { 18.6. Child standing position, she or he throws the ball } \\
\text { toward the adult, establishing a game }\end{array}$ & $\mathrm{C}$ & 1 & 0.96 & 0.93 & $0.0003^{*}$ \\
\hline 24.4. Child can help in housework for imitation* & $\mathrm{C}$ & 1 & 0.92 & 0.75 & \\
\hline \multirow[t]{2}{*}{ 24.7. Child use location in a chair to reach an object* } & $\mathrm{C}$ & 1 & 1 & 0.83 & $0.0424^{*}$ \\
\hline & Area & BR & MR & AR & P-values \\
\hline 1.9. Cries loud when is displeasure* & LE & 0.98 & 1.00 & 0.79 & $0.0275^{*}$ \\
\hline $\begin{array}{l}\text { 4.10. Child vocalizes spontaneously or in response to the } \\
\text { speaker's attention* }\end{array}$ & LE & 1 & 0.82 & 0.73 & $<0.0001^{*}$ \\
\hline $\begin{array}{l}\text { 8.9. Infant produces different sounds simple consonant- } \\
\text { vowel ba-ba, ta-ta, ma-ma }\end{array}$ & $\mathrm{LE}$ & 0.88 & 0.61 & 0.13 & $<0.0001^{*}$ \\
\hline 12.9. Child uses words: mom and dad inespecific* & LE & 0.94 & 0.73 & 0.07 & $<0.0001^{*}$ \\
\hline $\begin{array}{l}\text { 18.9. Child uses words appropriately like mama and dada } \\
\text { plus other three* }\end{array}$ & LE & 0.96 & 0.78 & 0.67 & $<0.0001^{*}$ \\
\hline 24.9. Child say two-word phrases* & LE & 1 & 0.88 & 0.17 & $<0.0001^{*}$ \\
\hline \multirow[t]{2}{*}{ 24.10. Child say your name or call yourself "baby" or "nene" } & LE & 0.92 & 0.58 & 0.08 & $<0.0001^{*}$ \\
\hline & Area & BR & MR & AR & P-values \\
\hline 1.10. Child calms when picked up and snuggle* & LR & 1.00 & 1.00 & 0.93 & \\
\hline 4.4. Social interaction playing or laughs ${ }^{*}$ & LR & 1 & 0.85 & 0.86 & \\
\hline 8.10. Responds to name & LR & 0.88 & 0.71 & 0.38 & $0.0003^{*}$ \\
\hline $\begin{array}{l}\text { 12.5. Sitting, using an overhand or underhand motion, she or } \\
\text { he throws or rolls the ball gently toward the adult, } \\
\text { establishing a game }\end{array}$ & LR & 1 & 0.83 & 0.71 & $0.0114^{*}$ \\
\hline $\begin{array}{l}\text { 12.10. Child performs simple orders with gesture like come } \\
\text { here, give me, do not do that* }\end{array}$ & LR & 1 & 0.9 & 0.57 & $0.0007^{*}$ \\
\hline
\end{tabular}


VANEDELA's Test Screening, Comparison Low, Middle, and High Risk in Mexican Population DOI: http://dx.doi.org/10.5772/intechopen.88729

\begin{tabular}{|c|c|c|c|c|c|}
\hline 18.4. Child identifies two objects or persons in pictures & LR & 1 & 1 & 0.87 & $<0.0001^{*}$ \\
\hline \multirow{2}{*}{$\begin{array}{l}\text { 18.10. Child identifies one or more body parts on himself or } \\
\text { herself }\end{array}$} & LR & 1 & 0.89 & 0.93 & $0.0248^{*}$ \\
\hline & Area & BR & MR & AR & P-values \\
\hline 1.2. Palmar grasp & MF & 1.00 & 0.90 & 0.64 & \\
\hline 1.4. Eye contact & MF & 1.00 & 0.90 & 0.79 & $0.0017^{*}$ \\
\hline 1.5. Eyes fellow the face $90^{\circ}\left(45^{\circ} / 45^{\circ}\right)$ & MF & 0.96 & 0.60 & 0.50 & \\
\hline 4.2. Contact grasp & MF & 1 & 0.91 & 0.77 & \\
\hline 4.5. Turns head to follow the ring $180^{\circ}$ & MF & 0.95 & 0.79 & 0.73 & $0.0072^{*}$ \\
\hline $\begin{array}{l}\text { 4.6. Child uses at least one hand to grasp the object in the } \\
\text { midline or while moving }\end{array}$ & MF & 1 & 0.73 & 0.32 & \\
\hline 8.3. Takes an object in each hand & MF & 0.92 & 0.86 & 0.75 & $0.0387^{*}$ \\
\hline 12.2. Picks up objects with thrumb-fingertip (pincer grasp) & MF & 1 & 0.83 & 0.43 & $<0.0001^{*}$ \\
\hline 12.4. Sitting. she or he grabs or lifts the ball & MF & 1 & 0.93 & 0.57 & $<0.0001^{*}$ \\
\hline $\begin{array}{l}\text { 18.5. Child in standing position, she or he throws the ball } \\
\text { with one or both hands }\end{array}$ & MF & 1 & 0.89 & 0.87 & $<0.0001^{*}$ \\
\hline \multirow[t]{2}{*}{ 24.3. Copy a line in any direction (trace a line) } & MF & 1 & 0.58 & 0.5 & $0.0004^{*}$ \\
\hline & Area & BR & MR & AR & P-values \\
\hline $\begin{array}{l}\text { 1.6 Child hold his or her head erect for at } 3 \text { seconds or try to } \\
\text { straighten it seated }\end{array}$ & MG & 1.00 & 0.60 & 0.50 & $<0.0001^{*}$ \\
\hline $\begin{array}{l}\text { 1.7. Child turns his or her head from one side by raising his or } \\
\text { her head off the supporting surface enough to clear the nose }\end{array}$ & MG & 0.98 & 0.80 & 0.57 & $0.0263^{*}$ \\
\hline $\begin{array}{l}\text { 1.8. Child is lying prone on the exam surface with flexion of } \\
\text { the limbs }\end{array}$ & MG & 1.00 & 0.70 & 0.71 & $0.0246^{*}$ \\
\hline $\begin{array}{l}\text { 4.7. Child holds onto your hands to seat it, the head is aligned } \\
\text { to the body. }\end{array}$ & MG & 1 & 0.91 & 0.64 & $0.0424^{*}$ \\
\hline $\begin{array}{l}\text { 4.8. Child pushes up using both arms so that the head and } \\
\text { chest are lifted off the exam surface }\end{array}$ & MG & 1 & 0.67 & 0.23 & $0.00134^{*}$ \\
\hline 4.9. Child is not discomfort by the prone position & MG & 1 & 0.64 & 0.32 & $<0.0001^{*}$ \\
\hline 8.2. Sits alone without support & MG & 0.92 & 1.00 & 0.75 & $0.0027^{*}$ \\
\hline $\begin{array}{l}\text { 8.6. Child when taking it to a sitting position puts his head } \\
\text { forward and stretches his legs }\end{array}$ & MG & 0.94 & 0.86 & 0.75 & $0.0086^{*}$ \\
\hline $\begin{array}{l}\text { 8.7. Child supports his weight on both hands. The head and } \\
\text { trunk should raised off the exam surface prone position }\end{array}$ & MG & 0.92 & 0.93 & 0.25 & $<0.0001^{*}$ \\
\hline $\begin{array}{l}\text { 8.8. Child shifts his weight from one arm to the other when } \\
\text { attempting to reach for the object prone position }\end{array}$ & MG & 0.92 & 0.86 & 0.13 & $<0.0001^{*}$ \\
\hline $\begin{array}{l}\text { 12.6. Child raises self to a standing position, using a } \\
\text { convenient object for support* }\end{array}$ & MG & 1 & 0.93 & 0.64 & $0.0004^{*}$ \\
\hline $\begin{array}{l}\text { 12.7. Child moves independently. Crawly styles: classic } \\
\text { hands-and-knees or cross crawl. Bear crawl. Bottom scooter. } \\
\text { Crab crawl. Rolling crawl. }\end{array}$ & MG & 0.97 & 0.8 & 0.57 & $0.0033^{*}$ \\
\hline $\begin{array}{l}\text { 12.8. Child walks by making coordinated steps, may hold on } \\
\text { to one hand for support }\end{array}$ & MG & 0.88 & 0.57 & 0.36 & $0.0009^{*}$ \\
\hline $\begin{array}{l}\text { 18.7. Child comes down from a standing position to a squat } \\
\text { position in a controlled manner and gets back on his feet* }\end{array}$ & MG & 0.96 & 0.81 & 0.93 & $0.0143^{*}$ \\
\hline 18.8. Child freely walks & MG & 0.83 & 0.78 & 0.53 & $0.0040^{*}$ \\
\hline
\end{tabular}




\begin{tabular}{lcccccc}
\hline 24.5. Child kick the ball standing unsupported & MG & 0.96 & 0.67 & 0.5 & $0.0072^{*}$ \\
\hline 24.6. Child can sit in a normal chair* & MG & 1 & 0.88 & 0.83 & \\
\hline 24.8. Child run without falling & MG & 0.92 & 0.96 & 0.58 & $0.0013^{*}$ \\
\hline & Area & BR & MR & AR & $\begin{array}{c}\text { Significance } \\
\text { level }\end{array}$ \\
\hline 1. Labyrinth optical reflex & & & & & \\
\hline 2. Straightening reflex of the head acting on the body & RD & 0.94 & 0.9 & 0.77 & \\
\hline 3. Landau's reflex & RD & 0.96 & 1 & 0.64 & $0.0008^{*}$ \\
\hline 4. Straightening reflex of the body acting on the body & RD & 0.86 & 0.91 & 0.5 & $<0.0001^{*}$ \\
\hline 5. Defense forward reflex & RD & 0.94 & 0.93 & 0.38 & $<0.0001^{*}$ \\
\hline 6.Sides protection reflex & RD & 0.84 & 0.75 & 0.25 & $<0.0001^{*}$ \\
\hline 7. Backwards protection reflex & RD & 1 & 0.93 & 0.5 & $<0.0001^{*}$ \\
\hline 8. Sitting balance reflex & RD & 0.82 & 0.77 & 0.29 & $0.0008^{*}$ \\
\hline 9. Balance in four points reflex & RD & 1 & 0.96 & 0.8 & $0.0339^{*}$ \\
\hline 10. Standing up balance reflex & RD & 1 & 0.85 & 0.4 & $<0.0001^{*}$ \\
\hline
\end{tabular}

Table 2.

Area and P-values correlations.

monitor child neurodevelopment, so that the professional at the first level of care can detect biological or social obstacles, to advise the caregivers and enable an optimal development necessary to channel it to diagnostic studies and specialized attention and continue with the monitoring of the child to see how the adaptations work.

When analyzing by areas of development, the VANEDELA's reagents in feeding (A) for infants of moderate risk taking the help of a cup and uncovering a sweet or easy fruit are kept low, as we have said it is not favored in the family possibly because it takes time and the caregivers prefer to solve the challenge quickly, in the consultation it has been found that the caregivers see it as an instrumental activity, not as moments for the child to put into play their motor, cognitive, and emotional skills for its development. In the sample of high risk, eating with a single cookie and candy, which is a behavior favored by parents, occurs with greater proportions.

Cognitive $(\mathrm{C})$ in moderate, the lowest proportions are in exploration behaviors taking the object to the mouth and attention and exploration of your face or another part of the body when the caregiver plays with him/her and is the antecedent of imitation, being an activity that little favor the caregivers, preferring to put the electronic systems. High risk, that in the sequence of development have greater proportions in permanence of the object to find partially hidden object, the contentcontinent to put and take the seeds or candy from a bottle, this skill is practiced with various objects and containers, the give and take relationship understanding the game and the use of a means to achieve an end.

In expressive language in moderate risk, the lowest proportions are in the emission of bisyllables and first words, highly related to the interaction with the caregiver and recognize their vocalizations and interpret them to give meaning, it is one of the scales that in Mexico leave lower, Rizzoli-Córdoba et al. [23] report it in their evaluation in open population. In receptive in moderate risk, a low proportion

\footnotetext{
${ }^{1}$ In Spanish, bebé or nene are synonymous commonly used to name a newborn, in English the translation is similar baby in this case used the Spanish words to show the differences.
} 
comes out in recognizing his name and responding when they call him, as he said previously in the Mexican population names are invented: bebé or nene $e^{1}$ is said to call them. At high risk, he consoles himself when carrying it, he smiles when he talk and he recognizes images and parts of the body that are closely linked to the cognitive aspect. Fine motor with lower proportions is the tracking that travels in the middle line and then draw a line, both are little favored, mostly caregivers prefer to give them the rattle and writing is considered a more school activity. In thick motor mainly prone behavior and walking on one hand are in a low proportion, in many parts of the Mexico, it is considered risky to grab one hand prefer to take it from the two and the prone position is not favored arguing that it is a position that the child does not like, they prefer to leave it in the car seat or carry it. At high risk, it has a higher proportion of squatting and climbing into a large chair, which would require better equilibrium reactions than at low ages.

The reactions of the development of protection forward and backward are presented in a lower percentage in the three types of risk and at high risk throughout the trajectory [24].

In Mexico, there are still risks such as malnutrition, acute and chronic diseases, social limitations with few opportunities for exploration and interaction at home and with other children, and so on. It is therefore difficult to develop early skills of movement, manipulation, attention, problem solving, language, and establishment of social relationships that can trace a path not optimal in the development cycle and impact the following educational processes and social inclusion. This condition is frequently reported in developing countries [8].

\section{Conclusions}

It is proposed to the professional in clinical practice to go beyond the classification of risk or non-risk, analyzing the behavior that the child has constructed and the possible obstacles that it presents, whether of an organic or social nature.

The VANEDELA's neurodevelopment screening test allows the first-level care professional using its four formats to have specific development references to establish when the child is and what the proximal area is to favor, designing strategies that allow the infant go building more complex competences.

The VANEDELA's design allows children to be assessed quickly through their six age cohorts, in which the different skills have been consolidated. However, its main limitation is that if the child is of intermediate age, we should wait for the confirmation of the risk. At present, we are working on intermediate milestones that will allow professionals to determine the evolution moment of the behaviors.

It is very important to consider that for both low- and high-risk children, their development must be monitored independently of the preventive or corrective medicine procedures that are carried out, in order to obtain, as proposed by WHO, the optimum development. 


\section{Author details}

Rosa Ivone Martínez-Vázquez ${ }^{1 *}$, Blásquez-Martínez Jorge Ulises ${ }^{2}$, Morales Ramírez Aline ${ }^{1}$ and Gerardo Alberto Alvarado-Ruiz ${ }^{1}$

1 Laboratorio de Seguimiento del Instituto Nacional de Pediatría, Mexico

2 Instituto Tepeyac, León, Mexico

*Address all correspondence to: ivone.martinez.vazquez@gmail.com

\section{IntechOpen}

(C) 2019 The Author(s). Licensee IntechOpen. This chapter is distributed under the terms of the Creative Commons Attribution License (http://creativecommons.org/licenses/ by/3.0), which permits unrestricted use, distribution, and reproduction in any medium, provided the original work is properly cited. (c) BY 


\section{References}

[1] Black M, Walker S, Fernald L, DiGirolamo A, Lu C, McCoy D, et al. Advancing early childhood development: From science to scale 1. Early childhood development coming of age: Science through the life course. The Lancet. 2017;389(7):78-90

[2] Walker SP, Wachs TD, GranthamMcGregor S, et al. Inequality in early childhood: Risk and protective factors for early child development. Lancet. 2011;378:1325-1338

[3] WHO. Developmental Difficulties in Early Childhood. Prevention, Early Identification, Assessment and Intervention in Low- and MiddleIncome Countries. Geneva: WHO Organizatión; 2012. Available from: http://apps.who.int/iris/bitstream/ 10665/97942/1/9789241503549_eng.pdf

[4] Accardo P, Capute A. The Capute Scales. Baltimore: Paul H. Brookes; 2005

[5] Martínez-Vázquez RI, Sánchez C, Rivera-González R. Instrumentos para el tamizaje del desarrollo en los dos primeros años de vida. In: En RiveraGonzález R, Sánchez C, editors. Vigilancia del desarrollo integral del niño. México: Editores de Textos Mexicanos S. A de C.V; 2009. pp. 17-24. ISBN: 978-607-7817-07-9

[6] Romo-Pardo B, Liendo-Vallejos S, Vargas-López G, Rizzoli-Córdoba A, Buenrostro-Márquez G. Pruebas de tamizaje de neurodesarrollo global para niños menores de 5 años de edad validadas en Estados Unidos y Latinoamérica: revisión sistemática y análisis comparativo. Boletín Médico del Hospital Infantil de México. 2012;69(6): 450-462

[7] Grantham-McGregor S, Cheung YB, Cueto S, Glewwe P, Ritcher L, Strupp B. Developmental potential in the first 5 years for children in developing countries. Lancet. 2007;369:60-70.

Available from: http://ac.els-cdn.com/ S0140673607600324/1-s2.0-

S0140673607600324-main.pdf

[8] Tirado K, Arvisu L, Martínez M, Guerrero M, Contreras L, Vegas G, et al. Prevalencia de alteraciones en el desarrollo psicomotor de 1 mes a 5 años valorados con la prueba EDI en un centro de salud en México en el periodo febrero-noviembre de 2015. European Scientific Journal. 2017;13(3):223-234

[9] American Academy of Pediatrics. Council on Children With Disabilities, Section on Developmental Behavioral Pediatrics, Bright Futures Steering Committee, Medical Home Initiatives for Children With Special Needs Project Advisory Committee. Identifying infants and young children with developmental disorders in the medical home: An algorithm for developmental surveillance and screening. Pediatrics. 2006;118(1):405-420

[10] Muñoz-Ledo Rábago P, Sánchez C, Mandujano-Váldez M, Rivera González R, Martínez-Vázquez RI, Alvarado-Ruiz G. Pruebas de tamizaje como estrategia preventiva de alteraciones en el neurodesarrollo y discapacidad. En: Martínez-López Y, Salvador Moysén JH, Delgado-Restrepo A, Cruz-Pérez F. Neurodesarrollo infantil: Diversas aproximaciones teóricas y aplicativas. Estado de Durango, Méx: Universidad del Estado de Durango. 2015 p. 33-54. ISBN: 9786075031842

[11] Secretaría de Salud. Norma Oficial Mexicana NOM-043-SSA2-2012, Servicios básicos de salud. Promoción y educación para la salud en materia alimentaria. Criterios para brindar orientación. Diario Oficial; 2013

[12] Sánchez MC, Benavides $\mathrm{H}$, Mandujano M, Rivera IR, Martínez VI, Alvarado RG. La Valoración 
Neuroconductual del Desarrollo del lactante (VANEDELA). 3er ed. México: Serie manuales DCBS. Universidad Autónoma Metropolitana-Xochimilco; 2007

[13] Martínez-Vázquez RI, AlvaradoRuiz GA, Sánchez C, Muñoz-Ledo Rábago P. Validity and reliability of the neurobehavioral evaluation of infant development (VANEDELA). Screening instrument from one to 24 months in primary health care in México. Salud Mental. 2018;41(2):57-63

[14] Consejo Nacional de Evaluación de la Política de Desarrollo Social (CONEVAL). Metodología para la medición multidimensional de la pobreza en México. Disponibleen. Available from: http://www.CONEVAL. gob.mx/medicion/paginas/Medici\% C3\%B3n/METODOLOGIA.aspx

[15] Gesell A, Amatruda C. Desarrollo Normal y Patológico. España: Paidós; 1981

[16] Alvarado-Ruiz GA, MartínezVázquez RI, Sánchez C. Modelo de vigilancia y seguimiento del neurodesarrollo infantil experiencia en la Clínica de Medicina Familiar Tlalpan. Revista de especialidades médicoquirúrgicas (Impresa). 2013, 2013;18: 19-30

[17] Costas M, Santos S, Godoy C, Martell M. Patrones de succión en el recién nacido de término y pretérmino. Revista Chilena de Pediatría. 2006; 77(2):198-212. DOI: 10.406715037041062006000200014

[18] Piaget J. El Nacimiento de la inteligencia del niño. España: Crítica; 2000. ISBN: 84-8432-074-X

[19] Fewtrell M, Bronsky J, Campoy C, et al. Complementary feeding: A position paper by the European Society for Paediatric Gastroenterology, Hepatology, and Nutrition (ESPGHAN)
Committee on Nutrition. JPGN. 2017; 64:119-132

[20] Adolph KE, Karasik LB. TamisLeMonda CS. Using social information to guide action: Infants' locomotion over slippery slopes. Neural Networks. 2010a;23:1033-1042. DOI: 10.1016/j. neunet. 2010.08.012. [PubMed: 20875725]

[21] Brazelton B, Greenspan S. Las necesidades básicas de la infancia. Editorial Graó: Barcelona; 2005. ISBN: 84-7827-391-3

[22] Pardío J, Lartigue T, MaldonadoDurán J, Plazas M, PérezLizaur A. Postura del Colegio Mexicano de Nutriólogos sobre dinámica de la alimentación y su relación con el fenómeno de separación-individuación del ser humano: una visión nutriológica y psicodinámica. Colegio Mexicano de Nutriólogos: México, D.F; 2006

[23] Rizzoli-Córdoba A, CamposMaldonado C, Vélez-Andrade V, Delgado-Ginebra I, Muñoz-Hernandez O. Evaluación diagnóstica del nivel de desarrollo en niños identificados con riesgo mediante la prueba de evaluación del desarrollo infantil. Boletín Médico del Hospital Infantil de México. 2016; 72(6):397-408. DOI: 10.1016/J. bmhimx.2015.11.005

[24] Alvarado-Ruiz GA, Sánchez C, Mandujano-Valdés M. EVANENE Evaluación de Neurodesarrollo del Neonato. México: Universidad Autónoma Metropolitana, Unidad Xochimilco; 2010 



\section{Edited by René Mauricio Barría}

Infant and neonatal health is one of the areas of greatest development and evolution within pediatrics. This edited volume Update on Critical Issues in Infant and

Neonatal Care is a collection of reviewed and relevant research chapters offering a comprehensive overview of recent developments in six topics about common newborn and infant health problems. In 6 chapters that address relevant issues about infant and neonatal care, the book seeks to contribute to the clinical work of the health teams of critical care units. Specialists in the field of pediatrics from different countries have developed these chapters and through them they hope to share part of their experience. 